\title{
Syntheses and solution properties of water-soluble poly(p-phenylene)s bearing oligo(ethylene oxide) and trialkylamino side groups
}

\author{
Steffen Traser, Patrick Wittmeyer, Matthias Rehahn*
}

Deutsches Kunststoff-Institut (DKI) and Institut für Makromolekulare Chemie, Technische Universität Darmstadt, Petersenstr. 22, 64287 Darmstadt, Germany; Fax +49 (0)6151 / 292855; mrehahn@dki.tu-darmstadt.de

(Received: May 17, 2002; published: July 7, 2002)

\begin{abstract}
Pd-catalyzed Suzuki coupling is used to prepare poly( $p$-phenylene)s (PPPs) bearing oligo(ethylene oxide)s (OEOs) and trialkylamino groups as lateral substituents. The OEO substituents require very specific reaction conditions during monomer synthesis - presumably due to their coordinating oxygen atoms - but do not affect the subsequent Pd-catalyzed polycondensation process. In contrast to this, the lateral amino groups lower the degree of polycondensation of the PPPs considerably when their nitrogen atom is placed in the $\beta$-position of the side chains. When there is a longer spacer group between the amino nitrogen and the aromatic ring to be coupled, however, high-molecular-weight PPPs can be obtained. Provided an appropriate substitution pattern and long OEO side chains are used, the resulting PPPs are readily soluble not only in organic solvents but even in aqueous media. For one of these PPPs, the degree of protonation has been determined as a function of $\mathrm{pH}$, using ${ }^{1} \mathrm{H}$ and ${ }^{13} \mathrm{C}$ NMR spectroscopy as well as potentiometry. It is shown that the polymer is completely deprotonated at $\mathrm{pH}>10.5$ and quantitatively protonated at $\mathrm{pH}<4.0$.
\end{abstract}

\section{Introduction}

Polyelectrolytes are key compounds in all living organisms as well as in many materials and processes of our daily life [1-3]. DNA [4-8] and xanthane [9-12] on the one hand, and flocculents, superabsorbers, ion exchangers and pharmaceutical polymers [1-3,13-15] on the other hand may serve as examples. In most cases, the polyelectrolytes develop their benefits only when either dissolved in water or when in close contact with an aqueous medium. Hence, in order to tailor-make polyelectrolytes for a specific application, profound understanding of their properties in aqueous solution is necessary. It is well-known that intra- and intermolecular electrostatic (Coulomb) forces, osmotic effects and conformational changes must be considered in detail to develop this understanding. Consequently, much effort has been spent in analyzing these effects using many different techniques [16-37]. However, profound interpretation of the collected data proved to be very difficult. This is in particular because the range and strength of the intra- and intermolecular Coulomb forces and hence all properties influenced by electrostatic interactions - greatly depend on the ionic strength: at very low ionic strength, the polyelectrolyte molecules repel each other over very long distances because of the Coulomb interaction of their charged main chains. In the case of conformationally flexible polyelectrolytes, the electrostatic 
forces additionally cause intramolecular repulsion of the chain segments. Stretching and stiffening of the polymer main chains, and hence coil expansion, are the consequences. Therefore, without profound theoretical understanding of the solution properties of flexible polyelectrolytes it is impossible to differentiate the macroscopically observed facets of polyelectrolyte behavior quantitatively according to the various contributions of the underlying inter- and intramolecular electrostatic, conformational and osmotic effects. This prevents the reliable prediction of a best polyelectrolyte structure for a specific aim. Vice versa, however, it is impossible to develop the needed basic knowledge about polyelectrolytes by just considering solutions of the conventional flexible systems. The complexity of their behavior is the central reason for our current situation where neither a generally accepted theoretical description nor a profound evaluation of the experimental data is available for aqueous solutions of conformationally flexible polyelectrolytes.

Rigid, rod-like polyelectrolytes, on the other hand, cannot change their shape significantly. Since conformational changes as a function of the ionic strength can be neglected, they represent ideal model systems for developing the required deeper understanding of polyelectrolyte behavior in solution. Here, the poly ( $p$-phenylene) (PPP) system seems to be one of the most appropriate polymer backbones because (i) it is intrinsically rod-like due to the all-para-connected phenylene moieties, and (ii) it is perfectly inert against hydrolysis and all other side reactions possible in aqueous media. Hence, much effort has been spent in developing powerful synthetic routes for the preparation of PPP-based polyelectrolytes [38-56].

In our early studies on PPP synthesis we successfully combined the Pd-catalyzed Suzuki reaction with the concept of solubilizing flexible side chains to make available high-molecular-weight but nevertheless readily soluble polymers [57-59]. Later on, we broadened the scope of this concept to the synthesis of rod-like PPP polyelectrolytes. In most cases, we renounced the apparently more convenient direct polyelectrolyte syntheses (general route A in Scheme 1). This was because parameters such as the average molar masses and the molar-mass distributions are important quantities for the profound interpretation of the polyelectrolytes' properties but are very difficult to determine using ionic polymers. Instead, we applied macromolecular substitution routes (general route B in Scheme 1) for our polyelectrolyte syntheses [38-42]. Here, the Pd-catalyzed polycondensation process (step 1) leads to a non-ionic precursor PPP which can be characterized using all conventional techniques of polymer analysis. Provided a sufficiently efficient and selective derivation process is available for the subsequent step 2, the fully analyzed precursors can be converted into the desired PPP polyelectrolytes while all molecular information determined in advance by means of the uncharged precursors remains valid.

Phenoxyalkyl groups were found to belong to the most appropriate precursor functionalities for this synthetic strategy [40-42]: they proved to be perfectly inert during the Pd-catalyzed polycondensation process but can be converted easily and quantitatively into many different electrolyte groups. Scheme 2 displays possible conversions of the phenoxyhexyl-substituted precursor PPP 1 via the reactive intermediate 2 into cationic PPP polyelectrolytes $\mathbf{3}$ - 5.

Using this precursor strategy, a variety of further polyelectrolytes was prepared like 9 - 11 (Scheme 3) as well as their anionic counterparts bearing, for example, carboxylic acid or sulfonic acid functionalities. However, only those polymers proved to be soluble in water which bear at least two cationic groups at each $p$-phenylene repeating unit as is the case in $\mathbf{3}$ and $\mathbf{4}$. All other polymers, even if four cationic groups are attached to every second phenylene moiety like in PPP 11 - which thus 
has the same overall charge density as its water-soluble counterpart $\mathbf{3}$ - are insoluble in water.
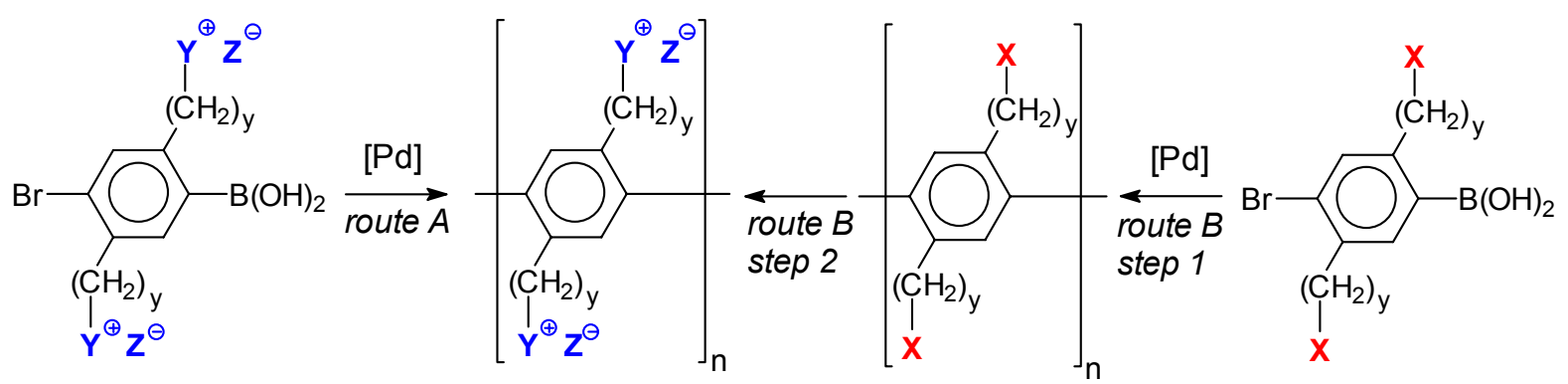

$$
\mathbf{Y}^{\oplus} \mathbf{Z}^{\ominus} \text { : electrolyte functionality } \mathbf{X} \text { : precursor functionality }
$$

Scheme 1. General presentation of direct syntheses (route A) and precursor routes (route B) leading to PPP polyelectrolytes
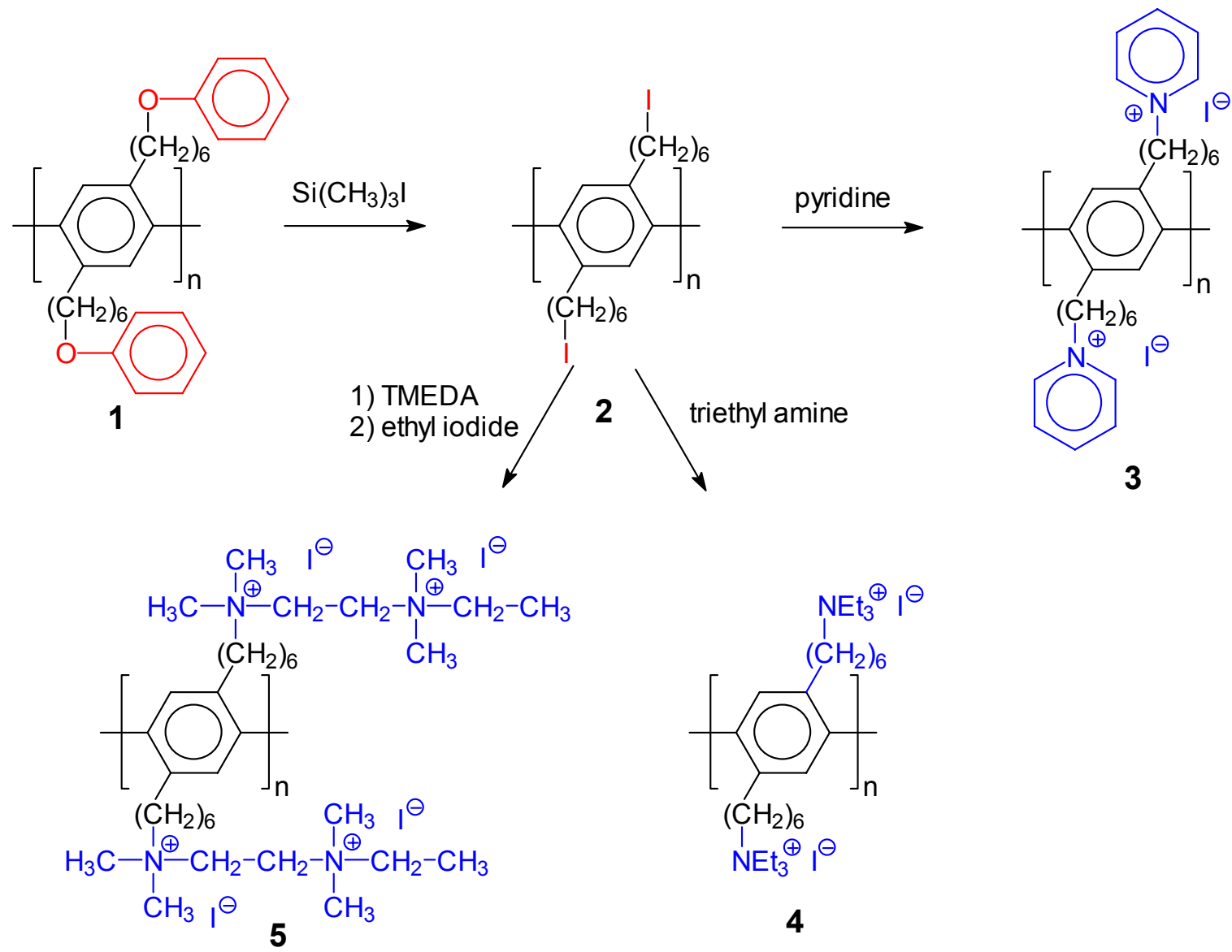

Scheme 2. Precursor syntheses leading to water-soluble cationic PPP polyelectrolytes

We assume that this strong influence of the molecular architecture on water solubility is due to the fact that the skeleton of all these PPPs is an apolar hydrocarbon. The water solubility of systems like $\mathbf{3}$ or $\mathbf{4}$ is therefore only generated by the cationic ammonium groups which cover the molecule's surface and thus prevent intermolecular hydrophobic interactions of the apolar macromolecule's interior. To be 
sufficiently effective in water, this polar cylinder shell seems to need (i) a minimum of charge-density and (ii) a sufficient homogeneity of charge distribution. If this is not the case, intermolecular hydrophobic interactions either cause aggregation leading to well-defined micellar systems - as in sulfonated PPPs described by Wegner et al. [51-56] - or agglomeration and precipitation - as in polymers like 9 - 11. Consequently, investigations on molecular-dispersely dissolved PPP polyelectrolytes in aqueous media have only been possible so far by means of the rod-like polyelectrolytes 3 - 5 [57-66]. In order to decide how the observed effects can be generalized, the corresponding investigations have to be carried out by means of PPP polyelectrolytes with lower charge density. Therefore we need a new strategy which makes available new PPP polyelectrolytes which remain soluble in water even at vanishing charge density.

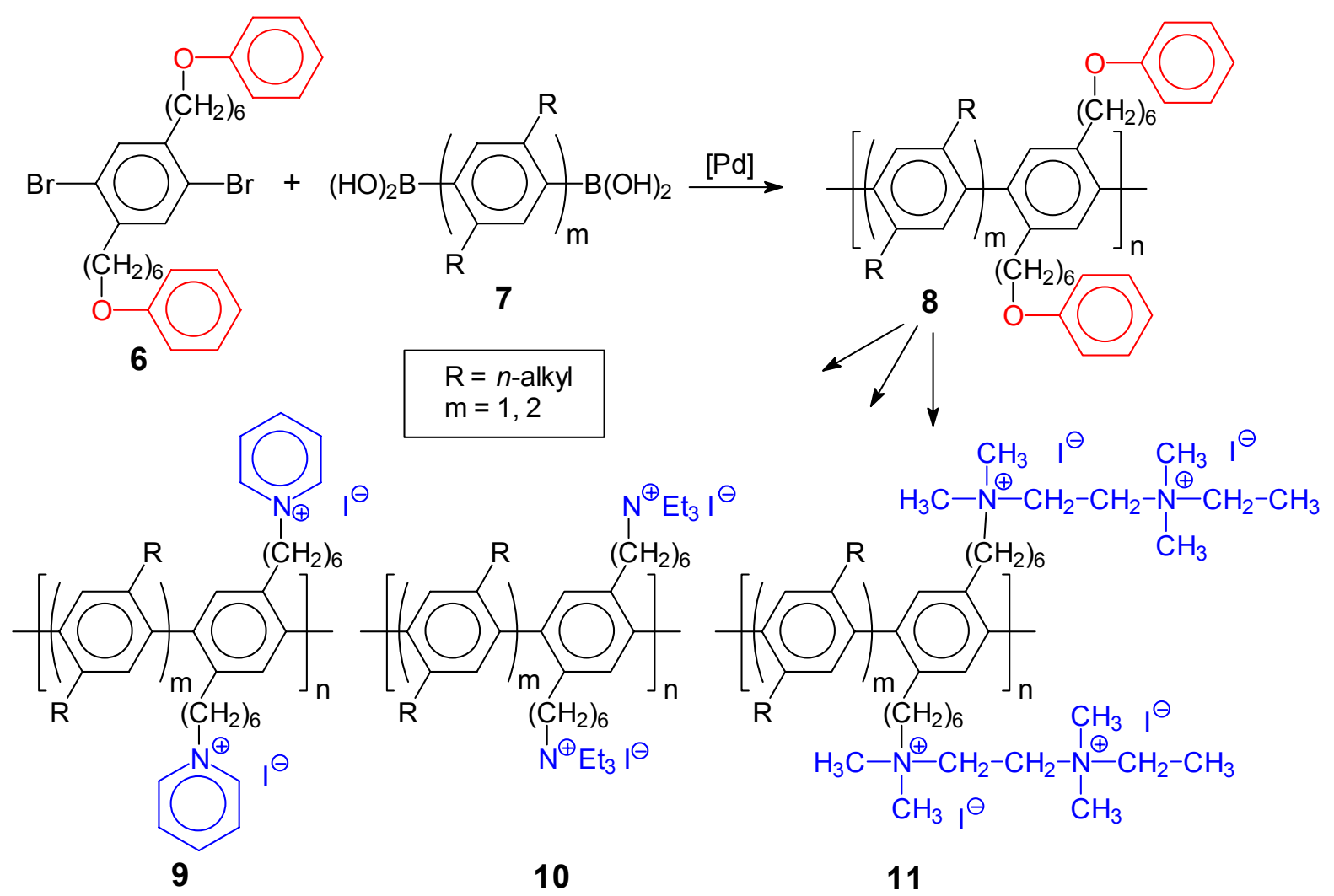

Scheme 3. Precursor syntheses leading to water-insoluble cationic PPP polyelectrolytes

\section{Strategy}

The attachment of oligo(ethylene oxide) (OEO) side chains was expected to increase the solubility of PPP-based polymeric systems in water tremendously: poly(ethylene oxide) is a water-soluble polymer which should efficiently lower the intermolecular hydrophobic interactions when attached as a lateral OEO substituent to the apolar PPP main chain. Advantage has already been taken of this useful effect in other cases. Luminescent PPP polyelectrolytes for LED applications [44], semiconducting polymers for sensors [67], and molecular composites for ion-conducting membranes [68] may serve as examples. Therefore, we decided to increase the solubility of polymers like $\mathbf{9}$ - 11 in water by using OEO substituents instead of the alkyl moieties used so far. 
When OEO side chains are present, however, it is impossible to use the powerful precursor strategy shown in Schemes 2 and 3 because ether cleavage is a key step there. When this treatment is applied to an OEO-substituted precursor PPP, it will cleave not only the phenoxyalkyl groups but also the OEO side chains. Therefore we had to fundamentally modify our precursor strategy.

In order to make available the new PPP polyelectrolytes, we decided to take advantage of amino groups as the precursor functionalities instead of the phenoxyalkyl ether groups used so far, and to introduce the quaternary ammonium groups later on via treatment of the polyamino precursors using low-molecular-weight alkyl halogenides (Scheme 4). Under these conditions, the OEO side chains will remain unchanged. A second advantage of this new strategy should be a clearly simplified and accelerated polyelectrolyte synthesis as the time-consuming ether cleavage on precursors such as $\mathbf{2}$ is no longer necessary.

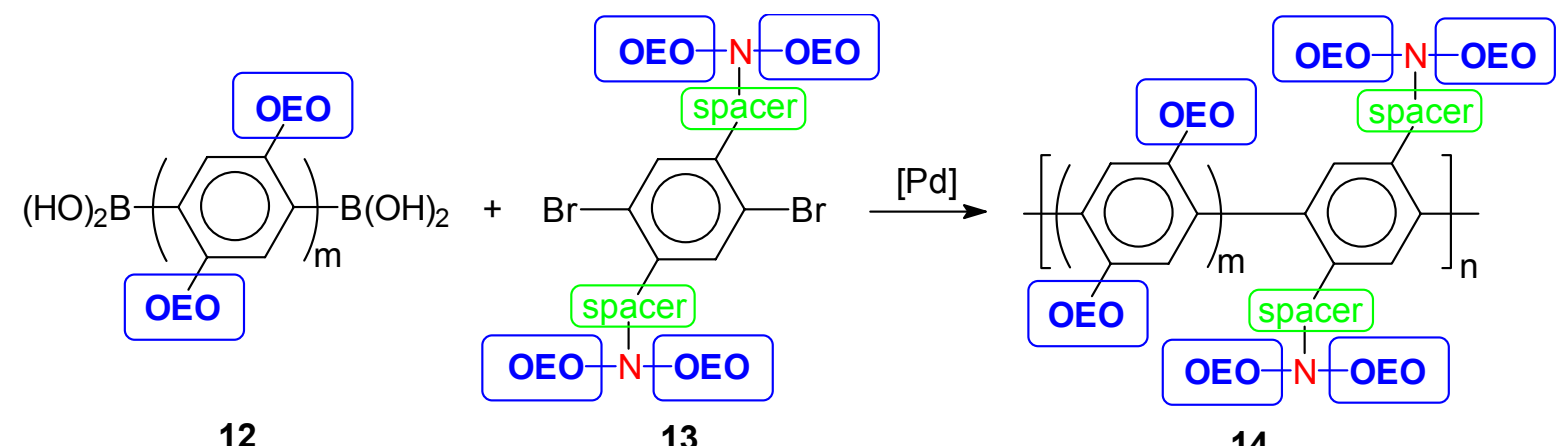

12

13

OEO: oligoethylene oxide

spacer: (a) $-\mathrm{CH}_{2^{-}}$, (b) $-\left(\mathrm{CH}_{2}\right)_{6}$ - or (c) - OEO

R': H, alkyl; X: Cl, Br. I

Colors are defined as follows:

Blue: polar subunits

Black: apolar subunits

Red: precursor functionalities

Green: either polar or apolar subunits

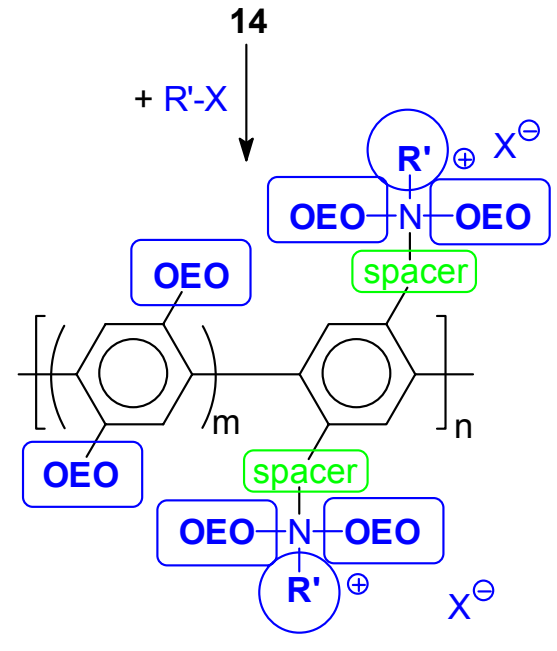

15

Scheme 4. General presentation of the new precursor strategy leading to OEOsubstituted PPP polyelectrolytes

In the present paper, we describe how we prepared the monomers required for the new synthetic pathway. Then, we discuss the structural requirements which the monomers must fulfil to guarantee a successful Pd-catalyzed polycondensation process. The synthesis of the desired OEO- and amino-functionalized precursor PPPs 14 and their profound constitutional characterization will follow. Finally, the results of some experiments are described dealing with the controlled step-by-step protonation of selected precursor PPPs 14. 


\section{Results and discussion}

\section{Monomer synthesis}

The new monomers required for the synthesis of amino-functionalized precursor PPPs 14 are, on the one hand, OEO-substituted benzenediboronic acid derivatives 12 and, on the other hand, 1,4-dibromobenzene derivatives 13 bearing lateral amino groups. The precursor functionalities should be attached to the aromatic rings via spacers of tailor-made length and polarity.

The OEO-substituted benzenediboronic acid derivatives 12 as well as their cyclic 1,3propanediol diesters $12^{*}$ were expected to be available in analogy to their well-known $n$-alkyl- or $n$-alkoxy-substituted counterparts $[58,68]$ :

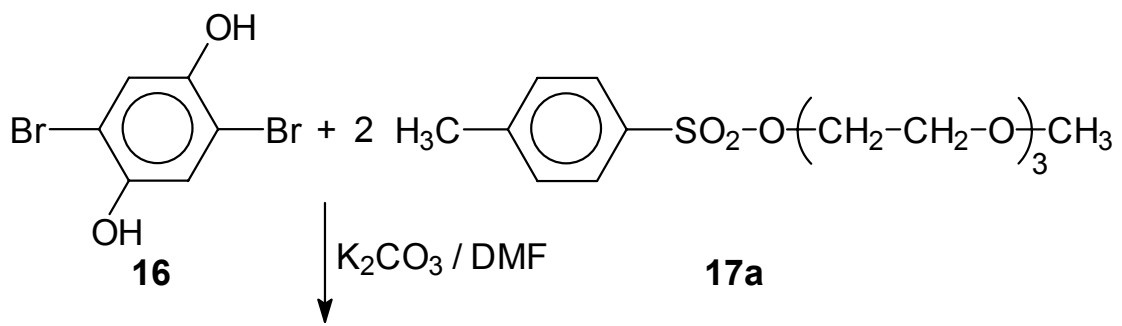

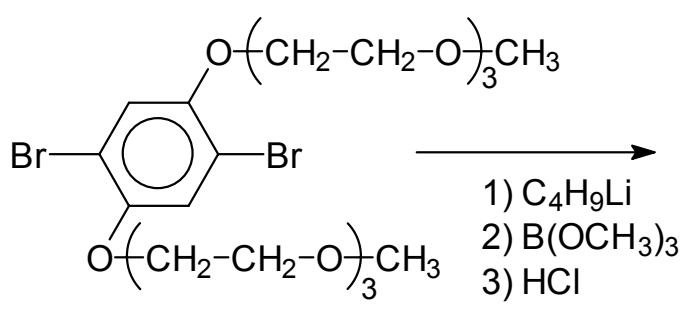

18<smiles>COCCOc1cc([18OH])c([18OH])cc1OCCOC</smiles>

12<smiles>CCOc1cc(B2OCCCO2)c(C([14CH2])=O)cc1B1OCCCO1</smiles>

Scheme 5. Synthesis of OEO-substituted 1,4-benzenediboronic acid derivatives 12 and $12^{*}$

In the first step, 2,5-dibromohydroquinone 16 was treated with tosylate 17a [69]. Pure 1,4-dibromobenzene derivative 18 was obtained in approx. $80 \%$ yield. The subsequent conversion of $\mathbf{1 8}$ into the diboronic acid derivatives 12, however, proved to be difficult. Standard reaction conditions reported to be successful for the synthesis of benzenediboronic acids are, for example, addition of $n$-butyllithium to the dibromobenzene derivative, dissolved in $n$-hexane or diethyl ether at $-78,-30,0$ or $60^{\circ} \mathrm{C}$, followed by trialkyl borate and final hydrolysis with dilute hydrochloric acid. When we applied these conditions here, we either recovered the starting material 18 nearly unchanged or obtained the dehalogenated starting material B (Scheme 6). Unchanged starting material $\mathbf{1 8}$ was mainly found in those cases where only a slight 
excess of $n$-butyllithium was applied. We interpreted this finding as a consequence of larger amounts of water present in 18 even after recrystallization and careful drying. This is reasonable because of the highly polar OEO side chains which are wellknown to retain moisture in the material. This moisture causes decomposition of the added organolithium reagent prior to the desired halogen-metal exchange $18 \rightarrow \mathrm{A}$ (Scheme 6). On the other hand, when we added a larger excess of $n$-buthyllithium, the halogen-metal exchange $18 \rightarrow$ A clearly proceeded, but after work-up, the dehalogenated hydroquinone derivative $\mathbf{B}$ was the main product.

$\mathbf{B}$ is clearly formed via hydrolysis of the dilithiated intermediate $\mathbf{A}$ and hence the latter conversions were somehow more successful than the former. However, in order to find appropriate reaction conditions for the formation of the required diboronic acids 12, we had to find out whether the hydrolyzed species $\mathbf{B}$ obtained so far is formed via a fast side-reaction of a highly reactive intermediate $\mathbf{A}$ already prior to the final hydrolysis, or whether it is alternatively formed during the final hydrolysis because $\mathbf{A}$ is not reactive enough to undergo the conversion with $\mathrm{B}\left(\mathrm{OCH}_{3}\right)_{3}$ under the selected conditions. To answer this question, we compared the rates of the halogen-metal exchange $18 \rightarrow \mathrm{A}$ of the subsequent lithium-boron exchange with the respective rates observed in the corresponding conversions of the $n$-alkyl- and $n$-alkoxysubstituted 1,4-dibromobenzene analogs.

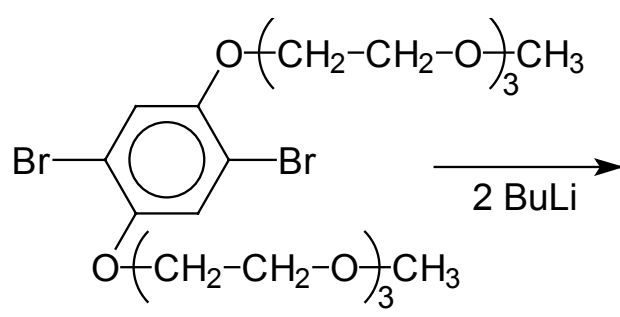

18

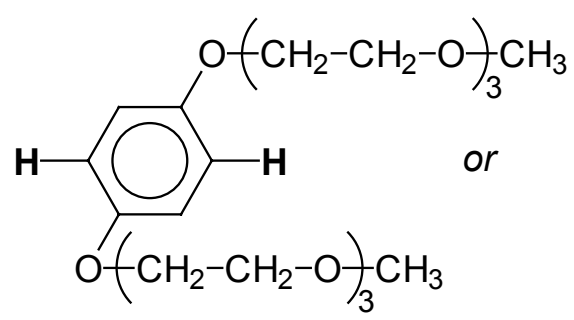

B

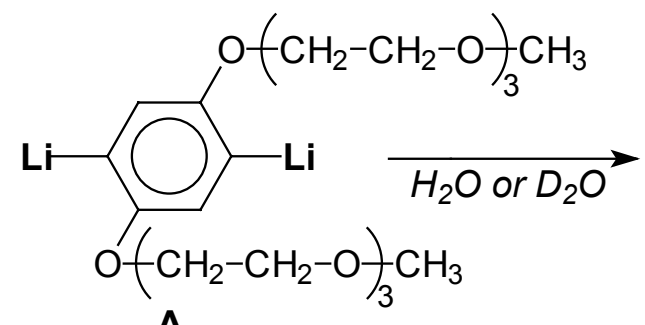

A

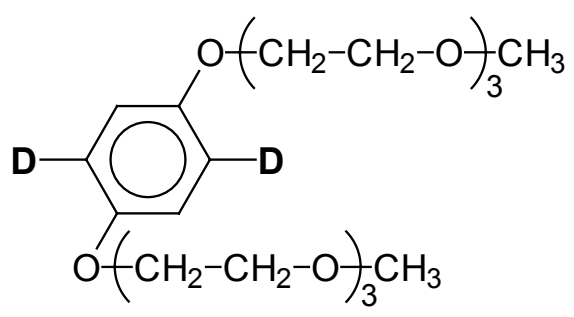

C

Scheme 6. Model reactions performed to optimize the reaction conditions leading to 1,4-benzenediboronic acid derivative 12

In practice, we first performed the halogen-metal exchange processes under different conditions, varying the applied lithium compound and its quantities, the solvent, the reaction temperature and the reaction time. Each entry was quenched using deuterium oxide which enables us to determine, using ${ }^{1} \mathrm{H}$ and ${ }^{13} \mathrm{C}$ NMR spectroscopy, whether or not lithium was attached to the aromatic ring just prior to hydrolysis (Scheme 6). These studies showed that the halogen-metal exchange is much faster for $18 \rightarrow$ A than in the corresponding $n$-alkyl- or $n$-alkoxy-substituted 1,4 -dibromobenzene derivatives: the bis-deuterated product $\mathbf{C}$ was obtained in excellent yields under standard reaction conditions, proving the 1,4-dilithiobenzene intermediates to live until the final addition of $\mathrm{D}_{2} \mathrm{O}$ and thus - in principle - until the addition of 
$\mathrm{B}\left(\mathrm{OCH}_{3}\right)_{3}$ as well. However, addition of $\mathrm{B}\left(\mathrm{OCH}_{3}\right)_{3}$ did not lead to the diboronic acid. This means that $\mathbf{A}$ is not reactive enough to undergo the desired conversion with $\mathrm{B}\left(\mathrm{OCH}_{3}\right)_{3}$ under the conditions tested so far.

In order to activate the dilithiobenzene intermediate $\mathbf{A}$, tetrahydrofuran (THF) was used as the solvent instead of $n$-hexane or diethyl ether. After quenching the new entries using deuterium oxide it became evident that the halogen-metal exchange 18 $\rightarrow \mathbf{A}$ is followed by a fast protolysis of the aryllithium intermediate $\mathbf{A}$ when unsuitable reaction temperatures or reaction times were applied. Compound $\mathbf{B}$ is then the main product, despite a final $\mathrm{D}_{2} \mathrm{O}$ hydrolysis. When reaction conditions and lithium reagents were suitably selected, however, the bis-deuterated product $\mathbf{C}$ was obtained in excellent yields from the entries where THF was the solvent. The highest yields of C were found when 2.2 equivalents of sec-butyllithium were added to the THF solution of 18 at $-90^{\circ} \mathrm{C}$, immediately followed by the addition of $\mathrm{D}_{2} \mathrm{O}$ at $-70^{\circ} \mathrm{C}$.

Maintaining all other parameters constant, trimethyl borate was now used instead of $\mathrm{D}_{2} \mathrm{O}$ to prepare the desired benzenediboronic acids 12 . After the reaction mixture was allowed to slowly warm up to room temperature, the desired benzenediboronic acid 12 was formed in excellent yields (NMR). This allows the conclusion that the halogen-metal exchange is certainly accelerated by the OEO side chains but the lithium-boron exchange is drastically retarded compared to the corresponding $n$-alkylor $n$-alkoxy-substituted 1,4-dibromobenzene derivatives. It is reasonable to assume that these two effects are consequences of the ability of the OEO side chains to coordinate the lithium functionality of $\mathbf{A}$, as is schematically shown in the following drawing [70].

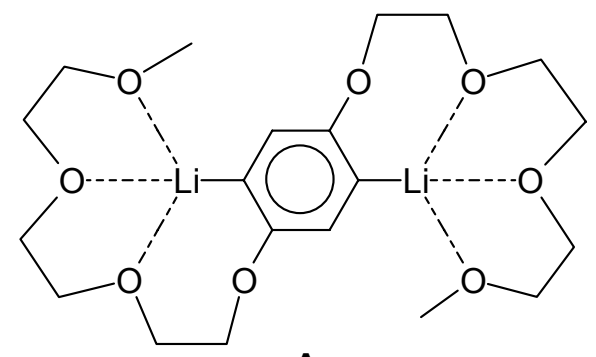

A

Finally, an efficient procedure was also required for the work-up of the benzenediboronic acids 12. Since large amounts of boric acid prevented isolation of 12, the excess of $\mathrm{B}\left(\mathrm{OCH}_{3}\right)_{3}$ required for the synthesis of 12 was removed by vaporization prior to hydrolysis as completely as possible. Then, the diboronic acid 12 was available in yields of $>50 \%$ and high purity $\left(>98 \% ;{ }^{1} \mathrm{H}\right.$ NMR). Finally, a portion of the boronic acid 12 was converted into the cyclic 1,3-propanediol diester $12^{*}$. In addition to the benzenediboronic acid derivatives 12 and $12^{*}$, further aryldiboronic acid derivatives 19 and 20 as well as their diester counterparts $19^{*}$ and $20^{*}$ were prepared according to the literature. They were needed primarily for model investigations performed to optimize the polycondensation process.

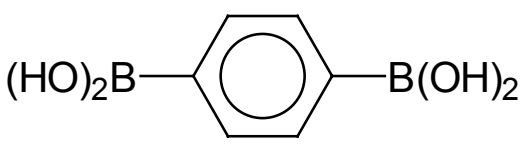

19

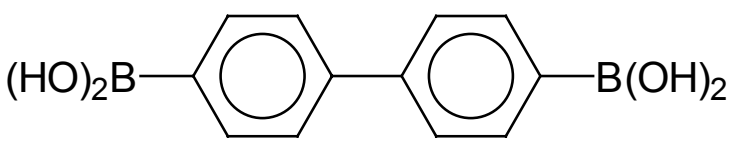


Amino-functionalized 1,4-dibromobenzene monomers of general structure 13 were the required counterparts of the benzenediboronic acid derivatives in the $\mathrm{Pd}$ catalyzed Suzuki synthesis according to Scheme 4. Therefore we prepared three monomers $13 \mathbf{a}-\mathbf{c}$ having different spacer groups between the aromatic ring and the amino nitrogen atoms, i.e., (a) $-\mathrm{CH}_{2-}^{-}$, (b) $-\left(\mathrm{CH}_{2}\right)_{6^{-}}$, and (c) $-\left(\mathrm{OCH}_{2} \mathrm{CH}_{2}\right)_{3^{-}}$(see Schemes 7 and 8). The two monomers $13 \mathbf{a}$ and $13 \mathbf{b}$ were obtained according to the route shown in Scheme 7: Monomer 13a was prepared from $p$-xylene 21 via its transformation into the brominated intermediates 22 and 23 [38,71], followed by treatment with a secondary amine $24(\alpha \beta \gamma)$. The competitive quaternization of the amino groups could be suppressed by applying a sufficiently high excess of $24(\alpha \beta \gamma)$ and very mild reaction conditions. Identical conditions were also found to be well appropriate for the last step in the synthesis of $13 \mathbf{b}$ : Here, the required tetrabromo compound $\mathbf{2 8}$ was obtained via Ni-catalyzed alkylation of 1,4-dichlorobenzene $\mathbf{2 5}$ using the Grignard species of 1-bromo-6-methoxy- $n$-hexane, followed by ether cleavage and bromination of intermediate 27 [40].

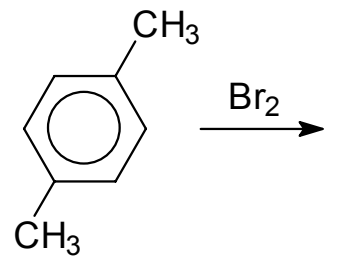

21

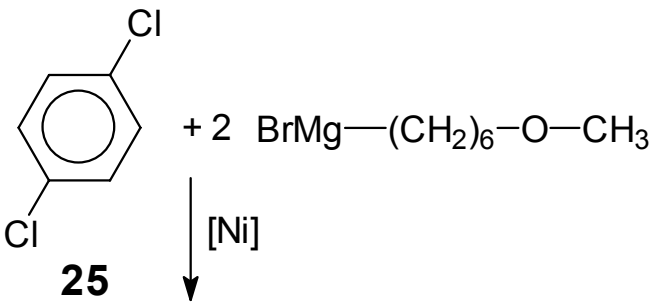<smiles>Cc1cc(Br)c(C)cc1Br</smiles>

22

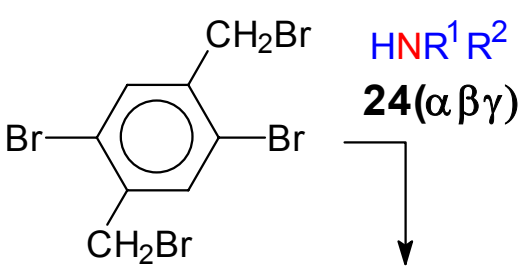

23<smiles>[R]N([R])NCc1cc(Br)c(Br)cc1CCN([R])N([R])[R]</smiles>

$13 a, b(\alpha \beta \gamma)$

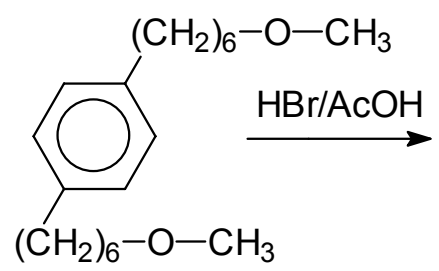

26

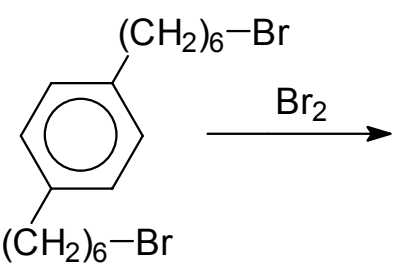

27

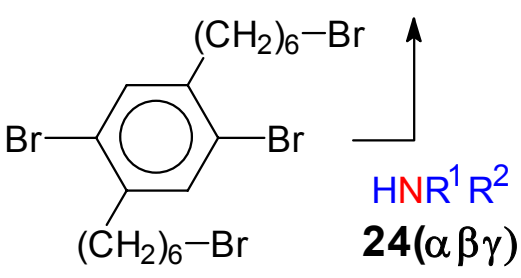

28

$$
\begin{aligned}
& \alpha: R^{1}=R^{2}=-C_{2} C_{2} \mathrm{CH}_{2} \mathrm{OCH}_{3}, \beta: R^{1}=-\mathrm{CH}_{2} \mathrm{CH}_{2} \mathrm{OCH}_{3}, \mathrm{R}^{2}=-\left(\mathrm{CH}_{2} \mathrm{CH}_{2} \mathrm{O}\right)_{3} \mathrm{CH}_{3} \\
& \gamma: R^{1}=-\mathrm{CH}_{2} \mathrm{CH}_{2} \mathrm{OCH}_{3}, \mathrm{R}^{2}=-\left(\mathrm{CH}_{2} \mathrm{CH}_{2} \mathrm{O}\right)_{8}-\mathrm{CH}_{3} \quad y=\mathbf{a}: 1, \mathbf{b}: 6
\end{aligned}
$$

Scheme 7. Synthetic routes used to prepare the amino-functionalized dibromobenzene derivatives $\mathbf{1 3 a , b}$

The third amino-functionalized 1,4-dibromobenzene monomer $13 \mathrm{c}$ bearing a tri(ethylene oxide) spacer group between the aromatic ring and the amino nitrogen atom was prepared according to the procedure shown in Scheme 8. In the first step, 2,5-dibromohydroquinone 29 was treated with an excess of 1-chlorotri(ethylene 
glycol) $\mathbf{3 0}$ under basic conditions. The hydroxy termini of the side chains of $\mathbf{3 1}$ were subsequently tosylated, leading to the reactive intermediate 32 in excellent yields [72]. Finally, conversion of $\mathbf{3 2}$ with a large excess of a secondary amine $24(\alpha \beta \gamma)$ and column chromatography afforded pure (>98\%; ${ }^{1} \mathrm{H}$ NMR) compound $13 \mathrm{c}$ in $>60 \%$ yield.<smiles>Oc1cc([18F])c(Br)cc1O</smiles><smiles>CCOc1cc(Br)c(OCCOO)cc1Br</smiles>

29

30<smiles>[R2]NO[13CH2]CCOc1cc(Br)c(OC)cc1Br</smiles>

$13 \mathrm{c}$
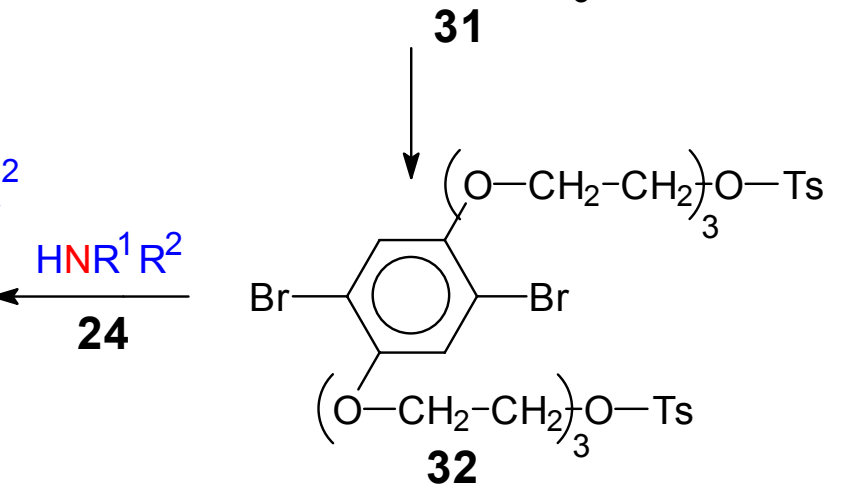

Scheme 8 . Synthetic route used to prepare the amino-functionalized dibromobenzene derivative 13c

We usually used bis $\left(\beta\right.$-methoxyethyl)amine $\left(\alpha ; \mathrm{R}^{1}=\mathrm{R}^{2}=\mathrm{CH}_{2} \mathrm{CH}_{2} \mathrm{OCH}_{3}\right)$ as the secondary amine 24. However, to be able to further increase the water solubility of the final PPP derivatives, we also prepared some secondary amines 24( $\beta \gamma)$ having one OEO chain of arbitrary (average) length. While synthetic approaches tailor-made for the preparation of secondary amines [74-79] failed for reasons we have been unable to identify so far, we succeeded in the synthesis of amines $\mathbf{2 4}(\beta \gamma)$ by applying the straight-forward synthesis shown in Scheme 9 [80]:

In the first step, the selected oligo(ethylene glycol) monomethyl ether 34a,b was treated with tosyl chloride 33 to give the respective tosylate $17 \mathbf{a}, \mathbf{b}$ which was then reacted with an excess of 2-methoxyethylamine 35. After removal of the excess of 35, the secondary amine $\mathbf{2 4}(\beta \gamma)$ was obtained in sufficient purity for the subsequent conversions according to Schemes 7 and 8 .

All monomers as well as the intermediates described above were characterized with regard to their molecular constitution using ${ }^{1} \mathrm{H}$ and ${ }^{13} \mathrm{C}$ NMR spectroscopy and mass spectrometry. As representative examples, Fig. $1 A, B$ shows the ${ }^{1} H$ NMR spectra of monomers 12 and $13 \mathrm{~b} \beta$. The analytical information was throughout in full agreement with the expected chemical constitution. The purities were determined to be $>98 \%$ for all monomers used in the subsequent polymerization experiments. 


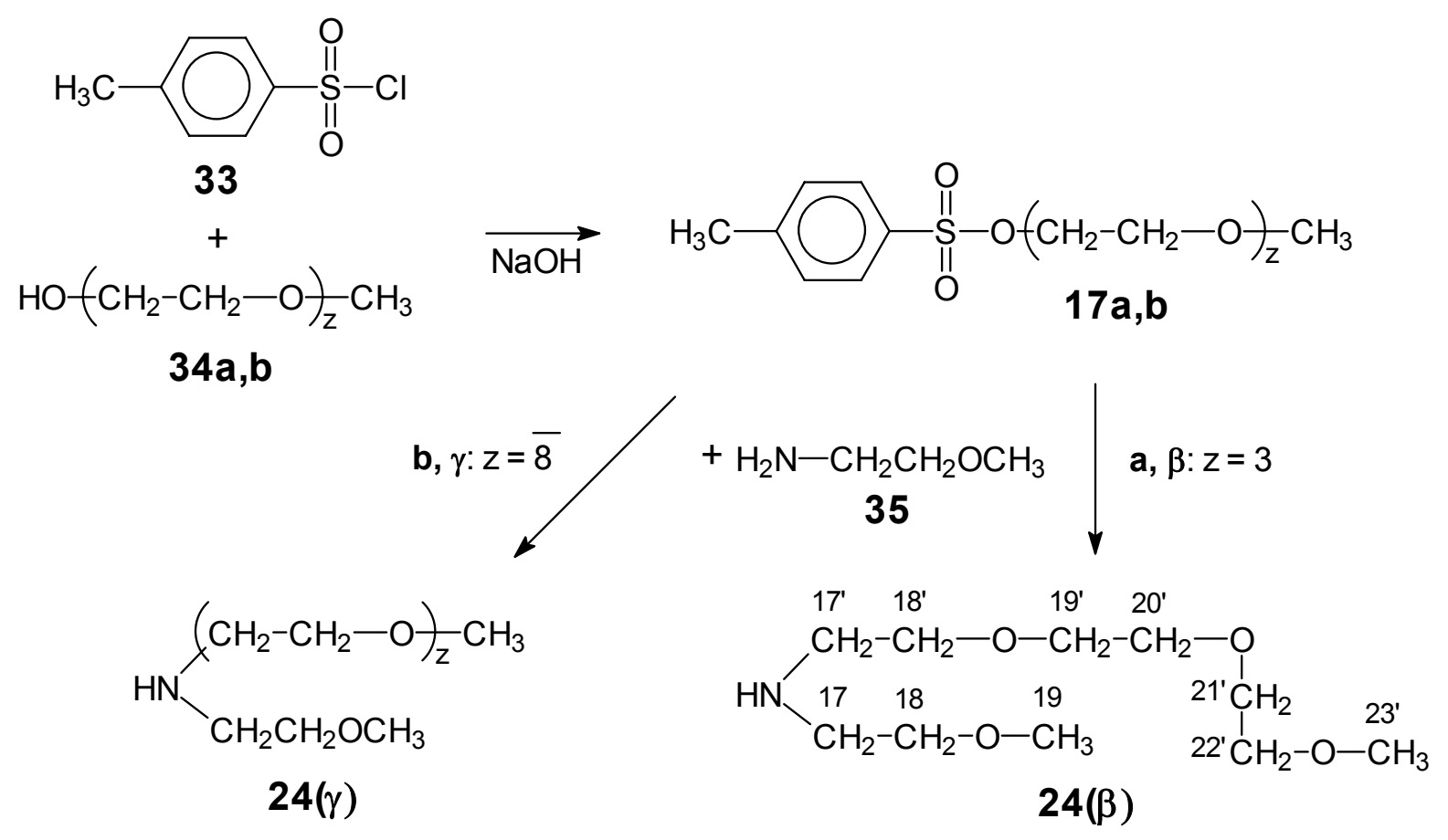

Scheme 9. Synthetic routes used to prepare secondary amines $\mathbf{2 4}(\beta \gamma)$

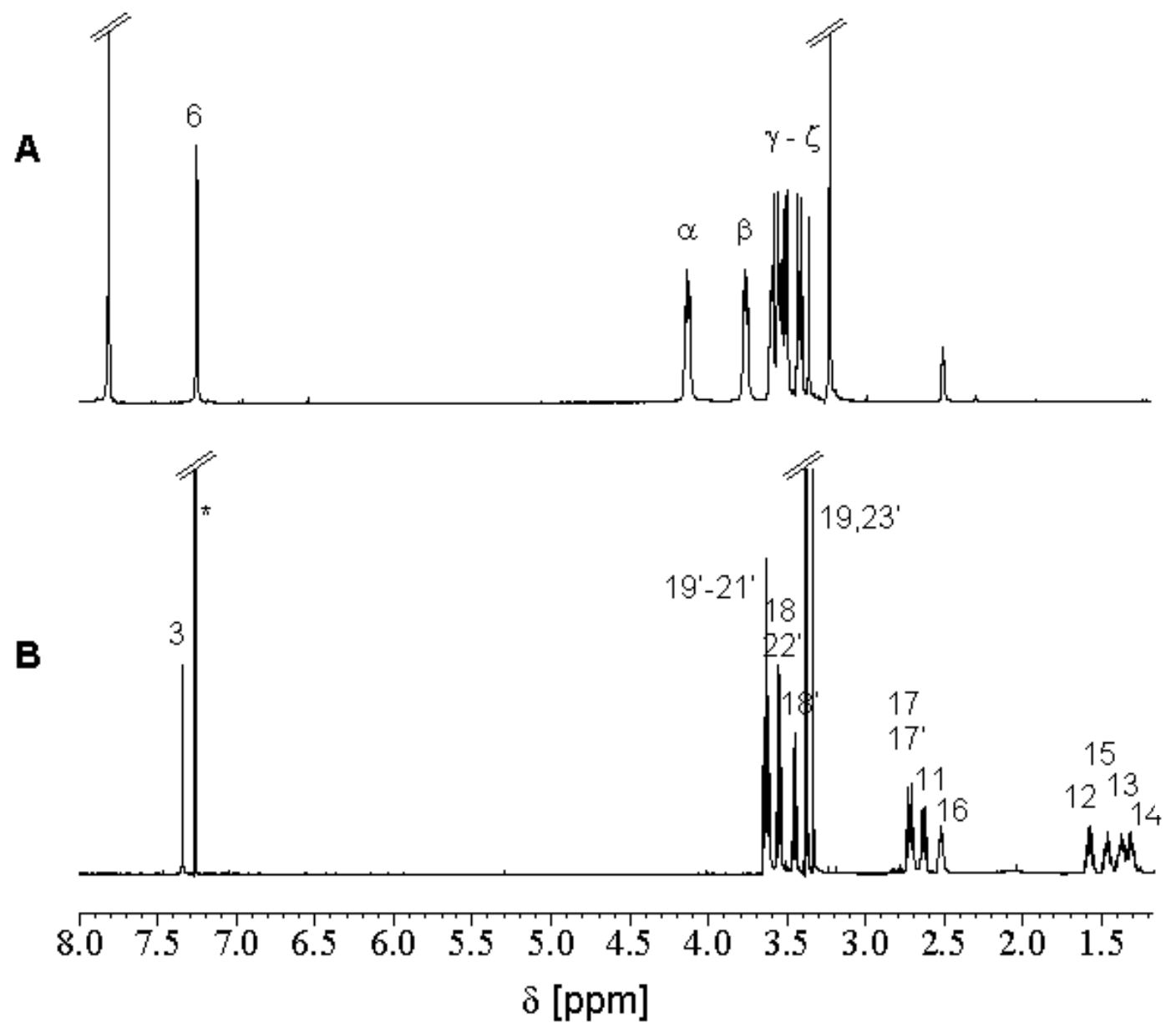

Fig. 1. ${ }^{1} \mathrm{H}$ NMR spectra of monomers $12(\mathrm{~A})$ and $13 \mathrm{~b} \beta(\mathrm{B})$, recorded in DMSO- $d_{6}(\mathrm{~A})$ and $\mathrm{CDCl}_{3}(\mathrm{~B})$ solutions at room temperature; the signal assignment is made in analogy to the numbering shown in Schemes 10 (for 12) and 9, 11 (for 13b $\beta$ ) 


\section{Model polycondensations}

The primary goal of the following model experiments was to analyze whether (a) the OEO side groups or $(b)$ the amino functionalities affect the Pd-catalyzed polycondensation process. Moreover, if the latter might be the case, we had to find out (c) which spacer groups between the aromatic ring and the tertiary amino groups can efficiently suppress this interaction. Finally, we had to analyze $(d)$ what the best reaction conditions, solvents, and catalysts are to couple the highly polar monomers under consideration here and (e) whether the free benzenediboronic acids 12 are more efficient as comonomers or the corresponding cyclic diesters $\mathbf{1 2}^{*}$.

In order to assess the influence of the polar OEO side groups on the Pd-catalyzed polycondensation process, we started our investigation by synthesizing the polymers $\mathbf{3 6}$ and $\mathbf{3 7}$ (Scheme 10). These model polymers are available from easily accessible starting materials and hence allow a profound analysis of the optimum reaction conditions for Suzuki polycondensations involving highly polar monomers. A sequence of polymerization experiments was carried out according to Scheme 10, varying the solvent (toluene or THF), the concentration of the aqueous base $\left(\mathrm{NaHCO}_{3}\right)$, the precursor complex of the catalytically active species $\left(\left[\mathrm{Pd}\left(\mathrm{PPh}_{3}\right)_{4}\right]\right.$, $\left.\left.\left[\mathrm{Pd}(\mathrm{PpTo})_{3}\right)_{3}\right],\left[\mathrm{PdCl}_{2}(\mathrm{dppf})\right],\left[\mathrm{Pd}(\mathrm{OAc})_{2}\right]\right)$, and the benzenediboronic acid derivative (free acids 12 compared to cyclic 1,3-propanediol diesters $12^{*}$; unsubstituted (19, 20, $\left.19^{*}, 20^{\star}\right)$ compared to OEO-substituted $\left(12,12^{\star}\right)$ species).

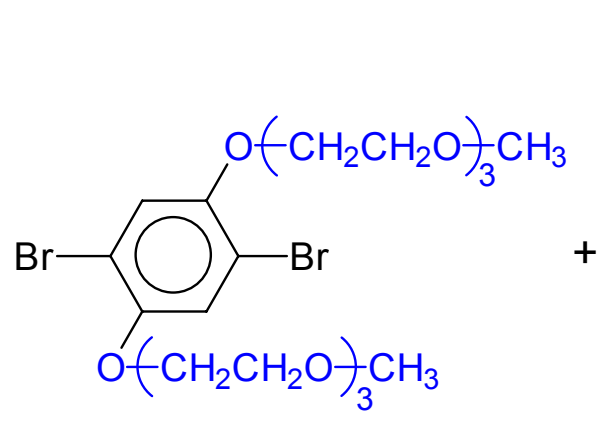

18
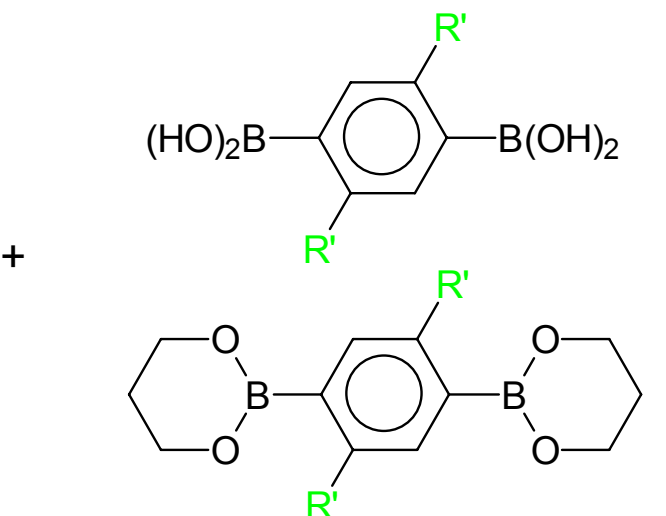

12 or 19

or

$12^{*}$ or $19^{*}$

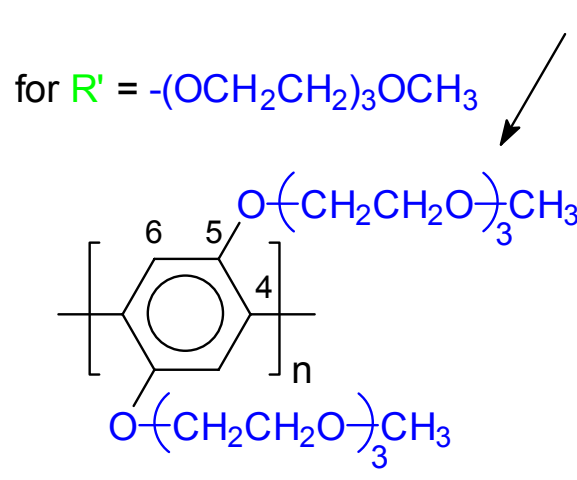

37

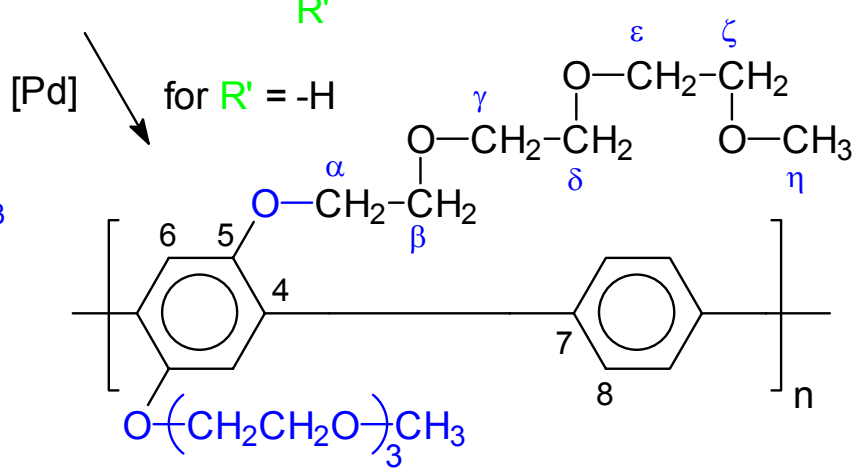

36

Scheme 10. Model polycondensations performed to analyze the influence of the polar OEO groups on the Pd-catalyzed Suzuki reaction

Throughout, exact equimolar amounts of the two respective co-monomers were heated and vigorously stirred for seven days. After four days, a small quantity of diboronic acid derivative was added to compensate potential weight errors caused by uncertainties of the water content of the diboronic acids. After six days, a small 
volume of bromobenzene was added to convert all remaining boronic acid functionalities into phenyl termini. This was done because boronic acid end groups are wellknown to aggregate and hence to affect the subsequent polymer characterization. Finally, the formed polymers were isolated by precipitation in $n$-hexane. The solid materials ( $>80 \%$ of the theoretically expected yield in all successful experiments) was analyzed using ${ }^{1} \mathrm{H}$ and ${ }^{13} \mathrm{C}$ NMR spectroscopy, mass spectrometry, sizeexclusion chromatography (SEC) and vapor-pressure osmometry (VPO) to prove the constitutional homogeneity of the polymers and their degrees of polycondensation. As examples, Fig. $2 \mathrm{~A}, \mathrm{~B}$ shows the ${ }^{1} \mathrm{H}$ NMR spectra of polymers $36(\mathrm{~A})$ and $37(\mathrm{~B})$, prepared in the THF / aqueous $\left.\mathrm{NaHCO}_{3} /\left[\mathrm{Pd}(\mathrm{PpTol})_{3}\right)_{3}\right]$ system using free diboronic acid 12 and diester $19^{*}$, respectively, as the comonomers.

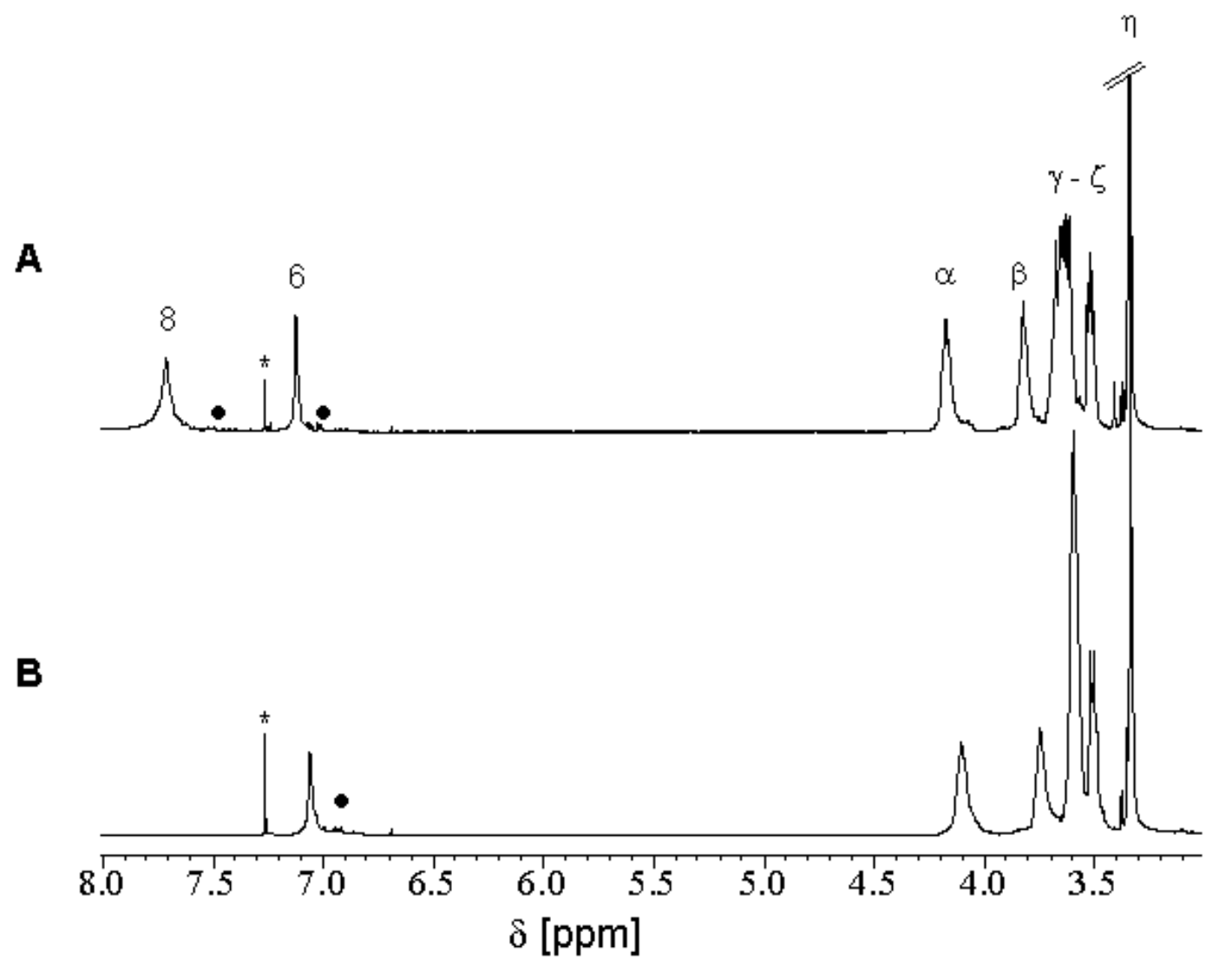

Fig. 2. ${ }^{1} \mathrm{H}$ NMR spectra of model polymers $36(\mathrm{~A})$ and $37(\mathrm{~B})$, recorded in $\mathrm{CDCl}_{3}$ at room temperature; the signal assignment is made according to the numbering shown in Scheme 10

It is evident that all intense absorptions observed in these spectra correspond to the hydrogen atoms of the inner-chain repeating units of polymers 36 and $\mathbf{3 7}$. Only some signals of minor intensity are detectable which could be assigned to the solvent $\left({ }^{*}\right)$, to residues of the catalyst, and to phenyl-, bromo- or hydrogen-bearing end groups (•). Moreover, because absorptions corresponding to structural irregularities cannot be observed, and because the signal intensity of the end group absorptions is very weak, an average degree of polycondensation $P_{\mathrm{n}} \approx 20$ was estimated for these polymers. This estimate was further supported by VPO and SEC studies. Very similar results were obtained when $\left[\mathrm{Pd}\left(\mathrm{PPh}_{3}\right)_{4}\right]$ was used instead of $\left.\left[\mathrm{Pd}(\mathrm{PpTo})_{3}\right)_{3}\right]$. This allows the conclusion that OEO side chains do not affect the Pd-catalyzed coupling 
reaction under the tested conditions. However, lower yields and lower values of $P_{\mathrm{n}}$ were found in many other coupling media. Hence, all subsequent polycondensation experiments were performed in tetrahydrofuran / $1 \mathrm{M}$ aqueous $\mathrm{NaHCO}_{3} /\left[\mathrm{Pd}\left(\mathrm{PPh}_{3}\right)_{4}\right]$ or $\left.\left[\mathrm{Pd}\left(\mathrm{PpTol}_{3}\right)_{3}\right)\right]$ as the coupling systems.

In the second step, we had to find out whether the amino groups present in the side chains affect the Pd-catalyzed polycondensation process. Therefore model investigations were carried out according to Scheme 11, using dibromobenzene derivatives $13 a, b$ as the monomers. While $13 a$ has a monomethylene spacer group between phenylene and amino moiety, there is a hexamethylene spacer group in $\mathbf{1 3 b}$. As diboronic acid counterparts, we used the unsubstituted compounds 19, 19*, 20 and 20*.
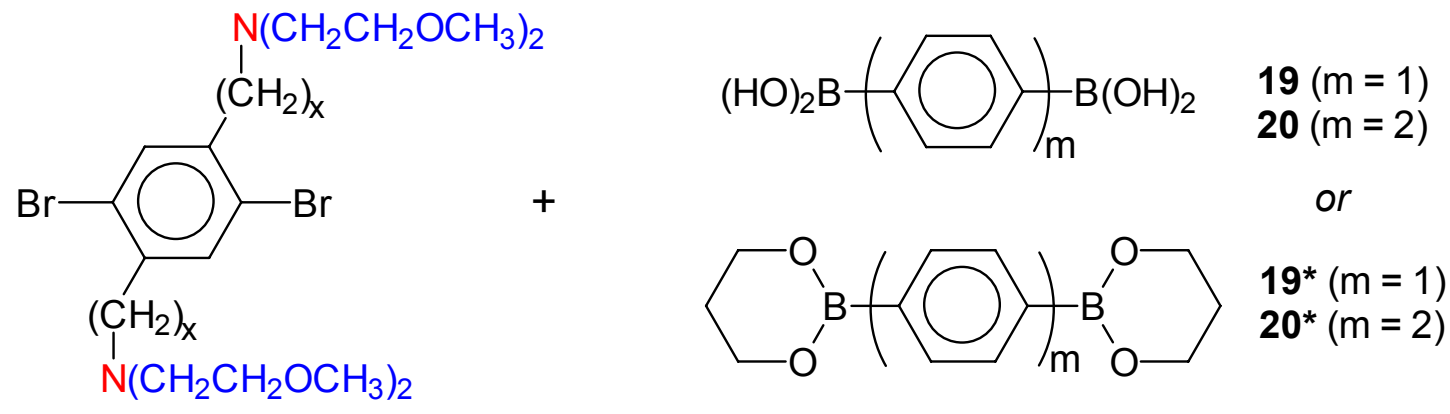

$13 a, b$
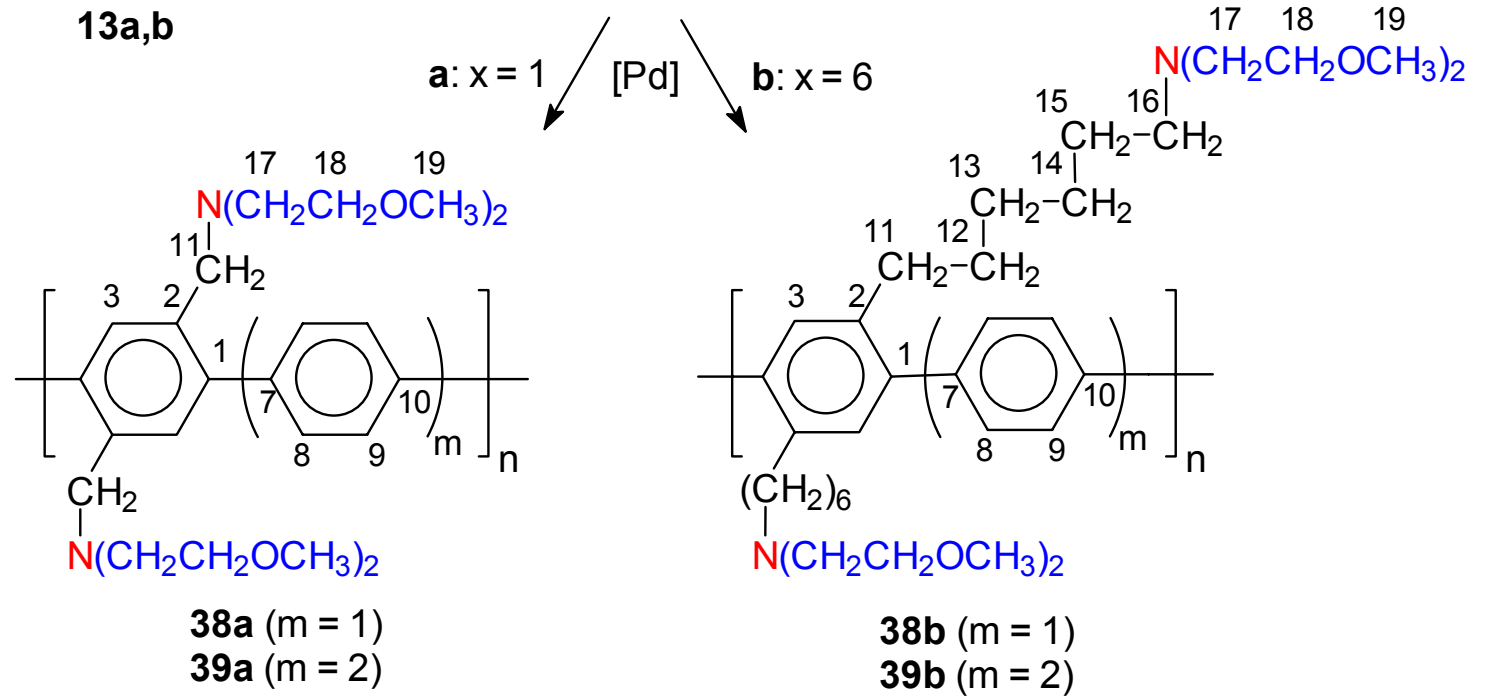

Scheme 11. Model polycondensations performed to analyze the influence of the amino groups on the $\mathrm{Pd}$-catalyzed Suzuki reaction (for the numbering of the aromatic protons and carbons, $7=10$ and $8=9$ for polymers with $\mathrm{m}=2$ )

The best results were obtained under the conditions which were found to be optimal for polymers $\mathbf{3 6}$ and $\mathbf{3 7}$ as well. On the other hand, we found lower yields and lower values of $P_{\mathrm{n}}$ in many experiments carried out in other coupling media. The finally produced PPPs 38 and 39 were analyzed using ${ }^{1} \mathrm{H}$ and ${ }^{13} \mathrm{C}$ NMR spectroscopy as well as VPO and SEC. As an example, Fig. 3 shows the SEC trace of polymer 38a prepared in THF / $1 \mathrm{M}$ aqueous $\mathrm{NaHCO}_{3} /\left[\mathrm{Pd}\left(\mathrm{PpTol}_{3}\right)_{3}\right]$. Fig. 4 and Fig. 5 show representative ${ }^{1} \mathrm{H}$ and ${ }^{13} \mathrm{C}$ NMR spectra of polymers $38 \mathrm{~b}(\mathrm{~A})$ and $39 \mathrm{a}(\mathrm{B})$ obtained under the same conditions, using the diboronic diesters $19^{*}$ and $20^{*}$, respectively, as the comonomers. 


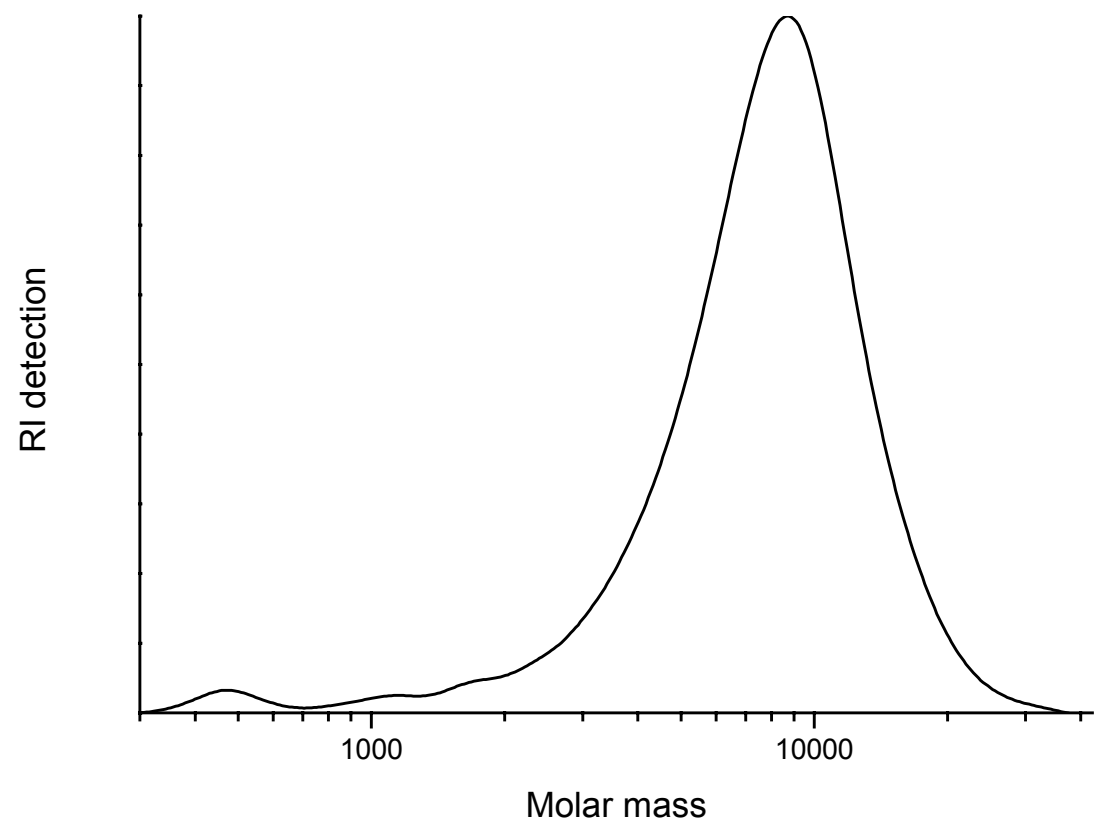

Fig. 3. SEC trace of polymer 37a, prepared in tetrahydrofuran / $1 \mathrm{M}$ aqueous $\mathrm{NaHCO}_{3}$ $/\left[\mathrm{Pd}(\mathrm{PpTol})_{3}\right]$ as the coupling system; measurement performed in THF solution at room temperature

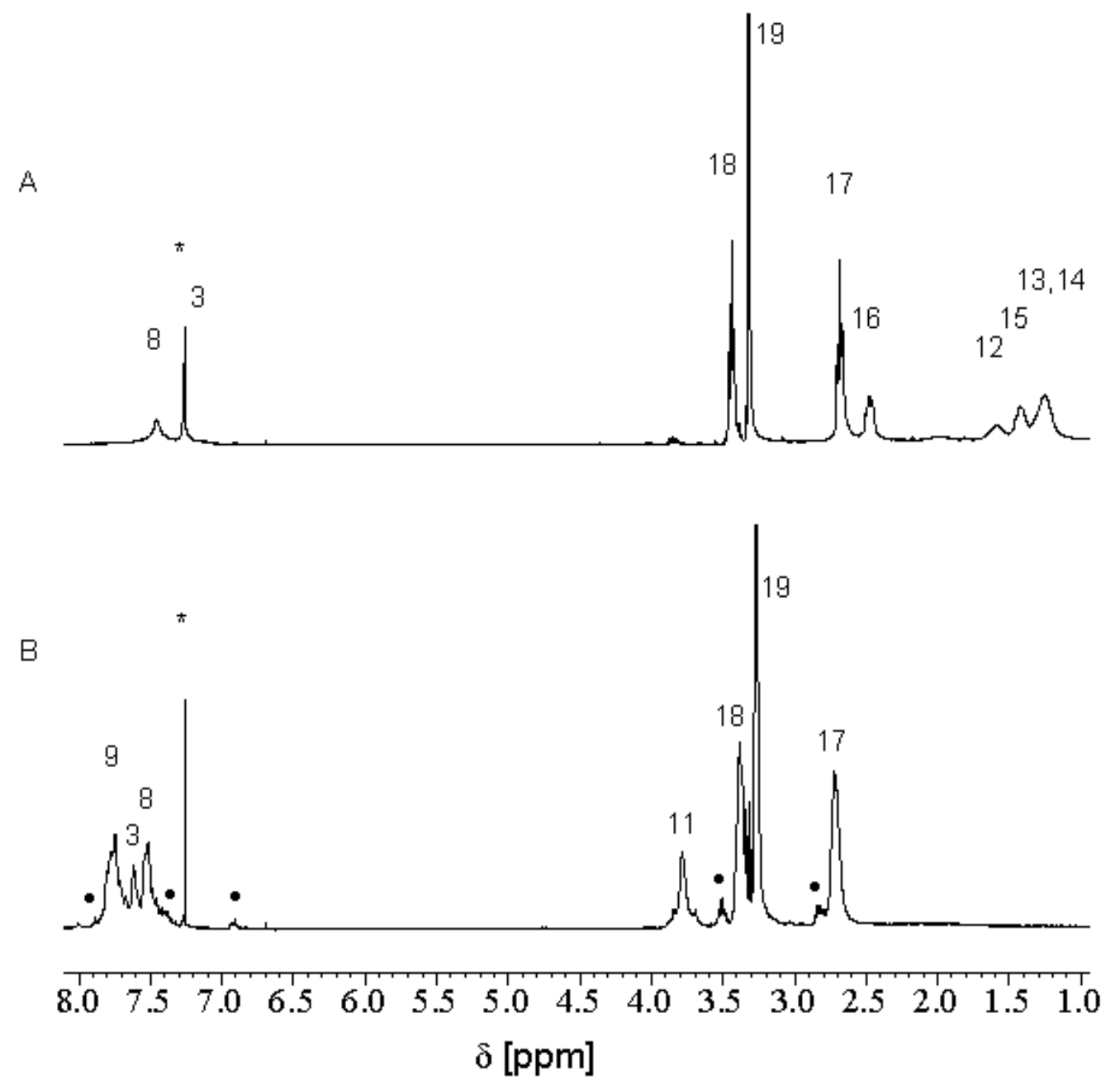

Fig. 4. Representative ${ }^{1} \mathrm{H}$ NMR spectra of polymers $38 \mathbf{b}(A)$ and $39 a(B)$, recorded in $\mathrm{CDCl}_{3}$ at room temperature; signal assignment is made according to the numbering shown in Scheme 11 


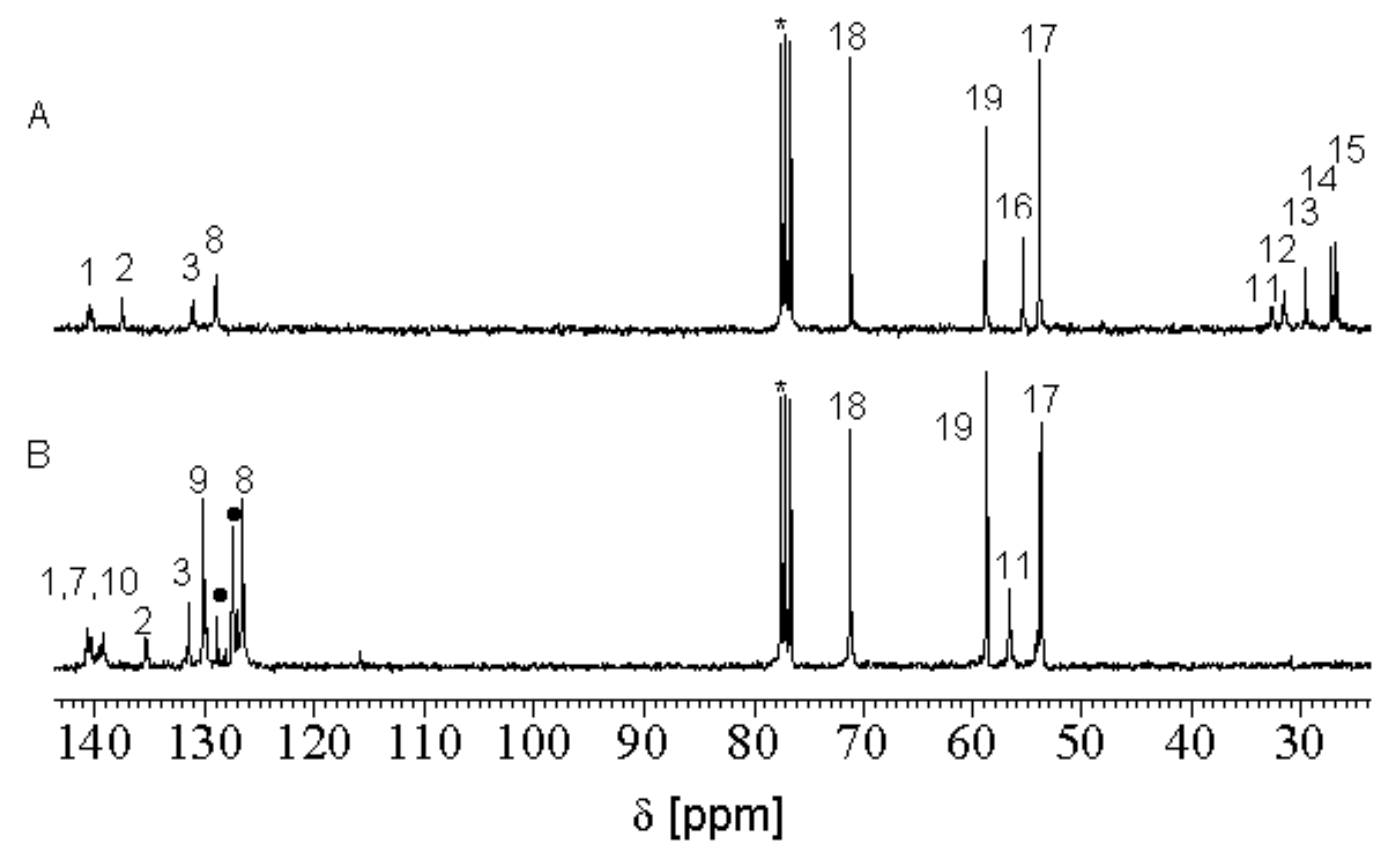

Fig. 5. Representative ${ }^{13} \mathrm{C}$ NMR spectra of polymers $38 \mathbf{b}(A)$ and $39 a(B)$, recorded in $\mathrm{CDCl}_{3}$ at room temperature; the signal assignment is made according to the numbering shown in Scheme 11

According to SEC, monomodal molecular weight distributions are given in the polymers, proving the homogeneity of the Pd-catalyzed coupling process. The NMR spectroscopical investigations support this statement: all intense absorptions observed in the NMR spectra clearly correspond to the inner-chain repeating units of the expected polymers. In addition, there are only some absorptions of minor intensity which can be assigned to the solvent $\left({ }^{*}\right)$, residues of the catalyst and chain termini $(\bullet)$.

The mentioned additional end group absorptions were found to be clearly more intensive for the polymers of the a-series (such as in Fig. 4B) where a monomethylene group is the spacer between the aromatic ring and the amino nitrogen atom. If a hexamethylene group was the spacer (b-series, see Fig. 4A), on the other hand, the end group absorptions were clearly weaker. The intensity of the latter end groups is found to be even lower than in the spectra of polymers 36 and 37 discussed above. This indicates that the values of $P_{\mathrm{n}}$ achieved here are similar to those obtained for model polymers 36 and 37.

Because this result proved to be reproducible under various reaction conditions, and because other reasons for the lower values of $P_{\mathrm{n}}$ in the a-series - such as a change of electron density in the aromatic ring to be coupled, caused by inductive or mesomeric effects due to the $\beta$-nitrogen atoms in the side groups of $13 a$ - are rather unlikely, we interpret this finding as a result of coordinative interactions between the amino nitrogen atoms and the catalytically active palladium species.

This interaction, however, seems to be rather weak because it depends strongly on the position of the nitrogen atom in the side chains: When it is in the $\delta$ - [43] or $\eta$ position (such as in 13b), hardly any influence on the Pd-catalyzed coupling process is observed. Therefore long spacer groups, and thus a larger distance between the nitrogen atom and the aromatic ring, result in a nearly unaffected Pd-catalyzed 
Suzuki reaction, leading to high-molecular-weight products. This general statement was supported by model investigations using monomer $13 \mathrm{c}$ having tri(ethylene oxide) spacer groups between the aromatic ring and the lateral amino nitrogen atoms.

\section{Precursor syntheses}

As expected, none of the model polymers $\mathbf{3 6}$ - $\mathbf{3 9}$ discussed so far was soluble in water. We therefore focused our efforts on the synthesis of presumably water-soluble precursor PPPs bearing both OEO and/or polar amino groups attached to every phenylene moiety. For this purpose, we mainly used the dibromobenzene derivatives of the $\alpha$-series, having two methoxyethylene groups attached to the amino nitrogen atom, because these compounds are best available (Scheme 12).

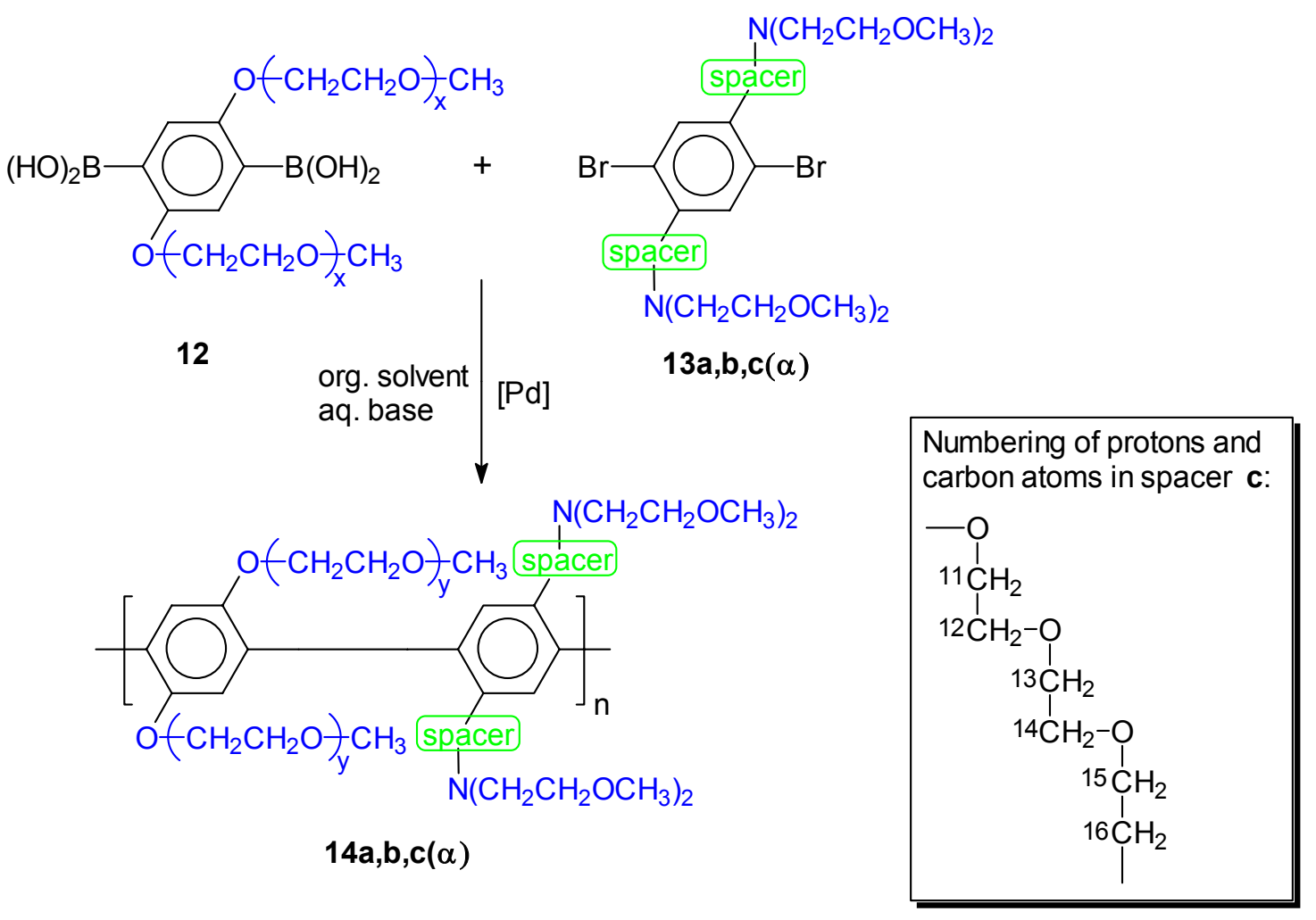

Scheme 12. Synthesis of precursor PPPs 14

Again, equimolar amounts of the respective comonomers were treated under the coupling conditions optimized above, and the polymers were finally isolated by precipitation in $n$-hexane. Here as well, ${ }^{1} \mathrm{H}$ and ${ }^{13} \mathrm{C}$ NMR spectra proved the homogeneous constitution of the obtained products and their high degrees of polycondensation. As representative examples, Fig. 6 shows the ${ }^{1} \mathrm{H}$ and (as an insert) ${ }^{13} \mathrm{C}$ NMR spectra of polymer $\mathbf{1 4 b}$ together with the full signal assignment.

All intense absorptions observed correspond to the inner-chain repeating units of a constitutionally homogeneous polymer $\mathbf{1 4 b}$. The weakness of the absorptions which we assign to the chain termini allows estimation that the values of $P_{\mathrm{n}}$ achieved are of the order $P_{\mathrm{n}} \approx 25$ for the polymer whose spectra are shown in Fig. 6 . 


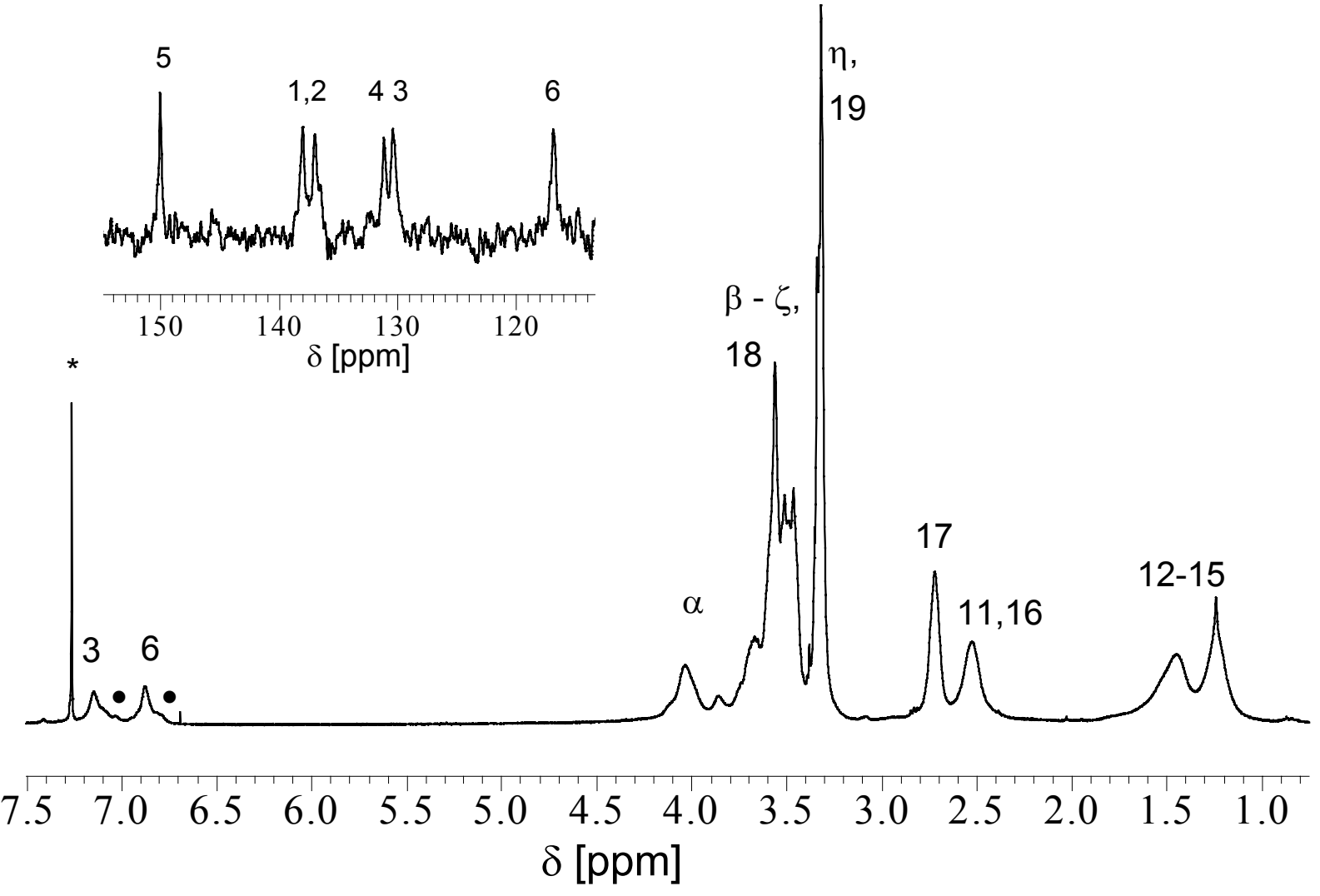

Fig. 6. Representative ${ }^{1} \mathrm{H}$ and (insert) ${ }^{13} \mathrm{C}$ NMR spectra of polymer $14 \mathbf{b}$, recorded in $\mathrm{CDCl}_{3}$ at room temperature; signal assignment is made according to the numbering shown in Schemes 10 and 11

For comparison purposes, we also prepared polymers 14 a having only a methylene spacer between the aromatic moieties and the amino functionalities. By analogy with the model precursors $38 \mathrm{a}$ and $39 \mathrm{a}$, the achieved molecular weights of 14a were clearly lower.

Very importantly, and in clear contrast to PPPs 36 - 39, the PPP derivative 14c proved to be readily soluble not only in organic solvents but even in pure water. Hence, the concept of introducing polar OEO side chains to increase the watersolubility of non-ionic PPP derivatives proved to be successful. Detailed investigations of the solution properties of PPP polyelectrolytes of low charge density will now be possible in aqueous media. Some first studies dealing with the step-by-step protonation of $14 \mathrm{c}$ will be presented in the last section of this article.

\section{Controlled protonation of polymers $14 \mathrm{c}$}

The precursor PPPs such as $14 \mathrm{c}$ described above represent polybases since they contain tertiary amino groups in their solubilizing side chains. Moreover, these polymers proved to be soluble in water already prior to their final quaternization leading to polyelectrolytes. First we had to answer the question whether this solubility in water is the result of the polar OEO side groups or whether it is additionally supported by a partial protonation of the amino groups even when dissolved in pure water.

For all subsequent analyses performed on aqueous solutions of precursor PPPs 14c it is of crucial importance to know the $\mathrm{pH}$ value at which the chains are completely 
deprotonated. We therefore determined the amount of protonated amino groups as a function of $\mathrm{pH}$.

NMR spectroscopy was expected to be an appropriate technique to quantitatively determine the degree of protonation. To evaluate the potential of this technique, we carried out some model titration experiments using low-molecular-weight monoamines such as $\mathbf{4 0}$, having a similar substitution pattern as the nitrogen atoms attached to the precursor PPPs 14c (Scheme 13).

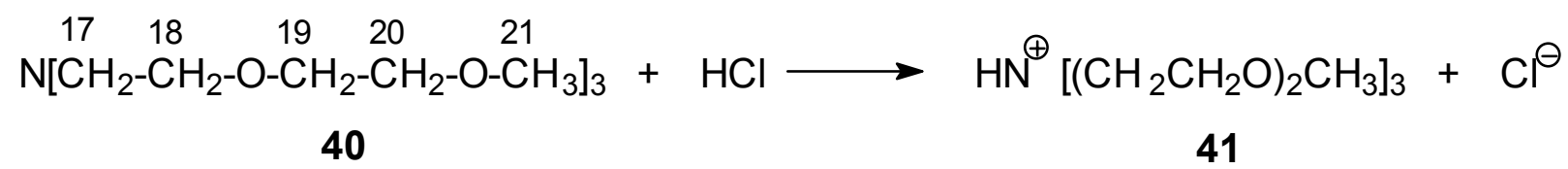

Scheme 13. Step-by-step protonation of monoamine $\mathbf{4 0}$ as a model reaction for the corresponding conversion of precursor PPPs 14

After dissolution of amine $\mathbf{4 0}(0.2 \mathrm{mmol})$ in $\mathrm{D}_{2} \mathrm{O}(10 \mathrm{~mL})$, a value of $\mathrm{pH} 11.4$ (determined using a $\mathrm{pH}$ electrode) was adjusted by dropwise addition of $1 \mathrm{~N} \mathrm{NaOD} / \mathrm{D}_{2} \mathrm{O}$. $\mathrm{A}$ small quantity of the resulting solution was then taken to record an initial NMR spectrum. Small amounts of $1 \mathrm{~N} \mathrm{DCl}$ in $\mathrm{D}_{2} \mathrm{O}$ were then added successively to the solution while taking NMR samples after each addition. A representative series of ${ }^{1} \mathrm{H}$ NMR spectra thus obtained is shown in Fig. 7.

It is clearly evident from these spectra that the $\mathrm{CH}_{2}$ protons directly attached to the nitrogen atom $\left(\mathrm{H}^{16}, \mathrm{H}^{17}\right)$ are very sensitive probes for the protonation state of the nitrogen atom: the spectra show the signal of the $\mathrm{N}-\mathrm{CH}_{2}$ protons shifting from $\delta=$ $2.82 \mathrm{ppm}$ at $\mathrm{pH} 11.41$ to $\delta=3.55 \mathrm{ppm}$ at $\mathrm{pH} 4.85$. This shift towards lower fields at decreasing $\mathrm{pH}$ value is a direct consequence of the less efficient magnetic shielding of the protons when the neighboring nitrogen atom is protonated. In case of complete protonation as well as complete deprotonation, sharp triplets can be detected for the $\mathrm{N}-\mathrm{CH}_{2}$ protons. In all other cases, the signal is very broad and unstructured. This is presumably due to proton interchange processes that occur at a rate comparable to the time window of the NMR experiment.

In the next step, we performed the above titration experiment using precursor PPP 14c. Here $0.1 \mathrm{mmol}$ of $14 \mathrm{c}$ was dissolved in $10 \mathrm{~mL} \mathrm{D}_{2} \mathrm{O}$ to achieve the same concentration of amino nitrogens in the solution as before for $\mathbf{4 0}$ (Scheme 14). The obtained series of ${ }^{1} \mathrm{H}$ NMR spectra is shown in Fig. 8. It is evident that the shift of the signals can be interpreted in full analogy to that found for the monoamine 40: again, a drastic shift towards lower field is found at decreasing values of $\mathrm{pH}$.

The ${ }^{13} \mathrm{C}$ NMR spectra shown in Fig. 9 are those of the completely deprotonated $(A)$ and completely protonated (B) monoamine $\mathbf{4 0}$ as well as of the deprotonated $(C)$ and protonated (D) precursor PPP 14c. It can be seen that in the case of ${ }^{13} \mathrm{C} N M R$ spectroscopy the $\mathrm{CH}_{2}$ group in $\beta$ position to the nitrogen atom $\left(\mathrm{C}^{18}\right)$ is subjected to the most evident shift upon (de)protonation. Moreover, in clear contrast to the results of ${ }^{1} \mathrm{H}$ NMR spectroscopy, the protonation causes a shift to higher fields in the ${ }^{13} \mathrm{C}$ NMR spectra: the absorption of the $\mathrm{N}-\mathrm{CH}_{2}-\mathrm{CH}_{2}$ carbons of the deprotonated amine 40 appears at $\delta=70.86 \mathrm{ppm}$ whereas the corresponding absorption of the protonated monoamine is detected at $\delta=66.81 \mathrm{ppm}$. This is obviously the inverse direction to that observed for the ${ }^{1} \mathrm{H}$ NMR shifts. 


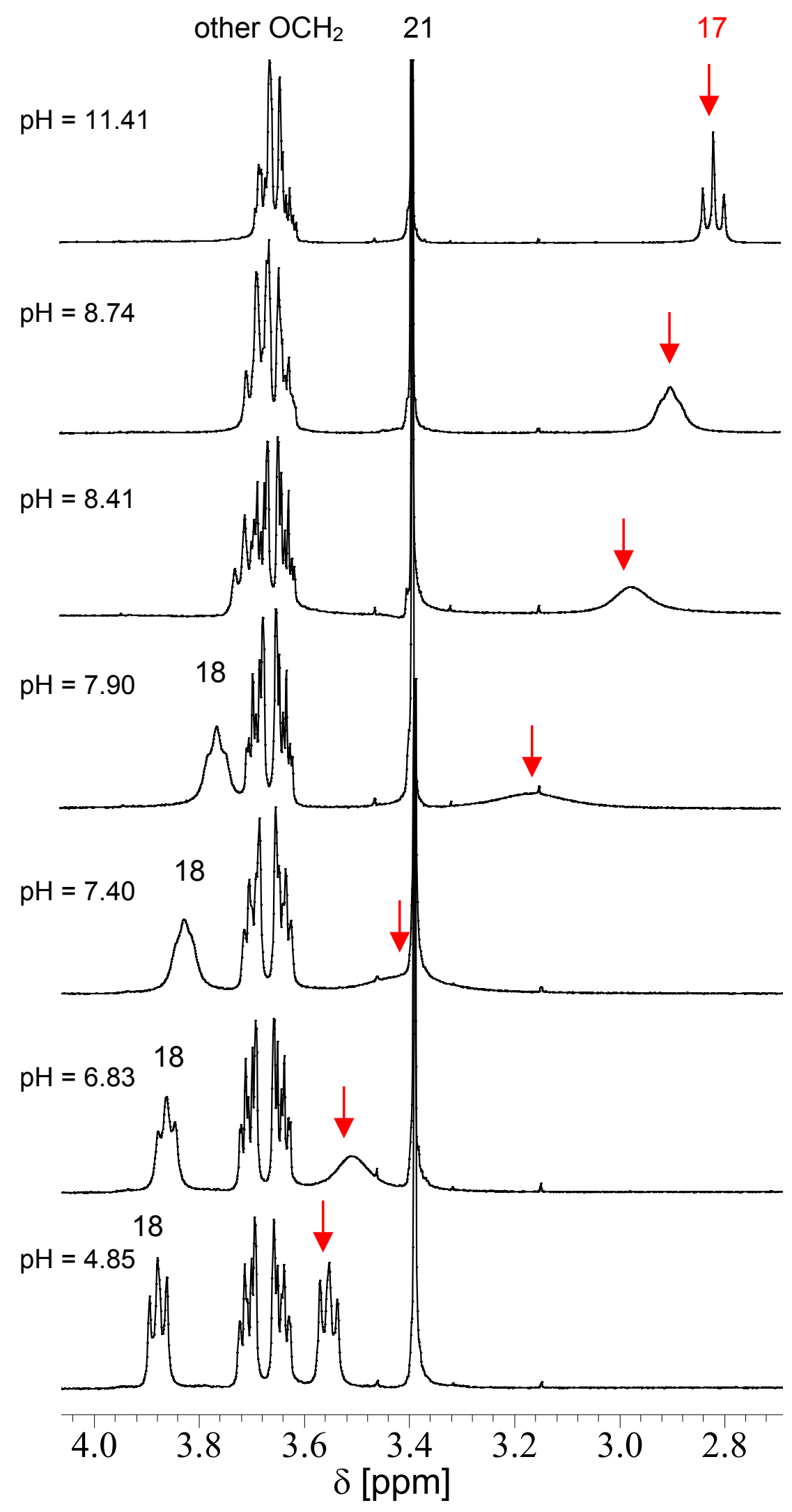

Fig. 7. ${ }^{1} \mathrm{H}$ NMR titration experiment using monoamine 40 as a model compound, performed in $\mathrm{D}_{2} \mathrm{O}$ at room temperature. The signal assignment is done according to the numbering shown in Schemes 11 and 13 


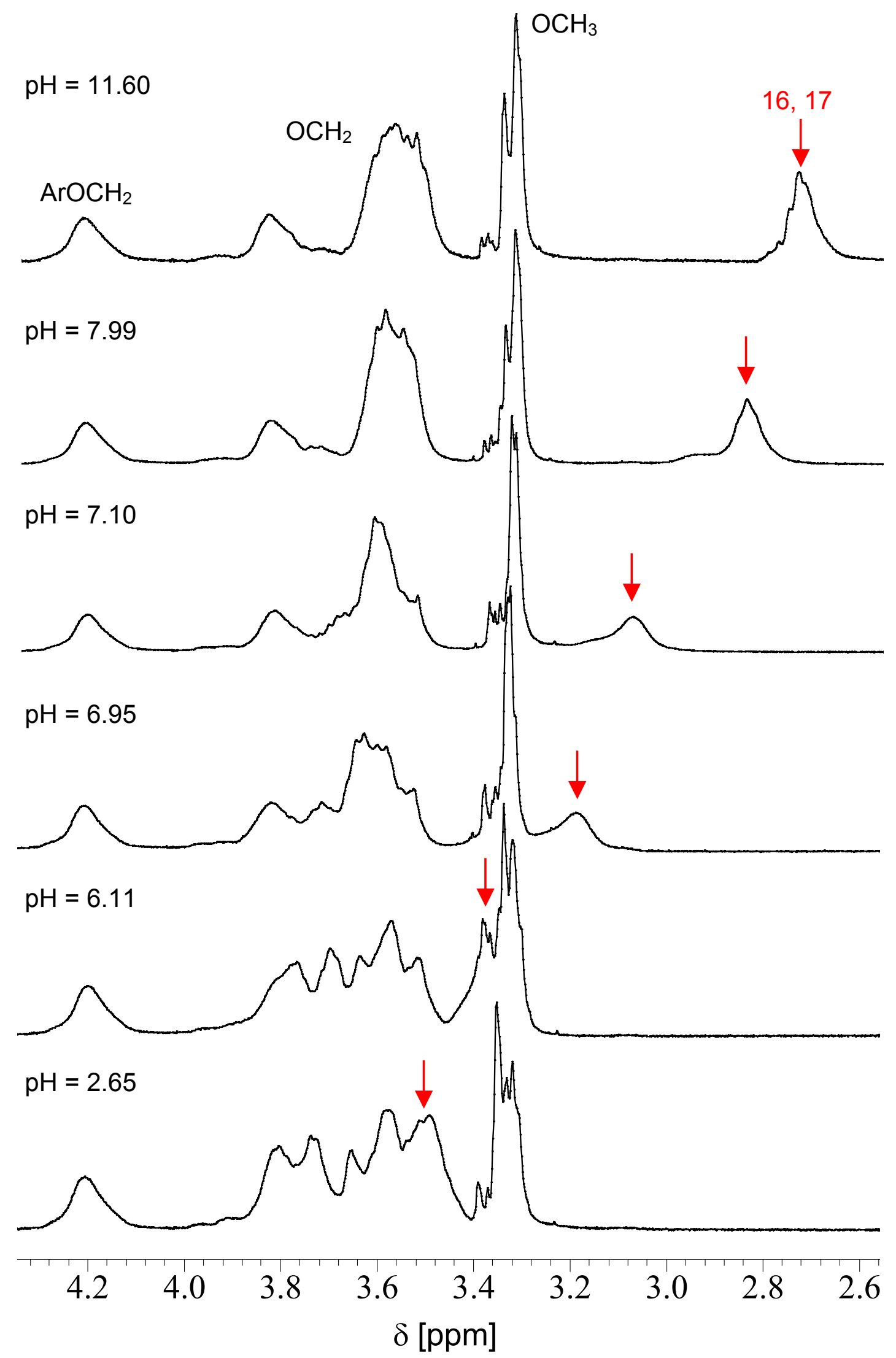

Fig. 8. ${ }^{1} \mathrm{H}$ NMR titration experiment using precursor PPP 14c, performed in $\mathrm{D}_{2} \mathrm{O}$ at room temperature. The signal assignment is done according to the numbering shown in Schemes 10 and 12 


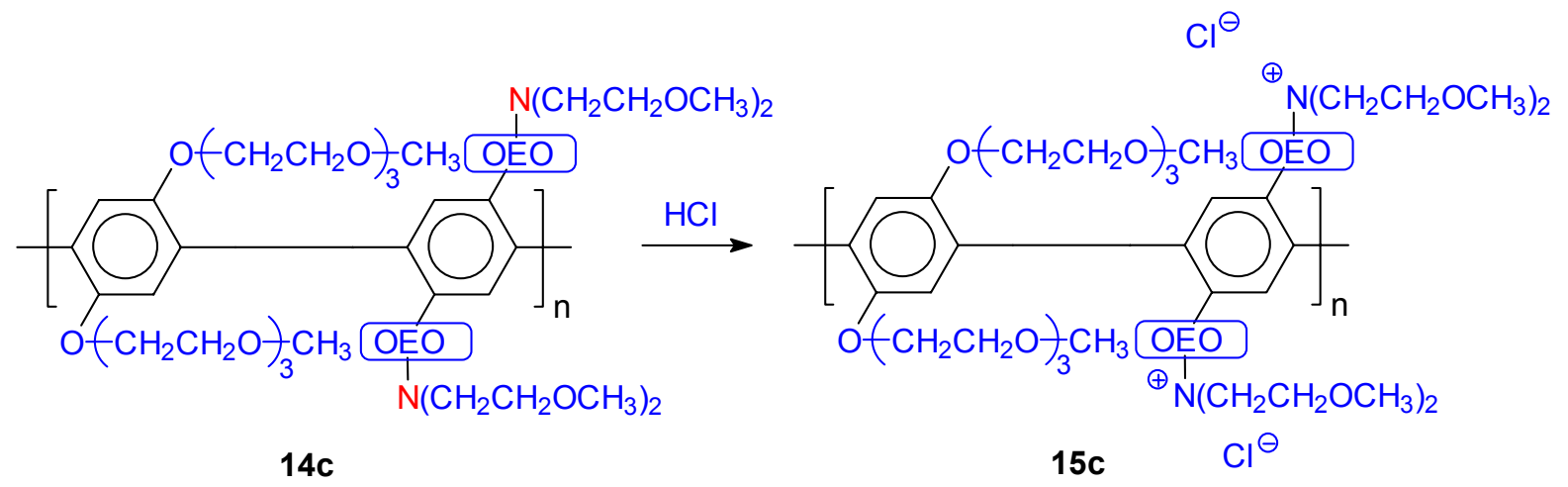

Scheme 14. Step-by-step protonation of precursor PPP 14c

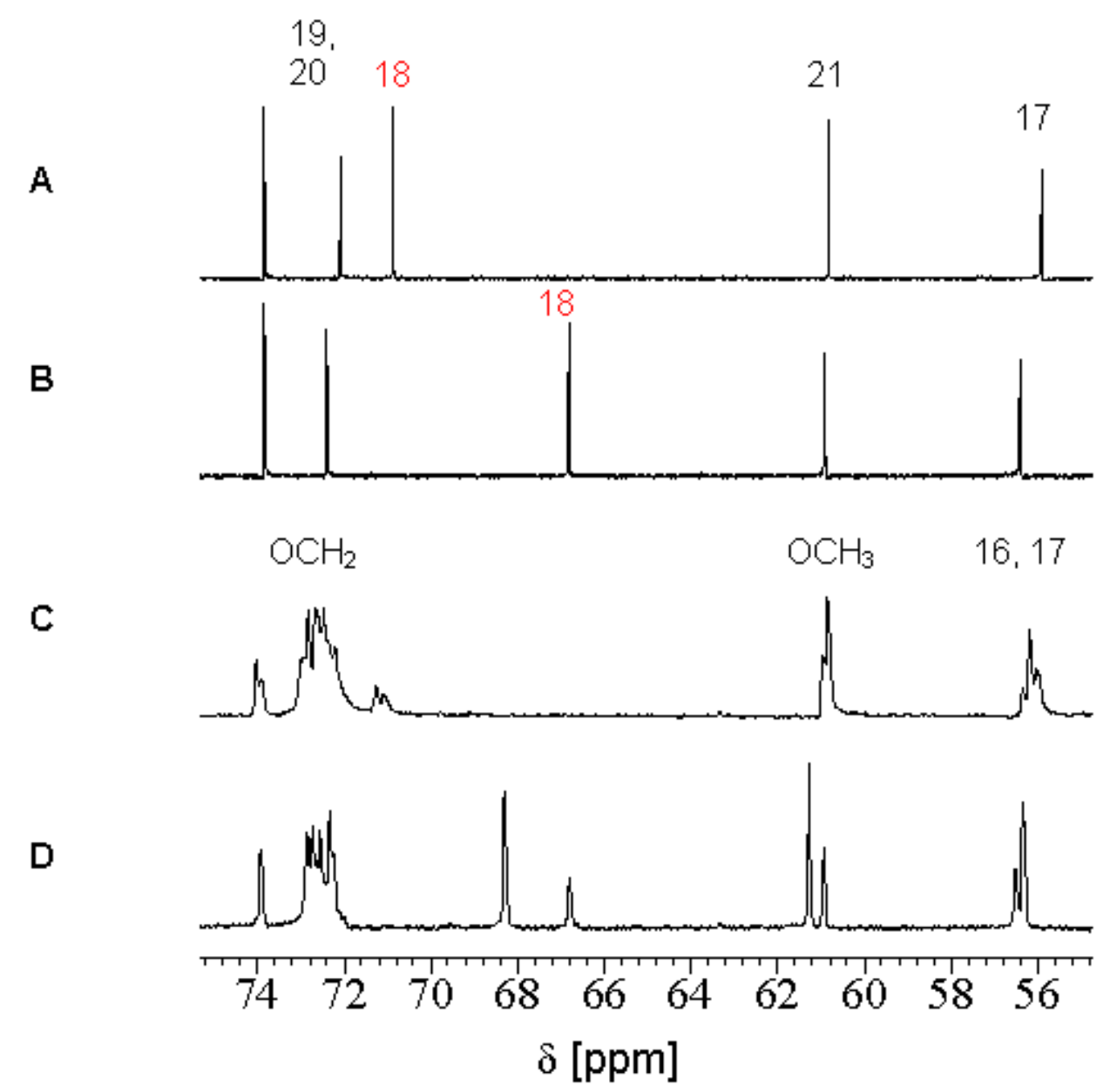

Fig. $9 .{ }^{13} \mathrm{C}$ NMR spectra (aliphatic region) of (A) deprotonated 40, (B) protonated $\mathbf{4 0}$, (C) deprotonated $14 \mathrm{c}$ and $(D)$ protonated $15 \mathrm{c}$, recorded in $\mathrm{D}_{2} \mathrm{O}$ at room temperature. The signal assignment is according to the numbering shown in Schemes 10 and 11

The correctness of the above peak assignment was verified using ${ }^{1} \mathrm{H}^{13} \mathrm{C}$ correlation experiments. $\mathrm{A}^{1} \mathrm{H}^{13} \mathrm{C}$ correlation spectrum of the completely protonated polymer $14 \mathrm{c}$ is shown in Fig. 10. Using this spectrum, a full signal assignment is possible. As an example, one can see that - assuming the ${ }^{13} \mathrm{C}$ NMR signal at $\delta=56.33 \mathrm{ppm}$ corresponds to the $\mathrm{N}-\mathrm{CH}_{2}$ carbons directly attached to the nitrogen atom $\left(\mathrm{C}^{16}, \mathrm{C}^{17}\right)$ - the ${ }^{1} \mathrm{H}$ NMR signal of the $\mathrm{N}-\mathrm{CH}_{2}$ protons appears at $\delta=3.51 \mathrm{ppm}$. 


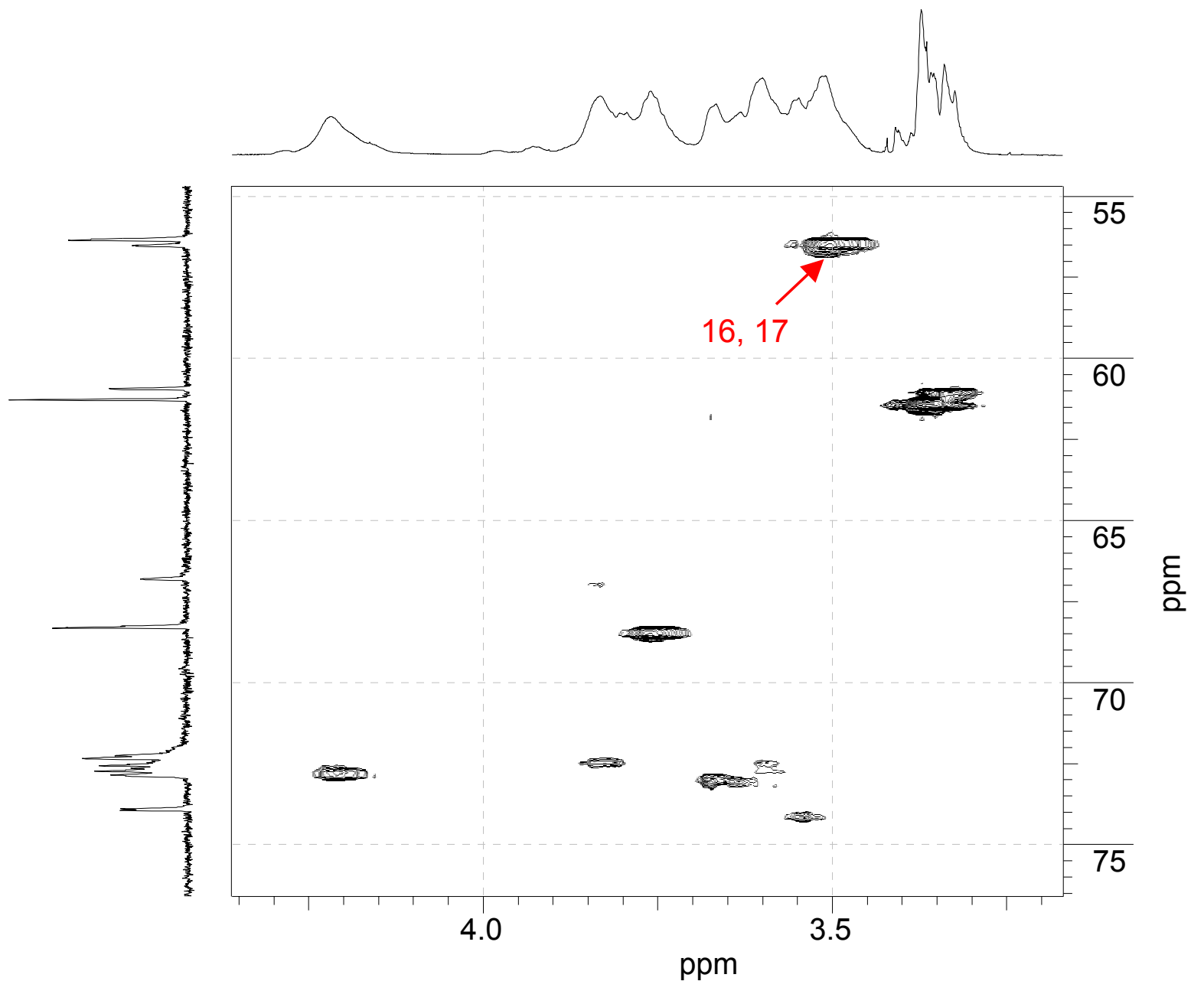

Fig. 10. ${ }^{1} \mathrm{H}^{13} \mathrm{C}$ correlation spectrum of completely protonated polymer $14 \mathrm{c}$, recorded in $\mathrm{D}_{2} \mathrm{O}$ at room temperature

Due to the fast proton-exchange processes it is impossible to quantify the degree of protonation in a partially protonated polymer using NMR spectroscopy in $\mathrm{D}_{2} \mathrm{O}$. In order to correlate the obtained ${ }^{1} \mathrm{H}$ NMR data for each value of $\mathrm{pH}$ quantitatively with the degrees of protonation, supporting titration experiments were carried out using $\mathrm{pH}$ electrodes. In these experiments, the low-molecular-weight monoamine $\mathbf{4 0}$ or the precursor PPP 14c were dissolved in $\mathrm{H}_{2} \mathrm{O}(0.2 \mathrm{mmol}$ amino nitrogens in $10 \mathrm{~mL})$ first. The resulting $\mathrm{pH}$ value was then determined. Starting from this point, $1 \mathrm{~N}$ aqueous $\mathrm{HCl}$ or $\mathrm{NaOH}$ was added in small portions. The $\mathrm{pH}$ values determined in the course of these experiments were plotted against the respective amounts of added $\mathrm{HCl}$ and $\mathrm{NaOH}$ (Fig. 11).

From these data it is obvious that the plot obtained for the precursor PPP $14 \mathrm{c}$ is completely shifted to the right compared to the plot of monoamine 40 . We assume this is due to the fact that the analyzed samples of precursor PPP 14c were already protonated to approx. $30 \%$, maybe because chloroform was used for the work-up and purification process that can contain traces of hydrochloric acid.

The protonation and deprotonation of monoamine $\mathbf{4 0}$ as well as of the precursor PPP 14c take place in the range between approx. $10>\mathrm{pH}>4$. The inflection points of the curves at $\mathrm{pH} \approx 10$ and $\approx 4$ represent the exact values of $0 \%$ and $100 \%$ protonation. 


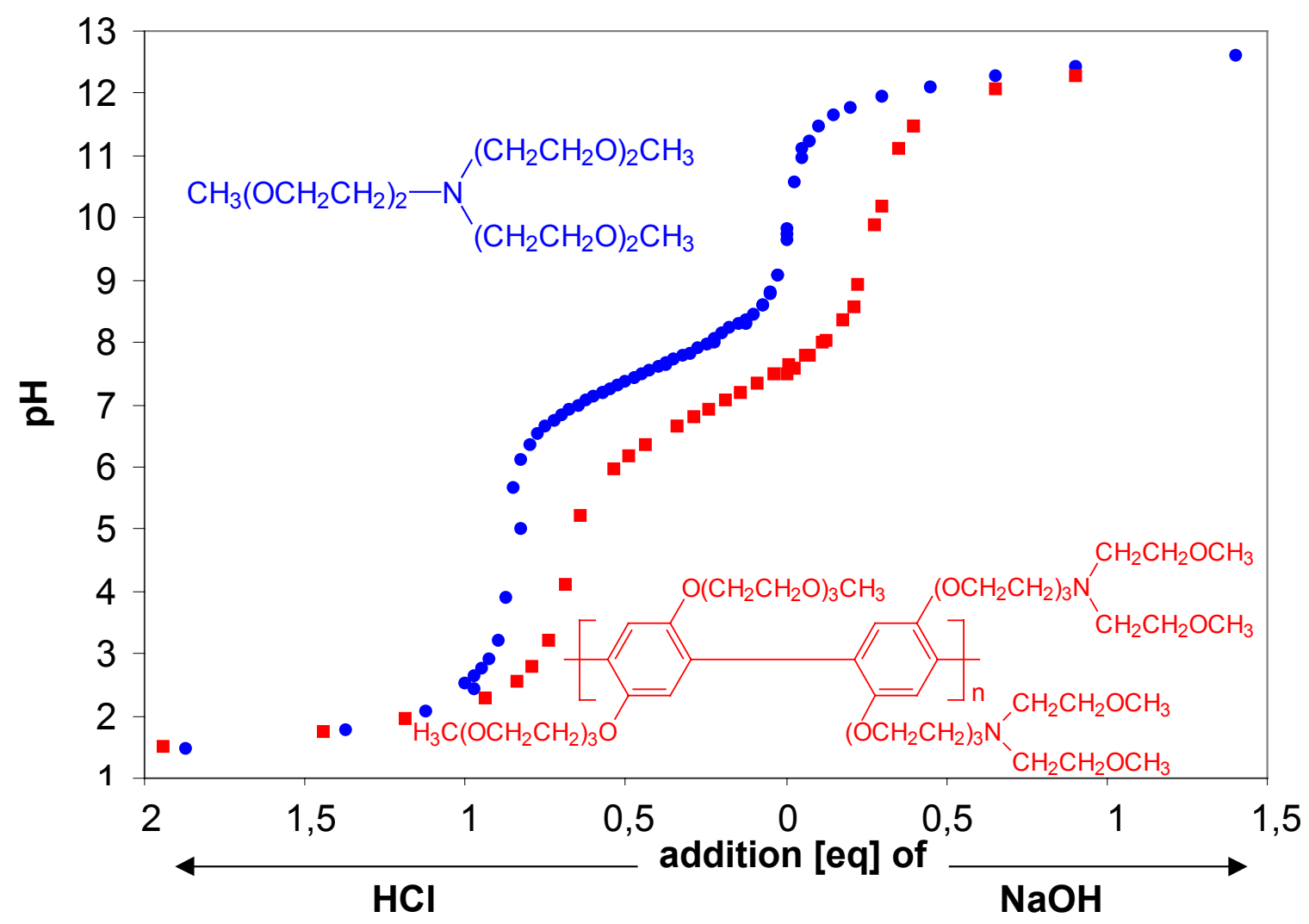

Fig. 11. $\mathrm{pH}$ of aqueous solutions of $\mathbf{4 0}$ and $\mathbf{1 4 c}$, plotted against the added equivalents of aqueous $\mathrm{HCl}$ and $\mathrm{NaOH}$, respectively

The absolute values of the degrees of protonation obtained by calibration with respect to these points of inflection are now plotted against the $\mathrm{pH}$ values for monoamine 40 as well as for precursor PPP 14c (Fig. 12). The blue circles and red dots are calculated from the experimental data determined using the $\mathrm{pH}$ electrode (values plotted at the left $y$-axis). The black triangles, on the other hand, are based upon the ${ }^{1} \mathrm{H}$ NMR chemical shifts of the respective $\mathrm{N}-\mathrm{CH}_{2}$ protons ( $\delta$-values plotted at the right $y$-axis).

From these data, one can determine a buffer region between $\mathrm{pH} \approx 6.5$ and $\approx 8.5$ for monoamine 40 , and between $\mathrm{pH} \approx 6.0$ and $\approx 8.0$ for polyamine $14 \mathrm{c}$. Accordingly, the precursor PPP $14 \mathrm{c}\left(\mathrm{pK}_{\mathrm{a}} \approx 7.0\right)$ seems to be a weaker base than monoamine 40 $\left(\mathrm{pK}_{\mathrm{a}} \approx 7.5\right)$.

Based on these results, and assuming that the equilibrium state was reached in all cases, we recalculated the curves based on the law of mass action for degrees of protonation between $10 \%$ and $90 \%$. The results are represented in Fig. 12 as solid lines. In the case of monoamine 40 , data determined using the $\mathrm{pH}$ electrode agree very well with the expected behaviour of a monobasic amine having a pK $\mathrm{K}_{\mathrm{a}}$ of 7.5.

For the polymeric amine, on the other hand, there is obviously a slight deviation: the slope of the calculated curve is larger than that of the measured values. Whether intramolecular interactions or other reasons are responsible for this deviation will be the subject of further investigations. The same applies for the deviations observed in the data acquired from ${ }^{1} \mathrm{H}$ NMR spectroscopy: here, the ratios of protonation are in 
perfect agreement with the results of $\mathrm{pH}$ titration in the case of precursor PPP 14c but do not agree perfectly in the case of monoamine 40.

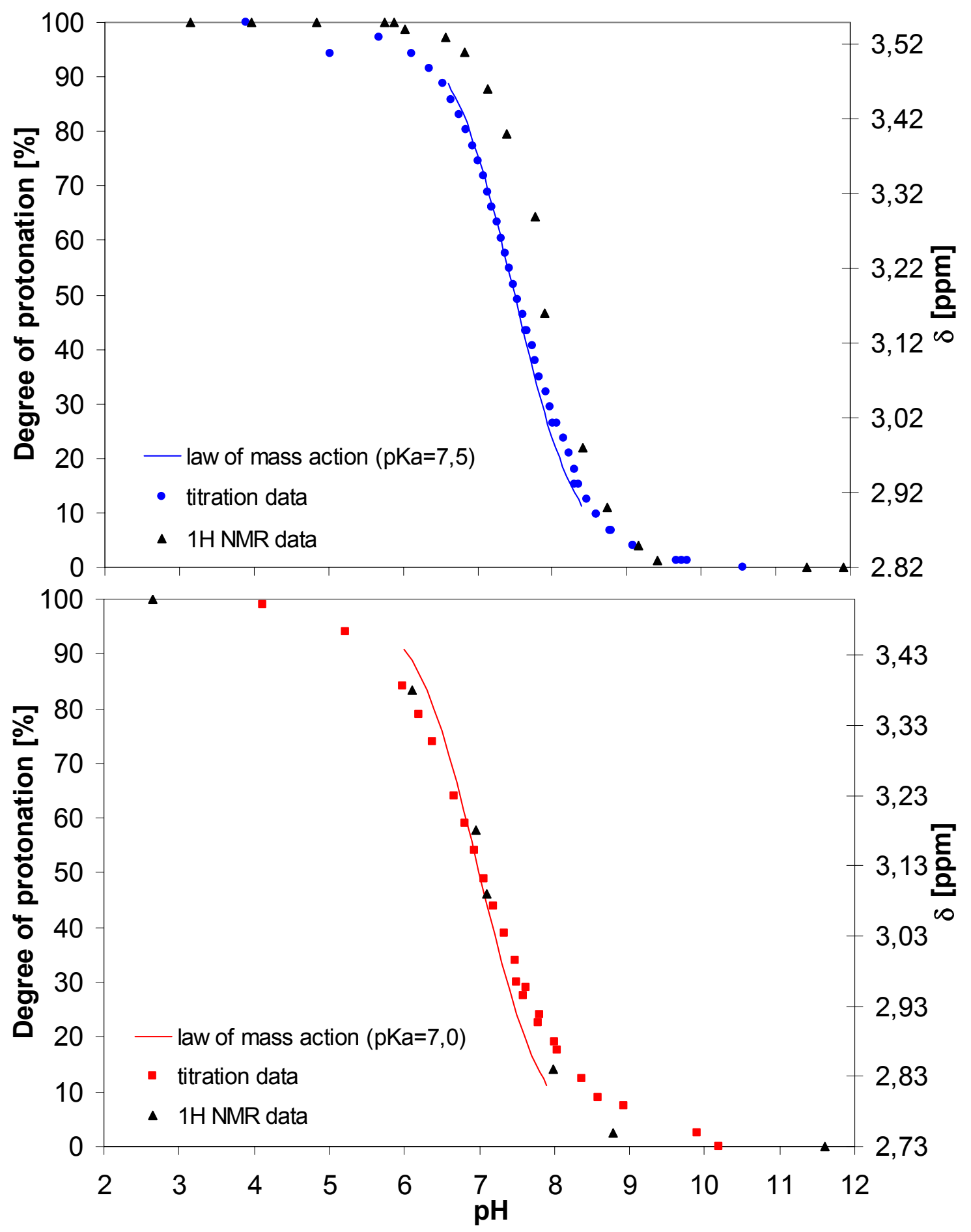

Fig. 12. Degrees of protonation and ${ }^{1} \mathrm{H}$ NMR chemical shifts of amine $40(A)$ and precursor PPP 14c (B), plotted as a function of the $\mathrm{pH}$ value

Finally, we want to emphasize that the dissolution of the amino-functionalized precursor PPPs such as 14 in solvents like chloroform at room temperature can already lead to protonation of at least a part of the amino groups. The ${ }^{1} \mathrm{H}$ NMR spectra of the products change accordingly and may lead to complications during the 
constitutional analysis. Traces of $\mathrm{HCl}$ present in solvents like chloroform are obviously sufficient to protonate some of the amino groups of 14c. Addition of a small amount of solid $\mathrm{Na}_{2} \mathrm{CO}_{3}$ prevents this problem.

\section{Conclusions and outlook}

A novel synthetic strategy is presented for the preparation of PPP polyelectrolytes which are water-soluble even at vanishing charge density. The key to this success is the attachment of long OEO side chains to all $p$-phenylene repeating units which do not bear amino or ammonium functionalities. The Pd-catalyzed polycondensation process is shown to be unaffected by the OEO side chains as well as by the lateral amino groups if the latter are attached via sufficiently long spacers. The aminofunctionalized precursor PPPs can be converted into PPP polyelectrolytes via stepby-step protonation. The degree of protonation can easily be adjusted via the $\mathrm{pH}$ value, ranging from $0 \%$ at $\mathrm{pH}>10.5$, approx. $50 \%$ at $\mathrm{pH} 7.0$ and up to $100 \%$ at $\mathrm{pH}<4.0$.

Hence, the new PPPs allow realization of a tailor-made average charge density and are therefore promising candidates for the development of a deeper understanding of polyelectrolyte behavior in aqueous media. In subsequent papers, we will report on the protonation process of $\mathbf{1 4}$ in more detail as well as on the transformation of precursor PPPs 14 into polyelectrolytes 15 via quaternization using alkyl halogenides.

\section{Experimental part}

\section{Materials}

All chemicals and solvents were purchased from Acros, Aldrich, Fluka and Lancaster Chemical Co. and used without further purification unless otherwise stated. In order to remove peroxide impurities and oxygen, tetrahydrofuran (THF) was refluxed with sodium and distilled under nitrogen. 1,4-Dibromo-2,5-bis( $\alpha$-bromomethyl)benzene 23 [71], 1,4-dibromo-2,5-bis( $\omega$-bromohexyl)benzene 28 [72], aryldiboronic acid derivatives 19 and 20 [81] as well as their cyclic 1,3-propanediol diesters $19^{*}$ and $\mathbf{2 0}^{*}$ were prepared according to the literature. The palladium catalysts $\left[\mathrm{Pd}\left(\mathrm{PPh}_{3}\right)_{4}\right][82]$ and $\left.\left[\mathrm{Pd}(\mathrm{PpTo})_{3}\right)_{3}\right][83]$ were obtained via procedures given in the literature.

\section{Methods}

NMR spectra were recorded using a Bruker AM 300 NMR spectrometer working at $300 \mathrm{MHz}\left({ }^{1} \mathrm{H}\right.$ NMR) and $75 \mathrm{MHz}\left({ }^{13} \mathrm{C}\right.$ NMR), and on a Bruker AM $500 \mathrm{NMR}$ spectrometer working at $500 \mathrm{MHz}\left({ }^{1} \mathrm{H}\right.$ NMR) and $125 \mathrm{MHz}\left({ }^{13} \mathrm{C}\right.$ NMR). The signal assignment in the ${ }^{1} \mathrm{H}$ and ${ }^{13} \mathrm{C}$ NMR spectra was done according to the numbering given for selected compounds in Schemes 9 - 13.

VPO measurements were carried out using the GONOTEC OSMOMAT 070-SA osmometer. The number-average molar mass $M_{\mathrm{n}}$ was determined in chloroform at $35^{\circ} \mathrm{C}$.

SEC chromatograms were recorded in THF solvent with a system consisting of a Waters 510 pump, the TSP AS 100 injector, the PL Gel Mixed-B, C and D columns as well as the Waters RI 410 differential refractometer. Data were collected using the 
WINGPC V. 6.01 software. Polystyrene was used as the standard. The given absolute values of molar masses should be taken with some care therefore.

MALDI-TOF measurements were carried out with the Analytical-Kompact MALDI 4 (Kratos) mass spectrometer. The mass spectrometer was calibrated externally with poly(ethylene oxide) standards before each measurement. The matrix, 1,8,9-trihydroxyanthracene, and the samples were dissolved in chloroform.

$\mathrm{pH}$ experiments were carried out at room temperature using a Knick 766 Climatic $\mathrm{pH}$ meter and the InLab ${ }^{\circledR} 423$ general purpose glass electrode (Mettler Toledo). The $\mathrm{pH}$ meter was calibrated with buffer solutions of $\mathrm{pH} 4.00$ (Merck, citrate/HCl), $\mathrm{pH} 7.00$ (Merck, phosphate), and $\mathrm{pH} 12.00$ (Merck, $\mathrm{KCl} / \mathrm{NaOH}$ ) before each measurement. $\mathrm{pH}$ readings using $\mathrm{D}_{2} \mathrm{O}$ instead of $\mathrm{H}_{2} \mathrm{O}$ were not corrected. The degree of protonation used in the evaluation of the experimental results was always based on the content of amino nitrogen.

\section{$\alpha$-(p-Tosyl)-tri(ethylene glycol) monomethyl ether, 17a}

Aqueous $\mathrm{NaOH}(60 \mathrm{~mL}, 5 \mathrm{M})$ was added to a solution of tri(ethylene glycol) monomethyl ether 34a $(32.8 \mathrm{~g}, 200 \mathrm{mmol}, 1.05 \mathrm{eq})$ in THF $(50 \mathrm{~mL})$. The mixture was cooled $\left(5^{\circ} \mathrm{C}\right)$, and tosyl chloride $33(36.2 \mathrm{~g}, 190 \mathrm{mmol}, 1.00 \mathrm{eq})$ in THF (50 mL) was added dropwise. The resulting mixture was stirred at room temperature for $2 \mathrm{~h}$. The organic layer was separated off, and the aqueous layer was extracted with tert-butyl methyl ether $(3 \times 50 \mathrm{~mL})$. The combined organic layers were washed (water, $3 \times$ $100 \mathrm{~mL})$, dried $\left(\mathrm{MgSO}_{4}\right)$, and the solvent was removed. The yield was $51.90 \mathrm{~g}(86 \%)$ of a yellowish oil.

${ }^{1} \mathrm{H} \mathrm{NMR}\left(\mathrm{CDCl}_{3}\right): \delta=2.45\left(\mathrm{~s}, 3 \mathrm{H}, \mathrm{ArC}_{3}\right), 3.37\left(\mathrm{~s}, 3 \mathrm{H}, \mathrm{OC}_{3}\right), 3.51-3.63(\mathrm{~m}, 8 \mathrm{H}$, $\left.\mathrm{OCH}_{2}\right), 3.68\left(\mathrm{t}, 2 \mathrm{H}, \operatorname{TosOCH}_{2} \mathrm{CH}_{2}\right), 4.16\left(\mathrm{t}, 2 \mathrm{H}\right.$, TosOC$\left.{ }_{2}\right), 7.34(\mathrm{~d}, 2 \mathrm{H}$, aromatic $\left.\mathrm{H}^{\text {meta }}\right), 7.79\left(\mathrm{~d}, 2 \mathrm{H}\right.$, aromatic $\left.\mathrm{H}^{\text {ortho }}\right)$.

${ }^{13} \mathrm{C}$ NMR $\left(\mathrm{CDCl}_{3}\right): \delta=21,73\left(\mathrm{Ar}_{\underline{C}} \mathrm{H}_{3}\right), 59,11\left(\mathrm{OC}_{\mathrm{CH}}\right), 68.73\left(\mathrm{TosO} \underline{C H}_{2}\right), 69.36$ $\left(\mathrm{Tos} \mathrm{OCH}_{2} \underline{\mathrm{C}} \mathrm{H}_{2}\right), 70.61,70.80\left(\mathrm{O}_{\underline{\mathrm{C}}}{ }_{2} \underline{\mathrm{C}} \mathrm{H}_{2} \mathrm{O}\right), 71.97\left(\underline{\mathrm{C}} \mathrm{H}_{2} \mathrm{OCH}_{3}\right), 128.06$ (aromatic $\left.\mathrm{C}^{\text {ortho }}\right), 129.92$ (aromatic $\left.\mathrm{C}^{\text {meta }}\right), 133.03\left(\mathrm{Ar}_{\underline{C} S O} \mathrm{R}\right), 144.91\left(\mathrm{Ar}_{\underline{C}} \mathrm{CH}_{3}\right)$.

\section{$\alpha$-(p-Tosyl)-oligo(ethylene glycol) monomethyl ether, $\mathbf{1 7 b}$}

Under an atmosphere of nitrogen, tosyl chloride $33(60 \mathrm{~g}, 314.3 \mathrm{mmol}, 1.1 \mathrm{eq})$ was dissolved in a mixture of pyridine $(80.0 \mathrm{ml}, 45.2 \mathrm{~g}, 571.4 \mathrm{mmol}, 4.0 \mathrm{eq})$ and chloroform $(300 \mathrm{~mL})$, and the resulting solution was cooled $\left(3^{\circ} \mathrm{C}\right)$. A solution of poly(ethylene glycol) monomethyl ether 34b (number-average degree of polymerization $x$ $=8, M_{\mathrm{n}}=350 ; 100 \mathrm{~g}, 285.7 \mathrm{mmol}, 1.0 \mathrm{eq}$ ) dissolved in chloroform (30 mL) was added dropwise. The reaction mixture was stirred at $3^{\circ} \mathrm{C}$ for $3 \mathrm{~h}$ and at room temperature for $2 \mathrm{~h}$. The resulting solution was poured into ice water $(250 \mathrm{~mL})$ and washed with methylene chloride $(250 \mathrm{~mL})$. The organic layer was washed with icecold $6 \mathrm{~N} \mathrm{HCl}(3 \times 150 \mathrm{~mL})$, water $(2 \times 200 \mathrm{~mL})$ and finally dried $\left(\mathrm{MgSO}_{4}\right)$. The solvent was removed, leading to a yellowish oil of pure $17 \mathrm{~b}(134.47 . \mathrm{g}, 93 \%)$.

${ }^{1} \mathrm{H}$ NMR $\left(\mathrm{CDCl}_{3}\right): \delta=2.44\left(\mathrm{~s}, 3 \mathrm{H}, \mathrm{ArCH}_{3}\right), 3.37\left(\mathrm{~s}, 3 \mathrm{H}, \mathrm{OCH}_{3}\right), 3.56(\mathrm{t}, 2 \mathrm{H}$, $\left.\mathrm{C}_{2} \mathrm{OCH}_{3}\right), 3.57-3.65\left(\mathrm{~m}, 8 \mathrm{H}, \mathrm{OC}_{2}\right), 3.68\left(\mathrm{t}, 2 \mathrm{H}, \mathrm{TosOCH}_{2} \underline{\mathrm{CH}}_{2}\right), 4.15$ (t, $2 \mathrm{H}$, $\left.\mathrm{TosOCH}_{2}\right), 7.32,7.35\left(2 \mathrm{~d}, 2 \mathrm{H}\right.$, aromatic $\left.\mathrm{H}^{\text {meta }}\right), 7.78,7.81\left(2 \mathrm{~d}, 2 \mathrm{H}\right.$, aromatic $\left.\mathrm{H}^{\text {ortho }}\right)$. 
${ }^{13} \mathrm{C}$ NMR $\left(\mathrm{CDCl}_{3}\right): \delta=21.61\left(\mathrm{ArCH}_{3}\right), 59.01\left(\mathrm{O}^{2} \mathrm{H}_{3}\right), 66.64\left(\mathrm{TosO}^{2} \mathrm{H}_{2}\right), 69.21$ (TosOCH $\left.\mathrm{CH}_{2}\right), 70.71,70.89\left(\mathrm{O}^{\mathrm{C}} \mathrm{H}_{2} \underline{\mathrm{C}} \mathrm{H}_{2} \mathrm{O}\right), 71.90\left(\underline{\mathrm{CH}}_{2} \mathrm{OCH}_{3}\right), 127.96$ (aromatic $\left.\mathrm{C}^{\text {ortho }}\right), 129.80$ (aromatic $\left.\mathrm{C}^{\text {meta }}\right), 132.95\left(\mathrm{ArCSO}_{3} \mathrm{R}\right), 144.75\left(\mathrm{Ar}^{\mathrm{C} C H}{ }_{3}\right)$.

\section{1,4-Dibromohydroquinone, 16}

Bromine $(64.0 \mathrm{~g}, 400 \mathrm{mmol}, 2 \mathrm{eq})$ was added to a stirred and cooled $\left(<35^{\circ} \mathrm{C}\right)$ suspension of hydroquinone $(22.0 \mathrm{~g}, 200 \mathrm{mmol}, 1 \mathrm{eq})$ in concentrated acetic acid $(200 \mathrm{~mL})$. After $20-30 \mathrm{~min}$, the product started to crystallize. After $2 \mathrm{~h}$, the precipitate was collected in a Büchner funnel and washed with a small amount of water $(50 \mathrm{~mL})$. Water $(500 \mathrm{~mL})$ was added to the remaining solution, and the resulting mixture was stored at $0^{\circ} \mathrm{C}$ for further $12 \mathrm{~h}$. The precipitate formed in that time was collected in a Büchner funnel and washed with water $(50 \mathrm{~mL})$. The combined solid materials were recrystallized twice from water. The yield was $35.2 \mathrm{~g}(66 \%)$ of colourless crystal plates; m.p.: $184^{\circ} \mathrm{C}$ (lit.: $188-189^{\circ} \mathrm{C}$ [68]).

${ }^{1} \mathrm{H}$ NMR (DMSO- $\left.d_{6}\right): \delta=7.05$ (s, 2H, $\left.\mathrm{H}^{6}\right), 9.85(\mathrm{~s}, 2 \mathrm{H}, \mathrm{OH})$.

${ }^{13} \mathrm{C}$ NMR (DMSO- $\left.d_{6}\right): \delta=108.14\left(C^{4}\right), 109.35\left(C^{6}\right), 147.22\left(C^{5}\right)$.

\section{1,4-Dibromo-2,5-bis(1,4,7,10-tetraoxaundecanyl)benzene, 18a}

Under an atmosphere of nitrogen, a suspension of $\alpha$-( $p$-tosyl)- $\omega$-methoxytris(oxyethylene) $17 \mathrm{a}(47.12 \mathrm{~g}, 148.0 \mathrm{mmol}, 2 \mathrm{eq})$, 1,4-dibromohydroquinone 16 (20.10 g, $75.0 \mathrm{mmol}, 1 \mathrm{eq})$ and potassium carbonate $(31.10 \mathrm{~g}, 225.0 \mathrm{mmol})$ in $\mathrm{N}, \mathrm{N}$-dimethylformamide (DMF) $\left(180 \mathrm{~mL}\right.$ ) was first stirred at $80^{\circ} \mathrm{C}$ for $5 \mathrm{~h}$, then at room temperature for $20 \mathrm{~h}$. The formed solid was filtered off and extracted with tert-butyl methyl ether $(3 \times 100 \mathrm{~mL})$. Water $(200 \mathrm{~mL})$ was added to the combined organic layers. The aqueous layer was extracted with tert-butyl methyl ether $(3 \times 200 \mathrm{~mL})$. The combined organic layers were washed successively with aqueous $\mathrm{NaOH}(2 \mathrm{M}, 2 \times 50 \mathrm{~mL})$ and water $(3 \times 100 \mathrm{~mL})$ and finally dried $\left(\mathrm{MgSO}_{4}\right)$. After filtration, the solvent was removed. The oily residue was recrystallized from ethanol $(1000 \mathrm{~mL})$ at $-20^{\circ} \mathrm{C}$. The yield was $32.76 \mathrm{~g}(78 \%)$ of colourless crystals; m.p.: $36-38^{\circ} \mathrm{C}$ (lit.: $33-34^{\circ} \mathrm{C}$ [68]).

${ }^{1} \mathrm{H}$ NMR $\left(\mathrm{CDCl}_{3}\right): \delta=3.38\left(\mathrm{~s}, 6 \mathrm{H}, \mathrm{OCH}_{3}\right), 3.55\left(\mathrm{~m}, 4 \mathrm{H}, \mathrm{H}_{3} \mathrm{COCH}_{2}\right), 3.65-3.70(\mathrm{~m}$, $\left.8 \mathrm{H}, \mathrm{OCH}_{2}\right), 3.77\left(\mathrm{~m}, 4 \mathrm{H}, \mathrm{ArOCH}_{2} \mathrm{CH}_{2} \mathrm{OCH}_{2}\right), 3.87$ (t, $\left.4 \mathrm{H}, \mathrm{ArOCH}_{2} \mathrm{CH}_{2}\right), 4.13$ (t, $4 \mathrm{H}$, $\left.\operatorname{ArOC}_{2}\right), 7.15\left(\mathrm{~s}, 2 \mathrm{H}, \mathrm{H}^{6}\right)$.

${ }^{13} \mathrm{C} \mathrm{NMR}\left(\mathrm{CDCl}_{3}\right): \delta=59.13\left(\mathrm{OCH}_{3}\right), 69.65\left(\mathrm{ArOCH}_{2}\right), 70.26,70.67,70.81,71.17$ $\left(\mathrm{OCH}_{2} \underline{\mathrm{C}} \mathrm{H}_{2} \mathrm{O}\right), 72.04\left(\underline{\mathrm{C}}_{2} \mathrm{OCH}_{3}\right), 111.42\left(\mathrm{C}^{4}\right), 119.19\left(\mathrm{C}^{6}\right), 150.38\left(\mathrm{C}^{5}\right)$.

\section{2,5-Bis(1,4,7,10-tetraoxaundecanyl)benzene-1,4-diboronic acid, 12a}

Under an atmosphere of nitrogen, a solution of sec-butyllithium in cyclohexane (1.3 $\mathrm{M}, 36.23 \mathrm{~mL}, 47.1 \mathrm{mmol}, 2.2 \mathrm{eq})$ was added to a cooled $\left(-90^{\circ} \mathrm{C}\right)$ solution of $1,4-$ dibromo-2,5-bis(1,4,7,10-tetraoxaundecanyl)benzene 18a $(12.0 \mathrm{~g}, 21.4 \mathrm{mmol}, 1 \mathrm{eq})$ in THF $(180 \mathrm{~mL})$. The reaction mixture was allowed to warm up to $-70^{\circ} \mathrm{C}$ within $5 \mathrm{~min}$. Undiluted trimethyl borate $(45 \mathrm{~mL}, 401 \mathrm{mmol}, 19 \mathrm{eq})$ was added quickly with vigorous stirring. The reaction mixture was allowed to slowly warm up to room temperature overnight. The resulting solution was filtered. Solvents and excess of trimethyl borate were removed in vacuo. Hydrochloric acid $(1 \mathrm{~N}, 40 \mathrm{~mL})$ was added to the obtained glassy material. The mixture was stirred for $24 \mathrm{~h}$ at room temperature. The obtained 
aqueous solution was extracted using chloroform $(3 \times 70 \mathrm{~mL})$. The combined organic layers were dried $\left(\mathrm{MgSO}_{4}\right)$, filtered, and the solvent was removed. Toluene $(200 \mathrm{~mL})$ and aqueous $\mathrm{HCl}(2 \mathrm{~N}, 3 \mathrm{~mL})$ were added to the obtained crude material, and the mixture was vigorously stirred for $24 \mathrm{~h}$. The formed solid material was isolated by filtration. It was recrystallized from toluene $(300 \mathrm{~mL})$ and dried in vacuo $\left(\mathrm{CaCl}_{2}\right)$. The yield was $5.66 \mathrm{~g}(54 \%)$ of colourless crystals.

${ }^{1} \mathrm{H}$ NMR (DMSO- $\left.d_{6}\right): \delta=3.23\left(\mathrm{~s}, 6 \mathrm{H}, \mathrm{OC}_{3}\right), 3.38-3.62\left(\mathrm{~m}, 16 \mathrm{H}, \mathrm{OCH}_{2}\right), 3.77(\mathrm{t}, 4 \mathrm{H}$, $\left.\mathrm{ArOCH}_{2} \mathrm{C}_{2}\right), 4.14\left(\mathrm{t}, 4 \mathrm{H}, \operatorname{ArOC}_{2}\right), 7.27\left(\mathrm{~s}, 2 \mathrm{H}, \mathrm{H}^{6}\right), 7.83\left(\mathrm{~s}, 4 \mathrm{H}, \mathrm{B}(\mathrm{OH})_{2}\right)$.

${ }^{13} \mathrm{C}$ NMR $\left(\mathrm{DMSO}-d_{6}\right): \delta=57.96\left(\mathrm{OCH}_{3}\right), 67.90,68.67,69.55,69.64,71.17\left(\mathrm{OCH}_{2}\right)$, $119.01\left(C^{6}\right), 124.90\left(C^{4}\right), 157.15\left(C^{5}\right)$.

\section{2-Methoxyethyl-2-methoxydiethoxyethylamine, $24 \beta$}

To a refluxed and stirred solution of methoxyethylamine $35(50 \mathrm{~mL}, 43.2 \mathrm{~g}, 575$ $\mathrm{mmol}, 4.0 \mathrm{eq})$ in isopropanol $(108 \mathrm{~mL}), \alpha$-(p-tosyl)-tri(ethylene glycol) monomethyl ether $17 \mathrm{a}(45.77 \mathrm{~g}, 144 \mathrm{mmol}, 1.0 \mathrm{eq})$ in isopropanol $(38 \mathrm{~mL})$ was added dropwise. After complete addition, the mixture was refluxed for further $20 \mathrm{~h}$. At room temperature, $\mathrm{NaOH}(6.62 \mathrm{~g}, 166 \mathrm{mmol}, 1.14 \mathrm{eq})$ was added, and stirring was continued for further $12 \mathrm{~h}$. The formed white solid was removed by filtration, and the solvent and the excess of methoxyethylamine were removed by distillation in vacuo. The residue was diluted with methylene chloride (approx. $30 \mathrm{~mL}$ ) and filtered again. The solvent was removed, and the oily residue was dried in vacuo. The yield was $27.5 \mathrm{~g}(86 \%)$ of a brown oil.

${ }^{1} \mathrm{H}$ NMR $\left(\mathrm{CDCl}_{3}\right): \delta=2.74,2.77\left(2 \mathrm{t}, 4 \mathrm{H}, \mathrm{H}^{17,17}\right), 3.29,3.32\left(2 \mathrm{~s}, 6 \mathrm{H}, \mathrm{H}^{19,23^{\prime}}\right), 3.44-$ $3.59\left(\mathrm{~m}, 12 \mathrm{H}, \mathrm{H}^{8,18^{\prime}-22^{\prime}}\right)$.

${ }^{13} \mathrm{C} \operatorname{NMR}\left(\mathrm{CDCl}_{3}\right): \delta=49.31\left(\mathrm{C}^{17,17^{\prime}}\right), 58.93,59.15\left(\mathrm{C}^{19,23^{\prime}}\right), 70.61,70.71\left(\mathrm{C}^{19^{\prime}-22^{\prime}}\right)$, $72.01\left(C^{18,18^{\prime}}\right)$.

\section{2-Methoxyethyl-w-methoxyoligoethoxyethylamine, $24 \gamma$}

The synthesis of $24 \gamma$ proceeded as described for $24 \beta$. For $x=8$, starting materials were: Methoxyethylamine $35(27.59 \mathrm{~mL}, 23.84 \mathrm{~g}, 317.4 \mathrm{mmol}, 4.0 \mathrm{eq})$ in isopropanol $(60 \mathrm{~mL}), \alpha$-(p-tosyl)-oligo(ethylene glycol) monomethyl ether $17 \mathrm{~b}(40 \mathrm{~g}, 79.35 \mathrm{mmol}$, $1.0 \mathrm{eq})$ in isopropanol $(30 \mathrm{~mL})$; after 3 days heating: $\mathrm{NaOH}(3.62 \mathrm{~g}, 90.46 \mathrm{mmol}, 1.14$ eq). Methylene chloride $(200 \mathrm{~mL})$ was added after filtration and removal of the solvent and the excess of methoxyethylamine. The $p$-toluenesulfonic acid precipitated and was removed by filtration. The solvent was removed and the oily residue was dried in vacuo. The yield was $25.89 \mathrm{~g} \mathrm{(83 \% )} \mathrm{of} \mathrm{a} \mathrm{brownish} \mathrm{oil.}$

${ }^{1} \mathrm{H}$ NMR $\left(\mathrm{CDCl}_{3}\right): \delta=2.78,2.80\left(2 \mathrm{t}, 4 \mathrm{H}, \mathrm{H}^{17,17}\right), 3.35,3.37\left(2 \mathrm{~s}, 6 \mathrm{H}, \mathrm{H}^{19,23}\right), 3.48-$ $3.55\left(\mathrm{~m}, 32 \mathrm{H}, \mathrm{H}^{18,} 18^{\prime}-22^{\prime}\right)$.

${ }^{13} \mathrm{C}$ NMR $\left(\mathrm{CDCl}_{3}\right): \delta=49.20\left(\mathrm{C}^{17,17^{\prime}}\right), 58.76,58.98\left(\mathrm{H}^{19,23^{\prime}}\right), 70.38,70.58\left(\mathrm{C}^{19^{\prime}-22^{\prime}}\right)$, $71.96,72.16\left(C^{18,18}\right)$.

\section{1,4-Dibromo-2,5-bis[ $\alpha$-(2-methoxyethyl)aminomethyl]benzene, 13a( $\alpha)$}

1,4-Dibromo-2,5-bis( $\alpha$-bromomethyl)benzene $23(5.0 \mathrm{~g}, 11.85 \mathrm{mmol})$, dissolved in chloroform $(500 \mathrm{ml})$, was added dropwise over a period of $6 \mathrm{~h}$ to vigorously stirred 
bis(2-methoxyethyl)amine $24 \alpha(70 \mathrm{ml}, 474 \mathrm{mmol})$. Subsequently, the mixture was heated to reflux for further $24 \mathrm{~h}$. The solvent and the excess of bis(2-methoxyethyl)amine were removed in vacuo $\left(0.1 \mathrm{mbar}, 40^{\circ} \mathrm{C}\right)$. The oily residue was dissolved in chloroform and transferred to a column filled with basic aluminium oxide (particle diameter: $0.05-0.15 \mathrm{~mm}$; $\mathrm{pH}$ 9.5). Using ethyl acetate as eluent, all impurities were retained by the aluminium oxide while the pure product eluated. The solvent was removed, and the crystalline product was dried in vacuo. The yield was $5.67 \mathrm{~g} \mathrm{(10.78}$ mmol, $91 \%$ ) of brown crystals.

${ }^{1} \mathrm{H}$ NMR $\left(\mathrm{CDCl}_{3}\right): \delta=2.80\left(\mathrm{t}, 8 \mathrm{H}, \mathrm{H}^{17}\right), 3.33\left(\mathrm{~s}, 12 \mathrm{H}, \mathrm{H}^{19}\right), 3.49\left(\mathrm{t}, 8 \mathrm{H}, \mathrm{H}^{18}\right), 3.75(\mathrm{~s}$, $\left.4 \mathrm{H}, \mathrm{H}^{11}\right), 7.79\left(\mathrm{~s}, 2 \mathrm{H}, \mathrm{H}^{3}\right)$.

${ }^{13} \mathrm{C}$ NMR $\left(\mathrm{CDCl}_{3}\right): \delta=54.43\left(\mathrm{C}^{17}\right), 58.60\left(\mathrm{C}^{11}\right), 58.91\left(\mathrm{C}^{19}\right), 71.26\left(\mathrm{C}^{18}\right), 122.70\left(\mathrm{C}^{1}\right)$, $133.94\left(C^{3}\right), 139.39\left(C^{2}\right)$.

\section{1,4-Dibromo-2,5-bis[ $\omega$-bis(2-methoxyethyl)aminohexyl]benzene, 13b( $\alpha)$}

A solution of 1,4-dibromo-2,5-bis( $\omega$-bromohexyl)benzene $28(5.0 \mathrm{~g}, 8.90 \mathrm{mmol})$ in chloroform $(420 \mathrm{ml})$ was added dropwise over a period of $6 \mathrm{~h}$ to vigorously stirred and heated bis(2-methoxyethyl)amine $24 \alpha(52.5 \mathrm{ml}, 355.5 \mathrm{mmol})$. Subsequently, the mixture was heated to reflux for further $24 \mathrm{~h}$. The solvent and the excess of bis(2methoxyethyl)amine were removed in vacuo $\left(0.1 \mathrm{mbar}, 40^{\circ} \mathrm{C}\right)$. The residue was dissolved in chloroform ( $5 \mathrm{~mL})$ and then transferred to a column filled with basic aluminium oxide (particle diameter: $0.05-0.15 \mathrm{~mm}$; $\mathrm{pH} 9.5$ ). Using ethyl acetate as eluent, all impurities were retained by the aluminum oxide while the pure product eluated. The solvent was removed, and the oily product was dried in vacuo. The yield was $5.51 \mathrm{~g}(8.27 \mathrm{mmol}, 93 \%)$ of a yellow viscous oil.

${ }^{1} \mathrm{H}$ NMR $\left(\mathrm{CDCl}_{3}\right): \delta=1.33\left(\mathrm{~m}, 4 \mathrm{H}, \mathrm{H}^{14}\right), 1.38\left(\mathrm{~m}, 4 \mathrm{H}, \mathrm{H}^{13}\right), 1.46\left(\mathrm{~m}, 4 \mathrm{H}, \mathrm{H}^{15}\right), 1.55(\mathrm{~m}$, $\left.4 \mathrm{H}, \mathrm{H}^{12}\right), 2.51\left(\mathrm{t}, 4 \mathrm{H}, \mathrm{H}^{16}\right), 2.63\left(\mathrm{t}, 4 \mathrm{H}, \mathrm{H}^{11}\right), 2.71\left(\mathrm{t}, 8 \mathrm{H}, \mathrm{H}^{17}\right), 3.34\left(\mathrm{~s}, 12 \mathrm{H}, \mathrm{H}^{19}\right), 3.46$ $\left(\mathrm{t}, 8 \mathrm{H}, \mathrm{H}^{18}\right), 7.34\left(\mathrm{~s}, 2 \mathrm{H}, \mathrm{H}^{3}\right)$.

${ }^{13} \mathrm{C}$ NMR $\left(\mathrm{CDCl}_{3}\right): \delta=26.87\left(\mathrm{C}^{15}\right), 27.30\left(\mathrm{C}^{14}\right), 29.31\left(\mathrm{C}^{13}\right), 29.85\left(\mathrm{C}^{12}\right), 35.54\left(\mathrm{C}^{11}\right)$, $54.93\left(C^{17}\right), 55.45\left(C^{16}\right), 58.95\left(C^{19}\right), 71.22\left(C^{18}\right), 123.13\left(C^{1}\right), 133.84\left(C^{3}\right), 141.32$ $\left(C^{2}\right)$.

\section{1,4-Dibromo-2,5-bis[bis-6-(2-methoxyethyl-2-methoxydiethoxyethyl)aminohexyl]- benzene, $13 b(\beta)$}

A solution of 1,4-dibromo-2,5-bis( $\omega$-bromohexyl)benzene 28 (4.5 g, $8 \mathrm{mmol}, 1 \mathrm{eq})$ in chloroform (350 mL) was added dropwise over a period of $4 \mathrm{~h}$ to vigorously stirred and heated $\left(85^{\circ} \mathrm{C}\right)$ 2-methoxyethyl-2-methoxydiethoxyethylamine $24 \beta(28.29 \mathrm{~g}, 128$ mmol, 16.0 eq). Subsequently, the mixture was heated to reflux for further 3 days. The solvent was removed. Chloroform $(100 \mathrm{~mL})$ was added to the oily residue, and the resulting solution was washed with water $(8 \times 200 \mathrm{~mL})$ until the aqueous layer did not show any yellow discoloration. The organic layer was dried $\left(\mathrm{MgSO}_{4}\right)$, filtered, and the solvent was removed in vacuo. The residue was dissolved in a small quantity of chloroform and then transferred onto a column filled with basic aluminium oxide (particle diameter: $0.05-0.15 \mathrm{~mm}$; $\mathrm{pH} 9.5$, deactivated using $15 \%$ of water). Using toluene / ethyl acetate (2:1) with two percent of triethyleneamine as the mobile phase, impurities remained on the top of the column while the pure product eluated. The 
solvent was removed, and the oily product was dried in vacuo. The yield was $1.17 \mathrm{~g}$ $(1.39 \mathrm{mmol}, 78 \%)$ of a yellow oil.

${ }^{1} \mathrm{H}$ NMR $\left(\mathrm{CDCl}_{3}\right): \delta=1.33\left(\mathrm{~m}, 4 \mathrm{H}, \mathrm{H}^{14}\right), 1.35\left(\mathrm{~m}, 4 \mathrm{H}, \mathrm{H}^{13}\right), 1.46\left(\mathrm{~m}, 4 \mathrm{H}, \mathrm{H}^{15}\right), 1.55(\mathrm{~m}$, $\left.4 \mathrm{H}, \mathrm{H}^{12}\right), 2.54\left(\mathrm{t}, 4 \mathrm{H}, \mathrm{H}^{16}\right), 2.63\left(\mathrm{t}, 4 \mathrm{H}, \mathrm{H}^{11}\right), 2.75,2.77\left(2 \mathrm{t}, 8 \mathrm{H}, \mathrm{H}^{17,}, 17\right), 3.34,3.38(2 \mathrm{~s}$, $\left.12 \mathrm{H}, \mathrm{H}^{19,23^{\prime}}\right), 3.45\left(\mathrm{t}, 4 \mathrm{H}, \mathrm{H}^{18^{\prime}}\right), 3.54\left(\mathrm{t}, 4 \mathrm{H}, \mathrm{H}^{22}\right), 3.55\left(\mathrm{t}, 4 \mathrm{H}, \mathrm{H}^{18}\right), 3.61-3.65(\mathrm{~m} ; 12 \mathrm{H}$, $\left.\mathrm{H}^{19^{\prime}-21^{\prime}}\right), 7.34\left(\mathrm{~s}, 2 \mathrm{H}, \mathrm{H}^{3}\right)$.

${ }^{13} \mathrm{C}$ NMR $\left(\mathrm{CDCl}_{3}\right): \delta=26.86\left(\mathrm{C}^{15}\right), 27.21\left(\mathrm{C}^{14}\right), 29.25\left(\mathrm{C}^{13}\right), 29.79\left(\mathrm{C}^{12}\right), 35.48\left(\mathrm{C}^{11}\right)$, 53.95, 54.07 $\left(C^{17,17}\right), 55.46\left(C^{16}\right), 58.84,59.04\left(C^{19,23}\right), 70.57,70.67\left(C^{19^{\prime}-22^{\prime}}\right), 123.10$ $\left(C^{1}\right), 133.79\left(C^{3}\right), 141.28\left(C^{2}\right)$.

\section{1,4-Dibromo-2,5-bis[bis-6-(2-methoxyethyl-2-(ethoxyoligoethoxyethyl)aminohexyl]- benzene, $13 b(\gamma)$}

A solution of 1,4-dibromo-2,5-bis( $\omega$-bromohexyl)benzene 28 (1.5 g, $2.67 \mathrm{mmol}, 1 \mathrm{eq})$ in chloroform $(100 \mathrm{~mL})$ was added dropwise over a period of $2 \mathrm{~h}$ to vigorously stirred and heated $\left(85^{\circ} \mathrm{C}\right)$ 2-methoxyethyl-2-methoxyoligoethoxyethylamine $24 \gamma(16.79 \mathrm{~g}$, $42.72 \mathrm{mmol}, 16.0 \mathrm{eq})$. Subsequently, the mixture was heated to reflux for further 5 days. The solvent was removed. Chloroform $(50 \mathrm{~mL})$ was added to the oily residue, and the resulting solution was washed with water $(8 \times 200 \mathrm{~mL})$ until the aqueous layer remained colorless. The organic layer was dried $\left(\mathrm{MgSO}_{4}\right)$, filtered, and the solvent was removed in vacuo. The residue was dissolved in a small quantity of chloroform and then transferred onto a column filled with basic aluminium oxide (particle diameter: $0.05-0.15 \mathrm{~mm}$; $\mathrm{pH}$ 9.5). Using ethyl acetate / toluene (3:1) with one percent of triethyleneamine as the mobile phase, impurities remained on the top of the column while the pure product eluated. The solvent was removed, and the oily product was dried in vacuo. The yield was $1.93 \mathrm{~g}(61 \%)$ of a brown viscous oil.

${ }^{1} \mathrm{H}$ NMR $\left(\mathrm{CDCl}_{3}\right): \delta=1.32\left(\mathrm{~m}, 4 \mathrm{H}, \mathrm{H}^{14}\right), 1.38\left(\mathrm{~m}, 4 \mathrm{H}, \mathrm{H}^{13}\right), 1.46\left(\mathrm{~m}, 4 \mathrm{H}, \mathrm{H}^{15}\right), 1.58(\mathrm{~m}$, $\left.4 \mathrm{H}, \mathrm{H}^{12}\right), 2.52\left(\mathrm{t}, 4 \mathrm{H}, \mathrm{H}^{16}\right), 2.63\left(\mathrm{t}, 4 \mathrm{H}, \mathrm{H}^{11}\right), 2.71,2.73\left(2 \mathrm{t}, 8 \mathrm{H}, \mathrm{H}^{17,}, 17\right), 3.33,3.38(2 \mathrm{~s}$, $\left.12 \mathrm{H}, \mathrm{H}^{19,33^{\prime}}\right), 3.45\left(\mathrm{t}, 4 \mathrm{H}, \mathrm{H}^{18^{\prime}}\right), 3.54\left(\mathrm{t}, 4 \mathrm{H}, \mathrm{H}^{32^{\prime}}\right), 3.55\left(\mathrm{t}, 4 \mathrm{H}, \mathrm{H}^{18}\right), 3.60-3.65(\mathrm{~m}$, $\left.20 \mathrm{H}, \mathrm{H}^{19^{\prime}-31^{\prime}}\right), 7.34\left(\mathrm{~s}, 2 \mathrm{H}, \mathrm{H}^{3}\right)$.

${ }^{13} \mathrm{C}$ NMR $\left(\mathrm{CDCl}_{3}\right): \delta=26.95\left(\mathrm{C}^{15}\right), 27.20\left(\mathrm{C}^{14}\right), 29.24\left(\mathrm{C}^{13}\right), 29.77\left(\mathrm{C}^{12}\right), 35.45\left(\mathrm{C}^{11}\right)$, 53.94, 54.06 ( $\left.\mathrm{C}^{17,17^{\prime}}\right), 55.44\left(\mathrm{C}^{16}\right), 58.81,59.01\left(\mathrm{C}^{19,33^{\prime}}\right), 70.45\left(\mathrm{C}^{32^{\prime}}\right) 70.56,70.66$ $\left(C^{19^{\prime}-31^{\prime}}\right), 123.06\left(C^{1}\right), 133.75\left(C^{3}\right), 141.26\left(C^{2}\right)$.

\section{1,4-Dibromo-2, 5-bis( $\omega$-hydroxytris(oxyethylene))benzene, 31}

Under an atmosphere of nitrogen, a suspension of 1,4-dibromohydroquinone 29 $(18.05 \mathrm{~g}, 67.4 \mathrm{mmol}, 1 \mathrm{eq})$ in tert-butanol $(75 \mathrm{~mL})$ was added to a stirred suspension of potassium tert-butanolate $(16.65 \mathrm{~g}, 148.4 \mathrm{mmol})$ in tert-butanol $(75 \mathrm{~mL})$. The mixture was stirred and heated $\left(90^{\circ} \mathrm{C}\right)$ for $2.5 \mathrm{~h}$. 2-(2-(2-Chloroethoxy)ethoxy)ethanol $30(25 \mathrm{~g}, 148.3 \mathrm{mmol}, 2.2 \mathrm{eq})$ was added dropwise over a period of $1.5 \mathrm{~h}$. After complete addition, the mixture was heated $\left(90^{\circ} \mathrm{C}\right)$ for further $65 \mathrm{~h}$. At room temperature, the mixture was filtered, and the formed solid was extracted with dichloromethane $(100 \mathrm{~mL})$. The solvents were removed from the combined organic solutions. The raw material obtained was dissolved in dichloromethane $(400 \mathrm{~mL})$. The solution was washed with aqueous $\mathrm{HCl}(2 \mathrm{~N}, 2 \times 50 \mathrm{~mL})$ and water $(100 \mathrm{~mL})$, dried $\left(\mathrm{MgSO}_{4}\right)$, filtered, and the solvent removed. The oily residue obtained was recrystallized from isopropanol $(800 \mathrm{~mL})$. The yield was $30.17 \mathrm{~g}(84 \%)$ of colourless crystals. 
${ }^{1} \mathrm{H}$ NMR $\left(\mathrm{CDCl}_{3}\right): \delta=2.65(\mathrm{t}, 2 \mathrm{H}, \mathrm{OH}), 3.51-3.71\left(\mathrm{~m}, 16 \mathrm{H}, \mathrm{OCH}_{2}\right), 3.81(\mathrm{t}, 4 \mathrm{H}$, $\left.\mathrm{ArOCH}_{2} \mathrm{C}_{2}\right), 4.06\left(\mathrm{t}, 4 \mathrm{H}, \mathrm{ArOC}_{2}\right), 7.08\left(\mathrm{~s}, 2 \mathrm{H}, \mathrm{H}^{3}\right)$.

${ }^{13} \mathrm{C}$ NMR $\left(\mathrm{CDCl}_{3}\right): \delta=61.83\left(\underline{\mathrm{C}} \mathrm{H}_{2} \mathrm{OH}\right), 69.66,70.22,70.55,71.21,72.63\left(\mathrm{O}^{\mathrm{C}} \mathrm{H}_{2}\right)$, $111.42\left(C^{1}\right), 119.17\left(C^{3}\right), 150.33\left(C^{2}\right)$.

\section{1,4-Dibromo-2,5-bis( $\omega$-(p-tosyl)-tris(oxyethylene))benzene, 32}

Under an atmosphere of nitrogen, pyridine $(11.8 \mathrm{~mL}, 144.4 \mathrm{mmol}, 4 \mathrm{eq})$ was added to a cooled $\left(2^{\circ} \mathrm{C}\right)$ solution of 1,4-dibromo-2,5-bis( $\omega$-hydroxytris(oxyethylene))benzene $31(19.23 \mathrm{~g}, 36.13 \mathrm{mmol}, 1 \mathrm{eq})$ in chloroform $(50 \mathrm{~mL})$. Tosyl chloride $(20.66 \mathrm{~g}$, $108.4 \mathrm{mmol}, 3 \mathrm{eq})$ was added in small portions to the cooled $\left(2^{\circ} \mathrm{C}\right)$ and stirred solution. After complete addition, stirring was continued at $2^{\circ} \mathrm{C}$ for $4 \mathrm{~h}$ and at room temperature overnight. Chloroform $(250 \mathrm{~mL})$ was added, and the resulting organic layer was washed consecutively with aqueous $\mathrm{HCl}(2 \times 80 \mathrm{~mL})$ and water $(2 \times$ $100 \mathrm{~mL})$. The organic layer was dried $\left(\mathrm{MgSO}_{4}\right)$, and the solvent was removed. The raw material obtained (which still contained some toluenesulfonic acid) could be used without further purification for the subsequent conversion. The yield was $29.77 \mathrm{~g}$ $(98 \%)$ of a lightly yellowish oil.

${ }^{1} \mathrm{H}$ NMR $\left(\mathrm{CDCl}_{3}\right): \delta=2.36\left(\mathrm{~s}, 6 \mathrm{H}, \mathrm{ArC}_{3}\right), 3.50-3.78\left(\mathrm{~m}, 16 \mathrm{H}, \mathrm{OC}_{2}\right), 4.02(\mathrm{t}, 4 \mathrm{H}$, $\left.\mathrm{ArOC}_{2}\right), 4.09\left(\mathrm{t}, 4 \mathrm{H}, \mathrm{TosOC} \underline{\mathrm{H}}_{2}\right), 7.06\left(\mathrm{~s}, 2 \mathrm{H}, \mathrm{H}^{3}\right), 7.26\left(\mathrm{~d}, 4 \mathrm{H}\right.$, aromatic $\left.\mathrm{H}^{\text {meta }}\right), 7.72$ (d, $4 \mathrm{H}$, aromatic $\mathrm{H}^{\text {ortho }}$ ).

${ }^{13} \mathrm{C}$ NMR $\left(\mathrm{CDCl}_{3}\right): \delta=21.76\left(\mathrm{Ar}^{-} \mathrm{H}_{3}\right), 68.84,69.41,69.70,70.25,70.92,71.12$ $\left(\mathrm{OCH}_{2}\right), 111.42\left(\mathrm{C}^{1}\right), 119.16\left(\mathrm{C}^{3}\right), 128.07$ (aromatic $\left.\mathrm{C}^{\text {ortho }}\right), 129.93$ (aromatic $\mathrm{C}^{\text {meta }}$ ), $133.05\left(\mathrm{Ar}^{\mathrm{CSO}} \mathrm{O}_{3} \mathrm{R}\right), 144.91\left(\mathrm{Ar} \underline{\mathrm{C}} \mathrm{CH}_{3}\right), 150.35\left(\mathrm{C}^{2}\right)$.

\section{1,4-Dibromo-2,5-bis( $\omega$-(bis(2-methoxyethyl)amine)-tris(oxyethylene))benzene, $13 \mathrm{c}$}

A solution of 1,4-dibromo-2,5-bis( $\omega$-( $p$-tosyl)-tris(oxyethylene))benzene 32 (12.00 g $14.27 \mathrm{mmol}, 1 \mathrm{eq})$ in chloroform $(175 \mathrm{~mL})$ was added within $3 \mathrm{~h}$ to heated $\left(65^{\circ} \mathrm{C}\right)$ and stirred bis(2-methoxyethyl)amine $24 \alpha(76.05 \mathrm{~g}, 571 \mathrm{mmol}, 40 \mathrm{eq})$. The mixture was refluxed for $12 \mathrm{~h}$. The solvent was removed. Chloroform $(100 \mathrm{~mL})$ was added to the oily residue and the resulting solution was washed with water $(4 \times 200 \mathrm{~mL})$. The organic layer was dried $\left(\mathrm{MgSO}_{4}\right)$ and the solvent was removed. The obtained raw material was purified by column chromatography [eluent: ethyl acetate / $n$-hexane: 1/1; stationary phase: basic aluminium oxide (particle diameter: $0.05-0.15 \mathrm{~mm}, \mathrm{pH}$ 9.5)]. The yield was $6.63 \mathrm{~g} \mathrm{(61 \% )}$ of a slightly yellowish oil.

${ }^{1} \mathrm{H}$ NMR $\left(\mathrm{CDCl}_{3}\right): \delta=2.76\left(\mathrm{t}, 8 \mathrm{H}, \mathrm{H}^{17}\right), 2.79\left(\mathrm{t}, 4 \mathrm{H}, \mathrm{H}^{16}\right), 3.32\left(\mathrm{~s}, 12 \mathrm{H}, \mathrm{H}^{19}\right), 3.45(\mathrm{t}$, $\left.8 \mathrm{H}, \mathrm{H}^{18}\right), 3.57\left(\mathrm{t}, 4 \mathrm{H}, \mathrm{H}^{15}\right), 3.62\left(\mathrm{~m}, 4 \mathrm{H}, \mathrm{H}^{14}\right), 3.73\left(\mathrm{~m}, 4 \mathrm{H}, \mathrm{H}^{13}\right), 3.85\left(\mathrm{t}, 4 \mathrm{H}, \mathrm{H}^{12}\right), 4.11$ (t, $\left.4 \mathrm{H}, \mathrm{H}^{11}\right), 7.08\left(\mathrm{~s}, 2 \mathrm{H}, \mathrm{H}^{3}\right)$.

${ }^{13} \mathrm{C} \mathrm{NMR}\left(\mathrm{CDCl}_{3}\right): \delta=54.46\left(\mathrm{C}^{16}\right), 54.55\left(\mathrm{C}^{17}\right), 58.76\left(\mathrm{C}^{19}\right), 69.55\left(\mathrm{C}^{12}\right), 69.81\left(\mathrm{C}^{15}\right)$, $70.25\left(C^{11}\right), 70.50\left(C^{14}\right), 71.07\left(C^{13}\right), 71.20\left(C^{18}\right), 111.41\left(C^{1}\right), 119.13\left(C^{3}\right), 150.35$ $\left(C^{2}\right)$.

Polymer syntheses: General procedure for approx. $1 \mathrm{~g}$ of polymer

Under an atmosphere of nitrogen, 1,4-dibromobenzene derivative (1 eq), benzene1,4-diboronic acid derivative (1 eq), $1 \mathrm{M}$ aqueous $\mathrm{NaHCO}_{3}$ (31 eq), THF, water and 
tris(tri-p-tolylphosphine)palladium $(0.24-0.67 \mathrm{~mol}-\%)$ were heated and vigorously stirred for 7 days. After 4 days, benzene-1,4-diboronic acid derivative (5 mol- $\%$ ) and $\mathrm{Pd}$ catalyst (0.1 - $0.2 \mathrm{~mol}-\%)$ were added. After 6 days, bromobenzene ( $3 \mathrm{eq})$ was added. After cooling the reaction mixture down to room temperature, the organic layer was separated off, the aqueous layer was extracted with chloroform ( $3 \mathrm{x}$ $30 \mathrm{~mL})$, and the combined organic layers were dried $\left(\mathrm{MgSO}_{4}\right)$, filtered, and the organic solvent was removed. The crude product was redissolved in chloroform $(15 \mathrm{~mL})$ and precipitated by adding $n$-hexane $(500 \mathrm{~mL})$.

\section{Specific polymer syntheses: Applied quantities, yields and analysis}

\section{Poly[2,5-bis(1,4,7,10-tetraoxaundecanyl)-1,4-phenylene-alt-1,4-phenylene], 36}

Initial quantities: 1,4-Dibromo-2,5-bis(1,4,7,10-tetraoxaundecanyl)benzene $\mathbf{1 8}$ $(0.881 \mathrm{~g}, 1.572 \mathrm{mmol}, 1 \mathrm{eq})$, bis(1,3-propanediol ester) of the benzene-1,4-diboronic acid $19(0.386 \mathrm{~g}, 1.572 \mathrm{mmol}, 1 \mathrm{eq})$, and $\mathrm{NaHCO}_{3}(4.2 \mathrm{~g}, 50 \mathrm{mmol}, 32 \mathrm{eq})$, THF $(60 \mathrm{~mL})$, water $(40 \mathrm{~mL})$ and tris(tri-p-tolylphosphine)palladium $(4 \mathrm{mg}, 0.004 \mathrm{mmol}$, $0.25 \mathrm{~mol}-\%)$. After 2 days: Diester $19^{*}(19 \mathrm{mg}, 0.08 \mathrm{mmol}, 5 \mathrm{~mol}-\%)$ and Pd catalyst (approx. $1 \mathrm{mg}, 0.001 \mathrm{mmol})$. After 6 days: Bromobenzene $(0.6 \mathrm{~mL}, 5.7 \mathrm{mmol})$. The yield was $615 \mathrm{mg}(82 \%)$ of a powdery polymer.

${ }^{1} \mathrm{H}$ NMR $\left(\mathrm{CDCl}_{3}\right): \delta=3.35\left(\mathrm{~b}, 6 \mathrm{H}, \mathrm{OCH}_{3}\right), 3.52\left(\mathrm{~m}, 4 \mathrm{H}, \mathrm{H}_{3} \mathrm{COCH}_{2}\right), 3.65(\mathrm{~m}, 12 \mathrm{H}$, $\left.\mathrm{OC}_{2}\right), 3.83\left(\mathrm{~m}, 4 \mathrm{H}, \mathrm{ArOCH}_{2} \underline{\mathrm{C}}_{2}\right), 4.18\left(\mathrm{~m}, 4 \mathrm{H}, \mathrm{ArOC}_{2}\right), 7.13\left(\mathrm{~b}, 2 \mathrm{H}, \mathrm{H}^{6}\right), 7.71(\mathrm{~b}$, $\left.4 \mathrm{H}, \mathrm{H}^{8}\right)$.

${ }^{13} \mathrm{C} \mathrm{NMR}\left(\mathrm{CDCl}_{3}\right): \delta=58.95\left(\mathrm{OCH}_{3}\right), 69.23\left(\mathrm{ArOCH}_{2}\right), 69.76,70.48,70.64,70.79$ $\left(\mathrm{O} \mathrm{H}_{2} \mathrm{CH}_{2} \mathrm{O}\right), 71.86\left(\mathrm{C}_{2} \mathrm{OCH}_{3}\right), 116.68\left(\mathrm{C}^{6}\right), 129.09\left(\mathrm{C}^{8}\right), 130.65\left(\mathrm{C}^{7}\right), 136.78\left(\mathrm{C}^{4}\right)$, $150.44\left(C^{5}\right)$.

\section{Poly[2,5-bis(1,4,7,10-tetraoxaundecanyl)-1,4-phenylene], 37}

Initial quantities: 1,4-Dibromo-2,5-bis(1,4,7,10-tetraoxaundecanyl)benzene $\mathbf{1 8}$ $(0.457 \mathrm{~g}, \quad 0.816 \mathrm{mmol}, \quad 1 \mathrm{eq}), \quad 2,5$-bis $(1,4,7,10$-tetraoxaundecanyl)benzene-1,4diboronic acid $12(0.400 \mathrm{~g}, 0.816 \mathrm{mmol}, 1 \mathrm{eq}), \mathrm{NaHCO}_{3}(2.1 \mathrm{~g}, 25 \mathrm{mmol}, 31 \mathrm{eq})$, THF $(15 \mathrm{~mL})$, water $(10 \mathrm{~mL})$ and tris(tri-p-tolylphosphine)palladium $(2 \mathrm{mg}, 0.002 \mathrm{mmol}$, $0.24 \mathrm{~mol}-\%)$. After 4 days: Diboronic acid $12(20 \mathrm{mg}, 0.04 \mathrm{mmol}, 5 \mathrm{~mol}-\%)$ and $\mathrm{Pd}$ catalyst $(6 \mathrm{mg}, 0.006 \mathrm{mmol})$. After 6 days: Bromobenzene $(0.1 \mathrm{~mL}, 0.9 \mathrm{mmol})$. The yield was $481 \mathrm{mg}(74 \%)$ of a powdery material.

${ }^{1} \mathrm{H}$ NMR $\left(\mathrm{CDCl}_{3}\right): \delta=3.34\left(\mathrm{~b}, 6 \mathrm{H}, \mathrm{OCH}_{3}\right), 3.50\left(\mathrm{~m}, 4 \mathrm{H}, \mathrm{H}_{3} \mathrm{COCH}_{2}\right), 3.60(\mathrm{~m}, 12 \mathrm{H}$, $\left.\mathrm{OCH}_{2}\right)$, $3.75\left(\mathrm{~m}, 4 \mathrm{H}, \mathrm{ArOCH}_{2} \mathrm{CH}_{2}\right), 4.10\left(\mathrm{~m}, 4 \mathrm{H}, \mathrm{ArOCH}_{2}\right), 7.06\left(\mathrm{~b}, 2 \mathrm{H}, \mathrm{H}^{6}\right)$.

${ }^{13} \mathrm{C} \mathrm{NMR}\left(\mathrm{CDCl}_{3}\right): \delta=58.91\left(\mathrm{OCH}_{3}\right), 69.03\left(\mathrm{ArOCH}_{2}\right), 69.82,70.42,70.56,70.65$ $\left(\mathrm{OCH}_{2} \mathrm{CH}_{2} \mathrm{O}\right), 71.84\left(\mathrm{CH}_{2} \mathrm{OCH}_{3}\right), 117.15\left(\mathrm{C}^{6}\right), 127.55\left(\mathrm{C}^{4}\right), 150.13\left(\mathrm{C}^{5}\right)$.

Poly[1,4-phenylene-alt-2,5-bis[bis-(2-methoxyethyl)aminomethylene]-1,4-phenylene], $38 \mathrm{a}$

Initial quantities: Dibromobenzene derivative 13a (999.97 mg, $1.90 \mathrm{mmol}, 1 \mathrm{eq})$, diboronic acid diester 19* (466.60 mg, $1.90 \mathrm{mmol}, 1 \mathrm{eq}), \mathrm{NaHCO}_{3}$ (5 g, $59.52 \mathrm{mmol}$, $31 \mathrm{eq})$, THF (49 mL), water (33.4 mL) and tris(tri-p-tolylphosphine)palladium(0) (6.7 $\mathrm{mg}, 0.007 \mathrm{mmol}, 0.36 \mathrm{~mol}-\%)$. After 4 days: Benzene-1,4-diboronic acid derivative 19* (23.3 mg, $0.09 \mathrm{mmol}, 5 \mathrm{~mol}-\%)$, Pd catalyst (2 mg, $0.002 \mathrm{mmol}, 0.1 \mathrm{~mol}-\%)$. After 
6 days: Bromobenzene $(0.6 \mathrm{~mL}, 5.69 \mathrm{mmol}, 3 \mathrm{eq})$. Specific work-up: After complete conversion, THF $(20 \mathrm{~mL})$ and water $(10 \mathrm{~mL})$ were added. The aqueous layer was separated off and washed with toluene $(2 \times 15 \mathrm{~mL})$ until the aqueous layer was colorless. The combined organic layers were rotavaporated to dryness. The residue was dissolved in methylene chloride (approx. $20 \mathrm{~mL}$ ), and the resulting solution was filtered. Methanol $(250 \mathrm{~mL})$ was added and the polymeric precipitate isolated using a centrifuge and dried ( $1^{\text {st }}$ fraction). The obtained solution was rotavaporated to dryness. The residue was dissolved in methylene chloride $(50 \mathrm{~mL})$ and filtered. The volume of the solution was concentrated down to a few milliiters, and $n$-hexane (250 $\mathrm{mL}$ ) was added. The polymer precipitated, was isolated using a centrifuge, and dried in vacuo over $\mathrm{CaCl}_{2}$. The yield was $60 \mathrm{mg}\left(0.14 \mathrm{mmol}, 7 \%\right.$; $1^{\text {st }}$ fraction $)$ of a colorless polymer and $200 \mathrm{mg}\left(0.45 \mathrm{mmol}, 24 \% ; 2^{\text {nd }}\right.$ fraction $)$ of a brownish polymer.

${ }^{1} \mathrm{H}$ NMR $\left(\mathrm{CDCl}_{3}\right): \delta=2.79\left(\mathrm{t}, 8 \mathrm{H}, \mathrm{H}^{17}\right), 3.29\left(\mathrm{~s}, 12 \mathrm{H}, \mathrm{H}^{19}\right), 3.42\left(\mathrm{t}, 8 \mathrm{H}, \mathrm{H}^{18}\right), 3.74(\mathrm{~s}$, $\left.4 \mathrm{H}, \mathrm{H}^{11}\right), 7.47\left(\mathrm{~d}, 4 \mathrm{H}, \mathrm{H}^{8}\right), 7.64\left(\mathrm{~s}, 2 \mathrm{H}, \mathrm{H}^{3}\right)$.

${ }^{13} \mathrm{C}$ NMR $\left(\mathrm{CDCl}_{3}\right): \delta=54.00\left(\mathrm{C}^{17}\right), 56.69\left(\mathrm{C}^{11}\right), 58.87\left(\mathrm{C}^{19}\right), 71.32\left(\mathrm{C}^{18}\right), 129.31\left(\mathrm{C}^{8}\right)$, $131.52\left(C^{3}\right), 135.35\left(C^{2}\right), 139.90,140.99\left(C^{1}, C^{7}\right)$.

Poly[4,4'-biphenylene-alt-2,5-bis[(bis-(2-methoxyethyl)aminomethylene]-1,4phenylene], 39a

Initial quantities: Dibromo compound 13a (1.5 g, $2.85 \mathrm{mmol}, 1 \mathrm{eq})$, diboronic acid diester 20* (918.6 mg, $2.85 \mathrm{mmol}, 1 \mathrm{eq}), \mathrm{NaHCO}_{3}(7.51 \mathrm{~g}, 89.34 \mathrm{mmol}, 31 \mathrm{eq})$, THF $(73.6 \mathrm{~mL})$, water $(50.2 \mathrm{~mL})$ and tris(tri-p-tolylphosphine)palladium(0) $(10.1 \mathrm{mg}$, $0.01 \mathrm{mmol}, 0.35 \mathrm{~mol}-\%)$. After 4 days: Diboronic acid diester 20* (45.93 mg, 0.14 $\mathrm{mmol}, 5 \mathrm{~mol}-\%)$ and $\mathrm{Pd}$ catalyst $(3 \mathrm{mg}, 0.003 \mathrm{mmol}, 0.1 \mathrm{~mol}-\%)$. After 6 days: Dibromobenzene $(0.9 \mathrm{~mL}, 8.54 \mathrm{mmol}, 3 \mathrm{eq})$. Specific work-up: After complete conversion, THF $(20 \mathrm{~mL})$ and water $(10 \mathrm{~mL})$ were added. The organic layer was separated off, the aqueous layer was washed with toluene $(2 \times 100 \mathrm{~mL})$. The combined organic layers were rotavaporated to dryness. The residue was dissolved in toluene $(50 \mathrm{~mL})$, heated (until a yellow solution was obtained), and filtered at increased temperature. The solution was concentrated down to a few milliliters, and the polymer was precipitated by adding $n$-hexane $(400 \mathrm{~mL})$. The precipitate was isolated using a centrifuge and dried in vacuo over $\mathrm{CaCl}_{2}$. The yield was $890 \mathrm{mg}$ $(1.72 \mathrm{mmol}, 60 \%)$ of a powdery polymer.

${ }^{1} \mathrm{H}$ NMR $\left(\mathrm{CDCl}_{3}\right): \delta=2.65\left(\mathrm{t}, 8 \mathrm{H}, \mathrm{H}^{17}\right), 3.20\left(\mathrm{~s}, 12 \mathrm{H}, \mathrm{H}^{19}\right), 3.39\left(\mathrm{t}, 8 \mathrm{H}, \mathrm{H}^{18}\right), 3.71(\mathrm{~s}$, $\left.4 \mathrm{H}, \mathrm{H}^{11}\right), 7.54\left(\mathrm{~s}, 2 \mathrm{H}, \mathrm{H}^{3}\right), 7.40,7.67\left(2 \mathrm{~d}, 8 \mathrm{H}, \mathrm{H}^{8,9}\right)$.

${ }^{13} \mathrm{C}$ NMR $\left(\mathrm{CDCl}_{3}\right): \delta=53.92\left(\mathrm{C}^{17}\right), 56.74\left(\mathrm{C}^{11}\right), 58.85\left(\mathrm{C}^{19}\right), 71.29\left(\mathrm{C}^{18}\right), 126.67$, $129.99\left(C^{8,9}\right), 131.59\left(C^{3}\right), 135.46\left(C^{2}\right), 139.39,140.49,140.90\left(C^{1,7,10}\right)$.

Poly[1,4-phenylene-alt-2,5-bis[bis-6-(2-methoxyethyl)aminohexyl]-1,4-phenylene], 38b

Initial quantities: Dibromobenzene derivative 13b $(1 \mathrm{~g}, 1.5 \mathrm{mmol}, 1 \mathrm{eq})$, diboronic acid diester 19* (368.3 mg, $1.5 \mathrm{mmol}, 1 \mathrm{eq}), \mathrm{NaHCO}_{3}(3.95 \mathrm{~g}, 47.02 \mathrm{mmol}, 31 \mathrm{eq})$, THF $(39.5 \mathrm{~mL})$, water $(26.3 \mathrm{~mL})$ and tris(tri-p-tolylphosphine)palladium(0) $(10.53 \mathrm{mg}$, $0.01 \mathrm{mmol}, 0.67 \mathrm{~mol}-\%)$. After 4 days: Diboronic acid diester 19* (18.42 mg, 0.08 $\mathrm{mmol}, 5 \mathrm{~mol}-\%$ ) and $\mathrm{Pd}$ catalyst ( $3 \mathrm{mg}, 0.003 \mathrm{mmol}, 0.2 \mathrm{~mol}-\%)$. After 6 days: Bromobenzene $(0.47 \mathrm{ml}, 4.46 \mathrm{mmol}, 3 \mathrm{eq})$. Specific work-up: After complete conversion, THF $(15 \mathrm{~mL})$ and water $(8 \mathrm{~mL})$ were added to ensure proper phase separation. The organic layer was separated off, the aqueous layer was washed with 
toluene $(2 \times 80 \mathrm{~mL})$. The combined organic layers were filtered, the solvent was removed, and the residue was redissolved in THF $(50 \mathrm{~mL})$. Methanol $(250 \mathrm{~mL})$ was added, and the formed precipitate was separated off by centrifugation. The obtained solution was rotavaporated to dryness, and the solid residue was re-dissolved in methylene chloride $(50 \mathrm{~mL})$. After filtration, the solution was concentrated down to a few milliliters and the polymer was precipitated by adding $n$-hexane $(250 \mathrm{~mL})$. The precipitated polymer was isolated using a centrifuge. The product was dried in vacuo over $\mathrm{CaCl}_{2}$. The yield was $600 \mathrm{mg}(1.03 \mathrm{mmol}, 67 \%)$ of a powdery polymer.

${ }^{1} \mathrm{H}$ NMR $\left(\mathrm{CDCl}_{3}\right): \delta=1.19\left(2 \mathrm{~m}, 8 \mathrm{H}, \mathrm{H}^{13,14}\right), 1.35\left(\mathrm{~m}, 4 \mathrm{H}, \mathrm{H}^{15}\right), 1.53\left(\mathrm{~m}, 4 \mathrm{H}, \mathrm{H}^{12}\right), 1.92$ $\left(\mathrm{m}, 4 \mathrm{H}, \mathrm{H}^{11}\right), 2.41\left(\mathrm{t}, 4 \mathrm{H}, \mathrm{H}^{16}\right), 2.62\left(\mathrm{t}, 8 \mathrm{H}, \mathrm{H}^{17}\right), 3.26\left(\mathrm{~s}, 12 \mathrm{H}, \mathrm{H}^{19}\right), 3.38\left(\mathrm{t}, 8 \mathrm{H}, \mathrm{H}^{18}\right)$, $7.20\left(\mathrm{~s}, 2 \mathrm{H}, \mathrm{H}^{3}\right), 7.39\left(\mathrm{~d}, 4 \mathrm{H}, \mathrm{H}^{8}\right)$.

${ }^{13} \mathrm{C}$ NMR $\left(\mathrm{CDCl}_{3}\right): \delta=27.01\left(\mathrm{C}^{15}\right), 27.49\left(\mathrm{C}^{14}\right), 29.79\left(\mathrm{C}^{13}\right), 31.78\left(\mathrm{C}^{12}\right), 32.86\left(\mathrm{C}^{11}\right)$, $54.03\left(C^{17}\right), 55.55\left(C^{16}\right), 58.94\left(C^{19}\right), 71.23\left(C^{18}\right), 129.11\left(C^{8}\right), 131.17\left(C^{3}\right), 137.62$ $\left(C^{2}\right), 140.39,140.64\left(C^{1,7}\right)$.

Poly[4,4'-biphenyl-alt-2,5-bis[bis-6-(2-methoxyethyl)aminohexyl]-1,4-phenylene], 39b

Initial quantities: Dibromo compound 13b (1.5 g, $2.25 \mathrm{mmol}, 1 \mathrm{eq})$, diboronic acid diester 20* (724.4 mg, $2.25 \mathrm{mmol}, 1 \mathrm{eq}), \mathrm{NaHCO}_{3}$ (5.92 g, $\left.70.47 \mathrm{mmol}, 31 \mathrm{eq}\right)$, THF $(59.2 \mathrm{~mL})$, water $(39.5 \mathrm{~mL})$ and tris(tri-p-tolylphosphine)palladium(0) (15.8 mg, 0.015 mmol, $0.67 \mathrm{~mol}-\%)$. After 4 days: Diboronic acid diester $20 *(36.22 \mathrm{mg}, 0.11 \mathrm{mmol}, 5$ mol- $\%$ ) and Pd catalyst ( $5 \mathrm{mg}, 0.005 \mathrm{mmol}, 0.2 \mathrm{~mol}-\%)$. After 6 days: Bromobenzene ( $0.7 \mathrm{~mL}, 6.64 \mathrm{mmol}, 3 \mathrm{eq})$. Specific work-up: After complete conversion, THF $(20 \mathrm{~mL})$ and water $(10 \mathrm{~mL})$ were added. The organic layer was separated off, the aqueous layer was washed with toluene $(2 \times 100 \mathrm{~mL})$. The combined organic layers were rotavaporated to dryness. The residue was dissolved in methylene chloride (approx. 30 $\mathrm{mL}$ ) and filtered. The solution was concentrated down to a few milliliters, and the polymer was precipitated by adding $n$-hexane $(400 \mathrm{~mL})$. The precipitate was isolated using a centrifuge and dried in vacuo over $\mathrm{CaCl}_{2}$. The yield was $1.0 \mathrm{~g}(1.52 \mathrm{mmol}$, $68 \%$ ) of a powdery polymer.

${ }^{1} \mathrm{H}$ NMR $\left(\mathrm{CDCl}_{3}\right): \delta=1.16\left(2 \mathrm{~m}, 8 \mathrm{H}, \mathrm{H}^{13,14}\right), 1.35\left(\mathrm{~m}, 4 \mathrm{H}, \mathrm{H}^{15}\right), 1.50\left(\mathrm{~m}, 4 \mathrm{H}, \mathrm{H}^{12}\right), 2.42$ $\left(\mathrm{t}, 4 \mathrm{H}, \mathrm{H}^{16}\right), 2.63\left(\mathrm{t}, 8 \mathrm{H}, \mathrm{H}^{17}\right), 3.25\left(\mathrm{~s}, 12 \mathrm{H}, \mathrm{H}^{19}\right), 3.38\left(\mathrm{t}, 8 \mathrm{H}, \mathrm{H}^{18}\right), 7.17\left(\mathrm{~s}, 2 \mathrm{H}, \mathrm{H}^{3}\right)$, $7.42,7.69\left(2 \mathrm{~d}, 8 \mathrm{H}, \mathrm{H}^{8,9}\right)$.

${ }^{13} \mathrm{C}$ NMR $\left(\mathrm{CDCl}_{3}\right): \delta=26.71\left(\mathrm{C}^{15}\right), 27.39\left(\mathrm{C}^{14}\right), 29.65\left(\mathrm{C}^{13}\right), 31.66\left(\mathrm{C}^{12}\right), 32.76\left(\mathrm{C}^{11}\right)$, $53.96\left(C^{17}\right), 55.44\left(C^{16}\right), 58.94\left(C^{19}\right), 71.10\left(C^{18}\right), 126.77,129.94\left(C^{8,9}\right), 131.11\left(C^{3}\right)$, $137.63\left(C^{2}\right), 139.25,140.40,141.04\left(C^{1,7,10}\right)$.

Poly[2,5-bis(1,4,7,10-tetraoxaundecanyl)-1,4-phenylene-alt-2,5-bis(bis-(2-methoxyethyl)aminomethylene)-1,4-phenylene], 14a

Initial quantities: 1,4-Dibromo-2,5-bis(bis(2-methoxyethyl)aminomethylene)benzene 13a $(0.843 \mathrm{~g}, 1.602 \mathrm{mmol}, 1 \mathrm{eq}), 2,5$-bis(1,4,7,10-tetraoxaundecanyl)benzene-1,4diboronic acid 12 (0.785 g, $1.602 \mathrm{mmol}, 1 \mathrm{eq}), \mathrm{NaHCO}_{3}(4.1 \mathrm{~g}, 49 \mathrm{mmol}, 31 \mathrm{eq})$, THF $(30 \mathrm{~mL})$, water $(20 \mathrm{~mL})$ and tris(tri-p-tolylphosphine)palladium (4 mg, $0.004 \mathrm{mmol}$, $0.25 \mathrm{~mol}-\%)$. After 4 days: Diboronic acid 12 (40 mg, $0.08 \mathrm{mmol}, 5 \mathrm{~mol}-\%)$ and tris(trip-tolylphosphine)palladium (12 mg, $0.012 \mathrm{mmol})$. After 6 days: Bromobenzene $(0.2$ $\mathrm{mL}, 1.8 \mathrm{mmol})$. Specific work-up: The oligomeric crude product doesn't precipitate from hexene and was not purified. The yield was $1.14 \mathrm{~g}(93 \%)$ of an oily residue. 
Poly[2,5-bis(1,4,7,10-tetraoxaundecanyl)-1,4-phenylene-alt-2,5-bis(bis-(2-methoxyethyl)-6-hexylamine)-1,4-phenylene], 14b

Initial quantities: 1,4-Dibromo-2,5-bis(bis(2-methoxyethyl)-6-hexylamino)benzene 13b $(0.544 \mathrm{~g}, \quad 0.816 \mathrm{mmol}, \quad 1 \mathrm{eq}), \quad 2,5$-bis(1,4,7,10-tetraoxaundecanyl)benzene-1,4-diboronic acid $12(0.400 \mathrm{~g}, 0.816 \mathrm{mmol}, 1 \mathrm{eq}), \mathrm{NaHCO}_{3}(2.1 \mathrm{~g}, 25 \mathrm{mmol}, 31 \mathrm{eq})$, THF $(15 \mathrm{~mL})$, water $(10 \mathrm{~mL})$ and tris(tri-p-tolylphosphine)palladium $(3 \mathrm{mg}, 0.003 \mathrm{mmol}$, $0.37 \mathrm{~mol}-\%)$. After 4 days: Diboronic acid $12(20 \mathrm{mg}, 0.04 \mathrm{mmol}, 5 \mathrm{~mol}-\%)$ and tris(tri$p$-tolylphosphine)palladium (8 mg, $0.008 \mathrm{mmol})$. After 6 days: Bromobenzene $(0.1$ $\mathrm{mL}, 0.9 \mathrm{mmol}$ ). Specific work-up: The obtained material was redissolved in dioxane $(10 \mathrm{~mL})$ and freeze-dried. The yield was $570 \mathrm{mg}(77 \%)$ of an elastomeric product.

${ }^{1} \mathrm{H}$ NMR $\left(\mathrm{CDCl}_{3}\right): \delta=1.24,1.47\left(\mathrm{~b}, 16 \mathrm{H}, \mathrm{H}^{12-15}\right), 2.55\left(\mathrm{~b}, 8 \mathrm{H}, \mathrm{H}^{11}, \mathrm{H}^{16}\right), 2.76(\mathrm{~b}, 8 \mathrm{H}$, $\left.\mathrm{H}^{17}\right), 3.33\left(\mathrm{~m}, 18 \mathrm{H}, \mathrm{H}^{19}, \mathrm{H}^{\eta}\right), 3.40-3.79\left(\mathrm{~m}, 28 \mathrm{H}, \mathrm{H}^{18}, \mathrm{H}^{\beta-\gamma}\right), 4.04\left(\mathrm{~m}, 4 \mathrm{H}, \mathrm{H}^{\alpha}\right), 6.88(\mathrm{~b}$, $\left.2 \mathrm{H}, \mathrm{H}^{6}\right), 7.15\left(\mathrm{~b}, 2 \mathrm{H}, \mathrm{H}^{3}\right)$.

${ }^{13} \mathrm{C}$ NMR $\left(\mathrm{CDCl}_{3}\right): \delta=26.75,27.52,29.97,31.14,33.09\left(\mathrm{C}^{11-15}\right), 53.79\left(\mathrm{C}^{17}\right), 55.45$ $\left(C^{16}\right)$, 58.79, $58.97\left(C^{19}, C^{\eta}\right), 69.17,69.61,70.48,70.63,70.77,71.86\left(C^{18}, C^{\alpha-\zeta}\right)$, $116.76\left(C^{6}\right), 130.27\left(C^{3}\right), 131.15\left(C^{4}\right), 137.02,137.95\left(C^{1}, C^{2}\right), 150.03\left(C^{5}\right)$.

Poly[2,5-bis(1,4,7,10-tetraoxaundecanyl)-1,4-phenylene-alt-2,5-bis( $\omega$-(bis(2-methoxyethyl)amine)-tris(oxyethylene))-1,4-phenylene], 14c

Initial quantities: 2,5-Dibromo-1,4-bis( $\omega$-(bis(2-methoxyethyl)amine)-tris(oxyethylene))benzene $13 \mathrm{c} \quad(0.614 \mathrm{~g}, \quad 0.805 \mathrm{mmol}, 1 \mathrm{eq}), 2,5$-bis(1,4,7,10-tetraoxaundecanyl)benzene-1,4-diboronic acid $12(0.394 \mathrm{~g}, 0.805 \mathrm{mmol}, 1 \mathrm{eq}), \mathrm{NaHCO}_{3}$ $(2.1 \mathrm{~g}, 25 \mathrm{mmol}, 31 \mathrm{eq})$, THF $(10 \mathrm{~mL})$, water $(10 \mathrm{~mL})$ and tris(tri-p-tolylphosphine)palladium $(3.7 \mathrm{mg}, 0.0036 \mathrm{mmol}, 0.45 \mathrm{~mol}-\%)$. After 4 days: diboronic acid 12 (20 mg, $0.04 \mathrm{mmol}, 5 \mathrm{~mol}-\%)$ and Pd catalyst $(8 \mathrm{mg}, 0.008 \mathrm{mmol})$. After 6 days: bromobenzene $(0.1 \mathrm{~mL}, 0.9 \mathrm{mmol})$. Specific work-up: The obtained crude material was redissolved in chloroform (15 mL) and reprecipitated in $n$-hexane $(500 \mathrm{~mL})$. The partially protonated material obtained was redissolved in chloroform (50 mL). Sodium carbonate $(1 \mathrm{~g})$ was added, and the mixture was stirred for $30 \mathrm{~min}$. The mixture was filtered, and the solvent was removed. Finally, the polymer was freeze-dried from dioxane. The yield was $679 \mathrm{mg}(84 \%)$ of a slightly yellow polymer.

${ }^{1} \mathrm{H}$ NMR $\left(\mathrm{CDCl}_{3}\right): \delta=2.75\left(\mathrm{~b}, 12 \mathrm{H}, \mathrm{H}^{16,17}\right), 3.32\left(\mathrm{~b}, 18 \mathrm{H}, \mathrm{H}^{19}, \mathrm{H}^{\eta}\right), 3.40-3.80(\mathrm{~m}$, $\left.44 \mathrm{H}, \mathrm{H}^{12-15}, \mathrm{H}^{18}, \mathrm{H}^{\beta-\zeta}\right), 4.10\left(\mathrm{~m}, 8 \mathrm{H}, \mathrm{H}^{11}, \mathrm{H}^{\alpha}\right), 7.06\left(\mathrm{~b}, 4 \mathrm{H}, \mathrm{H}^{3}, \mathrm{H}^{6}\right)$.

${ }^{13} \mathrm{C}$ NMR $\left(\mathrm{CDCl}_{3}\right): \delta=54.32,54.46\left(\mathrm{C}^{16,17}\right), 58.79,58.95\left(\mathrm{C}^{19}, \mathrm{C}^{\eta}\right), 68.8769 .05$, 69.61, 69.84, 70.44, 70.65, 71.05, $71.86\left(C^{11-15}, C^{18}, C^{\alpha-\zeta}\right), 117.15\left(C^{3}, C^{6}\right), 127.53$ $\left(C^{1}, C^{4}\right), 150.13\left(C^{2}, C^{5}\right)$.

Acknowledgement: The authors are grateful to Prof. M. Ballauff, Karlsruhe, Prof. W. Oppermann, Stuttgart, Dr. C. Holm, and Dr. M. Deserno, Mainz, for fruitful discussions. Important experimental support provided by Mrs. K. Lienkamp, Berlin, is gratefully acknowledged. The authors are grateful to Prof. N. A. Dencher (Institute for Biochemistry, Darmstadt) for the $\mathrm{pH}$ measurement facilities. The authors wish to thank the Deutsche Forschungsgemeinschaft (DFG) and the Fonds der Chemischen Industrie (FCl) for financial support. 
[1] Mandel, M.; "Polyelectrolytes in: Encyclopedia of Polymer Science and Engineering", 2n ${ }^{d}$ edition; Mark, F. H.; Bikales, N. M.; Overberger, C. G.; Menges, G., editors; Wiley, New York 1988, vol. 11, pp. 739ff.

[2] Schmitz, K. S.; "Macroions in solution and colloid suspension", VCH Publishers, New York 1993.

[3] Förster, S.; Schmidt, M.; Adv. Polym. Sci. 1995, 120, 51.

[4] Auer, H. E.; Alexandrowicz, Z.; Biopolymers 1969, 8, 1.

[5] Mandel, M.; Schouten, J.; Macromolecules 1980, 13, 11247.

[6] Nicolai, T.; Mandel, M.; Macromolecules 1989, 22, 438.

[7] Wang, L.; Bloomfield, V. A.; Macromolecules 1991, 24, 5791.

[8] Kassapidou, K.; Jesse, W.; Kuil, M. E.; Lapp, A.; Engelhaaf, S.; van der Maarel, J.

R. C.; Macromolecules 1997, 30, 2671.

[9] Sato, T.; Norisuye, T.; Fujita, H.; Macromolecules 1984, 17, 2696.

[10] Gamini, A.; Mandel, M.; Biopolymers 1994, 34, 783.

[11] Milas, M.; Rinaudo, M.; Duplessix, R.; Borsali, R.; Lindner, P.; Macromolecules 1995, 28, 3119.

[12] Berth, G.; Dautzenberg, H.; Christensen, B. E.; Harding, S. E.; Rother, G.; Smidsrod, O.; Macromolecules 1996, 29, 3491.

[13] Spoor, H.; Angew. Makromol. Chem. 1984, 123/124, 1.

[14] MacCallum, J. R.; Vincent, C. A., editors; "Polymer Electrolyte Reviews", Elsevier, London 1987.

[15] Gray, F. M.; "Solid Polymer Electrolytes”, VCH Publishers, New York 1991.

[16] Oppermann, W.; Makromol. Chem. 1988, 189, 927.

[17] Weill, G.; J. Phys. (France) 1989, 49, 1049.

[18] Förster, S.; Schmidt, M.; Antonietti, M.; Polymer 1990, 31, 781.

[19] Yamanaha, Y.; Matsuoka, H.; Hasegawa, M.; Ise, N.; J. Am. Chem. Soc. 1990, 112, 587.

[20] Fuoss, R. M.; Strauss, U. P.; J. Polym. Sci. 1948, 3, 246.

[21] Fuoss, R. M.; Strauss, U. P.; J. Polym. Sci. 1948, 3, 603.

[22] Fuoss, R. M.; Strauss, U. P.; J. Polym. Sci. 1949, 4, 96.

[23] Odijk, T.; J. Polym. Sci. 1977, 15, 479.

[24] Rabin, Y.; Phys. Rev. A 1987, 35, 3579.

[25] Vink, H.; Makromol. Chem. 1970, 131, 133.

[26] Vink, H.; J. Chem. Soc. Faraday Trans. 1987, 83, 801.

[27] Rabin, Y.; Cohen, J.; Priel, Z.; J. Polym. Sci., Polym. Lett. 1988, 26, 397.

[28] Rabin, Y.; Cohen, J.; Priel, Z.; Polym. Commun. 1988, 29, 235.

[29] Cohen, J.; Priel, Z.; Rabin, Y. ; J. Chem. Phys. 1988, 88, 7111.

[30] Cohen, J.; Priel, Z. ; Macromolecules 1989, 22, 2356.

[31] Cohen, J.; Priel, Z. ; Polym. Commun. 1989, 30, 223.

[32] Cohen, J.; Priel, Z. ; J. Chem. Phys. 1990, 93, 9063. 
[33] Hess, W.; Klein, R.; Adv. Phys. 1983, 32, 173.

[34] Borsali, R.; Vilgis, T. A.; Benmouna, M.; Macromolecules 1992, 25, 5313.

[35] Nishida, K.; Kanaya, T.; Kaji, K.; Polym. Prepr. Jpn. 1990, 39, 3953.

[36] Antonietti, M.; Briel, A.; Förster, S.; J. Chem. Phys. 1996, 105, 7795.

[37] Antonietti, M.; Briel, A.; Förster, S.; Macromolecules 1997, 30, 2700.

[38] Rau, I. U.; Rehahn, M.; Macromol. Chem. 1993, 194, 2225.

[39] Rau, I. U.; Rehahn, M.; Polymer 1993, 34, 2889.

[40] Rau, I. U.; Rehahn, M.; Acta Polym. 1994, 45, 3.

[41] Brodowski, G.; Horvath, A.; Ballauff, M.; Rehahn, M.; Macromolecules 1996, 29, 6962.

[42] Wittemann, M.; Rehahn, M.; J. Chem. Soc., Chem. Commun. 1998, 623.

[43] Balanda, P. B.; Ramey, M. B.; Reynolds, J. R.; Macromolecules 1999, 32, 3970.

[44] Harrison, B. S.; Ramey, M. B.; Reynolds, J. R.; Schanze, K. S.; J. Am. Chem. Soc. 2000, 122, 8561.

[45] Wallow, T. I.; Novak, B. M.; J. Am. Chem. Soc. 1991, 113, 7411.

[46] Wallow, T. I.; Novak, B. M.; Polym. Prepr. (Am. Chem. Soc., Div. Polym. Chem.) 1991, 32, 191.

[47] Wallow, T. I.; Novak, B. M.; Polym. Prepr. (Am. Chem. Soc., Div. Polym. Chem.) 1992, 33, 908.

[48] Wallow, T. I.; Novak, B. M.; Polym. Prepr. (Am. Chem. Soc., Div. Polym. Chem.) 2000, 201, 1009.

[49] Chield, A. D.; Reynolds, J. R.; Macromolecules 1994, 27, 1975.

[50] Kim, S.; Jackiw, J.; Robinson, E.; Schanze, K. S.; Reynolds, J. R.; Baur, J.; Rubner, M. F.; Boils, D.; Macromolecules 1998, 31, 964.

[51] Rulkens, R.; Schulze, M.; Wegner, G.; Macromol. Rapid Commun. 1994, 15, 669.

[52] Vanhee, S.; Rulkens, R.; Lehmann, U.; Rosenauer, C.; Schulze, M.; Köhler, W.; Wegner; G.; Macromolecules 1996, 29, 5136.

[53] Rulkens, R.; Wegner, G.; Thurn-Albrecht, T.; Langmuir 1999, 15, 4022.

[54] Baum, P.; Meyer, W. H.; Wegner, G.; Polymer 2000, 41, 965.

[55] Bockstaller, M.; Köhler, W.; Wegner, G.; Vlassopoulos, D.; Fytas, G.; Macromolecules 2000, 33, 3951.

[56] Bockstaller, M.; Köhler, W.; Wegner, G.; Vlassopoulos, D.; Fytas, G.; Macromolecules 2001, 34, 6359.

[57] Rehahn, M.; Schlüter, A.-D.; Feast, W. J.; Wegner, G.; Polymer 1989, 30, 1060.

[58] Rehahn, M.; Schlüter, A.-D.; Wegner, G.; Makromol. Chem. 1990, 191, 1991.

[59] Schlüter, A.-D.; Wegner, G.; Acta Polym. 1993, 44, 59.

[60] Guilleaume, B.; Blaul, J.; Ballauff, M.; Wittemann, M.; Rehahn M.; Goerigk, G.; Eur. Phys. J., submitted.

[61] Guilleaume, B.; Ballauff, M.; Goerigk, G.; Wittemann, M.; Rehahn, M.; Colloid Polym. Sci., submitted. 
[62] Mahltig, B.; Rehahn, M.; Stamm, M.; Polym. Bull. 2001, 45, 501.

[63] Derserno, M.; Holm, C.; Blaul, J.; Ballauff, M.; Rehahn, M.; Eur. Phys. J. E 2001, $5,97$.

[64] Engelking, J.; Wittemann, M.; Rehahn M.; Menzel, H.; Langmuir 2000, 16, 3407.

[65] Blaul, J.; Wittemann, M.; Ballauff, M.; Rehahn, M.; J. Phys. Chem. B 2000, 104, 7077.

[66] Guilleaume, B.; Blaul, J.; Wittemann, M.; Rehahn, M.; Ballauff, M.; J. Phys.: Condens. Matter. 2000, 12, A245.

[67] McQuade, D. T.; Hegedus, A. H.; Swager, T. M.; J. Am. Chem. Soc. 2000, 122, 12389.

[68] Lauter, U.; Meyer, W. H.; Wegner, G.; Macromolecules 1997, 30, 2092.

[69] Anelli, P.L.; Ashton, P.R.; Ballardini, R.; Balzani, V.; Delgado, M.; Gandolfi, M.T.; Goodnow, T.T.; Kaifer, A.E.; Philp, D.; Pietraszkiewicz, M.; Prodi, L.; Reddington, M.V.; Slawin, A. M. Z.; Spencer, N.; Stoddart, J. F.; Vicent, C.; Williams, D. J.; J. Am. Chem. Soc. 1992, 114, 193.

[70] Reich, H. J.; Goldenberg, W. S.; Gudmundson, B. Ö.; Sanders, A. W.; Kulicke, K. J.; Simon, K.; Guzei, I. A.; J. Am. Chem. Soc. 2001, 123, 8067.

[71] (a) Marzin, A.; J. Prakt. Chem. 1933, 138, 103; (b) Ruggli, R.; Brandt, F.; Helv. Chim. Acta 1944, 27, 274; (c) Offermann, W.; Vögtle, F.; Synthesis 1977, 272.

[72] (a) Anelli, P. L.; Ashton, P. R.; Ballardini, R.; Balzani, V.; Delgado, M.; Gandolfi, M. T.; Goodnow, T. T.; Kaifer, A. E.; Philip, D.; Pietrasuzkiewicz, M.; Prodi, L.; Reddington, M. V.; Slawin, A. M. Z.; Spencer, N.; Stoddart, J. F.; Vicent, C.; Williams, D. J.; J. Am. Chem. Soc. 1992, 114, 193; (b) Kabalka, G. W.; Varma, M.; Varma, R. S.; J. Org. Chem. 1986, 51, 2386.

[74] Lecher, H.; Graf, F.; Justus Liebigs Ann. Chem. 1925, 445, 61.

[75] Marckwald, W.; Droste-Hülshoff, A. v.; Ber. Chem. Ges. 1898, 31, 3261.

[76] Hinsberg, O.; Justus Liebigs Ann. Chem. 1891, 265, 178.

[77] Traube, W.; Engelhardt, A.; Ber. Chem. Ges. 1911, 44, 3148.

[78] Traube, W.; Kegel, F.; Schulz, P. H. E.; Angew. Chem. 1926, 39, 1465.

[79] Vliet, E. B.; Organic Syntheses 1932, coll. vol. 1, 201.

[80] Gerhardt, W.; Kucharski, S.; J. Prakt. Chem. 1977, 319, 705.

[81] Coutts, I. G. C.; Goldschmid, H. R.; Musgrave, O. C.; J. Chem. Soc. 1970, 488.

[82] Coulon, D. R.; Inorg. Synth. 1972, 13, 121.

[83] Tolman, C. A.; Seidel, W. C.; Gerlach, D. H.; J. Am. Chem. Soc. 1972, 94, 2669. 